\title{
RETROACTIVE CORPORATE IDENTITY
}

BY

PATRICK THOMPSON

\begin{abstract}
A thesis
submitted to the Victoria University of Wellington

in partial fulfilment of the requirements for the degree of

Master of Architecture
\end{abstract}

Victoria University of Wellington 



\begin{abstract}
Corporate identity and corporate architecture are two vital parts of a corporation that co-exist to express goals and values. However, due to an unsynchronised relationship there is a lack of synergy between corporate identity and corporate architecture. A review of corporate identity history, strategies, tools and methods, and chronological interpretations of corporate architecture found that there is a lack of systematic approaches to translate and implement corporate identity to corporate architecture. Fisher \& Paykel Appliances' corporate identity was translated and implemented to 215 Lambton Quay, Wellington through a design case study. This translation and implementation to existing corporate architecture showed that a systematic approach to address lack of synergy was possible through the use of an architectural mission statement and five implementation techniques. Furthermore, translation and implementation shall be treated as a system and not a step-by-step approach, therefore allowing any further research to adapt to the context of the corporate identity and corporate architecture ensuring a synergetic relationship.
\end{abstract}





\section{ACKNOWLEDGEMENTS}

I am extremely grateful for all the help and support I have received. Firstly, I would like to thank the amazing staff at Victoria University of Wellington, especially my supervisor, Tobias Danielmeier for his overall support and persistence in pushing me to solidify my ideas. Also, I would like to thank Chris McDonald, for coordinating all the great support from VUW staff and external professionals including himself, Dr Peter Parkes, Peter Johnstone, Mark Newdick, Kerstin Thompson and Peggy Deamer. Furthermore, I would like to thank all other VUW staff that assisted me, including technical, workshop, library staff and other academics that I have had excellent and helpful conversations with. Finally I would like to thank my highly supportive colleagues and friends, my family, especially my parents, Marianne and Ronald, and my partner Samantha Muller. It has been an amazing experience and I could not have achived this without the attentive support of the people mentioned here. 



\section{TABLE OF CONTENTS}

ABSTRACT 3

ACKNOWLEDGEMENTS

$\begin{array}{lll}1.0 & 14\end{array}$

$\begin{array}{lll}2.0 & \text { CORPORATE IDENTITY } & 16\end{array}$

$\begin{array}{lll}2.1 & \text { DEFINITIONS } & 16\end{array}$

2.2 THE FULL CIRCLE OF CORPORATE IDENTITY 18

2.3 TRANSLATION + IMPLEMENTATION: STRATEGIES, TOOLS

AND METHODS 25

2.4 SPEED THEORY - CORPORATE ARCHITECTURE BREAKDOWN 31

2.5 RETROACTIVE CORPORATE IDENTITY 34

2.6 REFERENCES 34

3.0 RETROACTIVE CORPORATE IDENTITY - TRANSLATION 36

3.1 CORPORATION SELECTION 36

3.2 FISHER \& PAYKEL - THE CORPORATE IDENTITY 37

3.3 CORPORATE MISSION STATEMENT 41

3.4 ARCHITECTURAL MISSION STATEMENT $\quad 44$

3.5 REFERENCES 48

4.0 RETROACTIVE CORPORATE IDENTITY - IMPLEMENTATION 50

4.1 THE EXISTING CORPORATE ARCHITECTURE - 215

4.2 IMPLEMENTATION 62

4.3 URBAN INTEGRATION 64

4.4 PODIUM DISINTEGRATION 68

$\begin{array}{lll}4.5 & \text { CENTRAL ATRIUM } & 74\end{array}$

$\begin{array}{lll}4.6 & \text { SECONDARY ATRIA } & 80\end{array}$

4.7 COMMUNICATIVE FAÇADES 84

$\begin{array}{lll}4.8 & \text { REFERENCES } & 87\end{array}$

5.0 DISCUSSION / CONCLUSION 88

5.1 CORPORATE IDENTITY TO CORPORATE ARCHITECTURE 90

5.2 IMPLEMENTATION OF CORPORATE IDENTITY 91

5.3 FURTHER CORPORATE IDENTITY INVESTIGATION 93

5.4 CONCLUSIONS
5.5

$\begin{array}{lll}5.5 & \text { REFERENCES } & 96\end{array}$

$\begin{array}{lll}6.0 & \text { APPENDIX } & 98\end{array}$

6.2 BIBLIOGRAPHY 98

6.1 ARCHITECTURAL MISSION STATEMENT TABLE 102

6.3 EXISTING BUILDING PHOTOS 106

6.4 MODEL PHOTOS 108

$\begin{array}{lll}6.5 & \text { INTERIM REVIEW PRESENTATIONS } & 110\end{array}$ 



\section{TABLE OF FIGURES}

\subsection{CORPORATE IDENTITY}

Figure 1: Margarethenhöhe Settlement, Georg Metzendorf, 1906. From Corporate architecture: Development, concepts, strategies (p. 31), by J. Messedat, 2005, Ludwigsburg: AV Edition.

Figure 2: $\quad$ Timber Mill, Owhata, Northland, New Zealand. Taken by Northwood Brothers, c 1910, Wellington: Alexander Turnbull Library.

Figure 3: $\quad$ A Group of Ford Factory Employees. Adapted from Ford Factory Facts, Ford Motor Company, 1915, Retrieved from http://www.mtfca.com/books/15_factory.htm.

Figure 4: Highland Park Factory, Albert Kahn, 1910. From From autos to architecture: Fordism and architectural aesthetics in the twentieth century (p. 47). F, Gartman, 2009, New York: Princeton Architectural Press.

Figure 5: $\quad$ AEG brochure design featuring factory design. From Corporate architecture: Development, concepts, strategies (p. 43), by J. Messedat, 2005, Ludwigsburg: AV Edition.

Figure 6: $\quad$ Lever Building, Skidmore Owings \& Merril, 1952. From www.SOM.com, by Skidmore, Owings \& Merrill, Retrieved from http://www.som.com/content.cfm/lever_house.

Figure 7: $\quad$ Seagram Building, Mies Van der Rohe, 1957. From www. wikipedia.com, by Noroton, 2008, Retrieved from http://en. wikipedia.org/wiki/File:NewYorkSeagram_04.30.2008.JPG.

Figure 8: $\quad$ Olivetti Corporate Design manual. From Corporate architecture: Development, concepts, strategies (p. 79), by J. Messedat, 2005, Ludwigsburg: AV Edition.

Figure 9: $\quad$ Olivetti Typewriter, 1969. From www. wikipedia.com, By Folletto, 2007, Retrieved from http://en.wikipedia.org/wiki /File:Olivetti-Valentine.jpg.

Figure 10: Duck + Decorated Shed. From Learning from Las Vegas (p. 65), by R. Venturi, 1972, New York: Routledge.

Figure 11: Olivetti training centre, Hampshire, England, James Stirling, 1969-1972. Retrieved from http://talkingarchitecture.files. wordpress.com/2010/09/olivetti-bigger.jpg.

Figure 12: Before and after retrofit of an insurance building in Munich, Architects: Baumschlager \& Eberle. The retrofit reused the existing building and now uses $75 \%$ less energy than the existing. From Insurance Building in Munich, In C. Schittich 
(Ed.), In detail: Building in existing fabric: refurbishment, extensions, new design (pp. 114-123). by C, Schittich, 2003,

Boston: Birkhäuser.

Figure 13: (Left) Times Square 1919. From www.nyc-architecture.com, by Convention and visitors Bureau, 1919, New York: Convention and Visitors Bureau. Retrieved from http://www.nycarchitecture.com/MID/MID-TimesSquare3.htm) (Right) Times Square 2009. From www. wikipedia.com, by Terabass, 2009, Retrieved from http://en.wikipedia.org/wiki/ File:New_york_times_square-terabass.jpg.

Figure 14: Early experimental interpretation of architectural corporate metamorphosis. By author, 2010.

Figure 15: $\quad$ Summary of Jons Messedat's (2005, pp. 262-268) strategies to implement corporate identity. By author, 2010.

Figure 16: $\quad$ Summary of Jons Messedat's (2005, pp. 269-270) phases of corporate identity design integration. By author, 2010.

Figure 17: $\quad$ Summary of Jons Messedat's (2005, p. 271) Components of corporate architecture. By author, 2010.

Figure 18: $\quad$ Summary of Susanne Knittle-Ammerschuber's (2006) strategies to implement corporate identity. By author, 2010.

Figure 19: $\quad$ Messedat + Knittle-Ammerschuber within project timeline. By author, 2010.

Figure 20: $\quad$ Shell, Services, Scenery and sets life cycles. From "Measuring Building Performance," by F. Duffy, 1990, Facilities, 8(5), p. 17-20.

Figure 21: Reinterpretation of Duffy's layers. Adapted (by author, 2010) from Rethinking technology: a reader in architectural theory (p. 438), Edited by William W. Braham, J. A. H., and John Stanislav Sadar, 2007, New York: Routledge.

Figure 22: $\quad$ Shearing layers of change. Adapted (by author, 2010) from How buildings learn: what happens after they're built p. 13). By S. Brand, 1994, London: Phoenix Illustrated.

Figure 23: $\quad$ SL.A Changing Speeds. Adapted (by author, 2010) from Smart architecture (p. 25), By SL.A, 2003, Rotterdam: 010 Publishers

\subsection{RETROACTIVE CORPORATE IDENTITY - TRANSLATION}

Figure 24: $\quad$ Fisher \& Paykel founders, Woolf Fisher (left) and Maurice Paykel (right). From Fisher \& Paykel ImageBank, 1934,

Auckland: www.imagebank.fisherpaykel.com.

Figure 25: Position of FPA offices and factories. From 2010 Annual Report (p. 17), By Fisher \& Paykel, 2010.

Figure 26: $\quad$ Key FPA products, Fridge (1930), Double DishDrawer (1997). 
From Fisher \& Paykel ImageBank, Auckland: www.imagebank.

fisherpaykel.com.

Figure 27: Carlaw Park Lane Factory. From Fisher \& Paykel ImageBank,

c 1940, Auckland: www.imagebank.fisherpaykel.com.

Figure 28: $\quad$ Existing FPA plant, East Tamaki Auckland, Original Plan. From "Industrial: Fisher and Paykel, East Tamaki," R. Barry, 1991,

Architecture New Zealand (September/October), p. 44-47.

Figure 29: $\quad$ Dunedin Plant. From Fonterra buys F\&P site to expand dairy storage, by Stephen Jaquiery, 2008, Otago: Otago Daily TImes, Retrieved from http://www.odt.co.nz/news/business/32144/ fonterra-buys-fampp-site-expand-dairy-storage.

Figure 30: $\quad$ Project Ironside. From "Project Ironside," by P. Davies, 2008, Artichoke(25), p. 59-60.

Figure 31: Fisher \& Paykel Experience Centre, Hangzhou, China. From 2010 Annual Report (p. 17), By Fisher \& Paykel, 2010.

Figure 32: DNA Mission statement. From Fisher \& Paykel ImageBank, Auckland: www.imagebank.fisherpaykel.com.

Figure 33: Experience Mission statement. Screenshot by author from www.fisherpaykel.co.nz, by Fisher \& Paykel, 2010.

Figure 34: Mission statement comparison. By author, 2010.

Figure 35: Translation matrix. By author, 2010.

Figure 36: Architectural mission statement matrix example (See appendix 6.2 for full matrix). By author, 2010 . 46

Figure 37: $\quad$ Final Architectural mission statement. By author, 2010.

\subsection{RETROACTIVE CORPORATE IDENTITY - IMPLEMENTATION}

Figure 38: National Movements. By author, 2010.

Figure 39: Wellington Office Relocations and Consolidation. Adapted by author, 2010, from map produced by: Urban Design Team, R. Leblanc, 10 Aug. 2009, Wellington: Wellington City Council.

Figure 40: $\quad$ Southern perspective of building. By author, 2010.

Figure 41: Northern perspective of building. By author, 2010.

Figure 42: Esprit Store. By author, 2010.

Figure 43: $\quad$ Existing Building. By author, 2010.

Figure 44: Presentation Perspective, Friedrichstrasse Skyscraper, Berlin, 1921, Mies Van der Rohe. From The Mies van der Rohe Archive (Vol. 1) (p. 48), Drexler, A., \& Schulze, F. (Eds.), 1986, New York: Garland Pub.

Figure 45: Typical Floor Plan, Friedrichstrasse Skyscraper, Berlin, 1921, Mies Van der Rohe. From The Mies van der Rohe Archive 
(Vol. 1) (p. 51), Drexler, A., \& Schulze, F. (Eds.), 1986, New

York: Garland Pub.

Figure 46: Building evolution. By author, 2010.

Figure 47: $\quad$ Existing Site. By author, 2010.

Figure 48: Wellington waterfront history. Adapted by author, 2010, from map produced by: Urban Design Team, R. Leblanc, 10 Aug. 2009, Wellington: Wellington City Council.

Figure 49: Urban Links. Adapted by author, 2010, from original consent documents, Peddle Thorpe Architects, 1978, retrieved from Wellington City Archives.

Figure 50: Grey Street Park, Eastern End. By author, 2010.

Figure 51: Grey Street Park, Western End. By author, 2010.

Figure 52: Sunlight Study. By author, 2010.

Figure 53: $\quad$ Structure. By author, 2010.

Figure 54: Structural System. By author, 2010.

Figure 55: $\quad$ Stacked Floor Plates, 1:100 Model. By author, 2010.

Figure 56: Circulation. By author, 2010.

Figure 57: Typical Floor Plan. Adapted by author, 2010, from original consent documents, Peddle Thorpe Architects, 1978, retrieved from Wellington City Archives. 59

Figure 58: Envelope. By author, 2010. 60

Figure 59: Curtain Wall system. By author, 2010.

Figure 60: $\quad$ Curtain Wall System, Detail. By author, 2010.

Figure 61: Typical Spandrel Detail. From original consent documents, Peddle Thorpe Architects, 1978, retrieved from Wellington City Archives.

Figure 62: $\quad$ Holistic implementation of Architectural Mission statement. By author, 2010.

Figure 63: Implementation Key. By author, 2010.

Figure 64: Urban Integration. By author, 2010.

Figure 65: $\quad$ Existing Park, 1:100 Model. By author, 2010.

Figure 66: Park Sketch plan. By author, 2010.

Figure 67: Image of park, 1:200 model. By author, 2010.

Figure 68: Park Plan. By author, $2010 \quad 65$

Figure 69: Grey Street Park Cross Section. By author, 2010.

Figure 70: Scale reduction features. By author, 2010.

Figure 71: View of park from Lambton Quay. By author, 2010.

Figure 72: $\quad$ Podium Disintegration. By author, 2010.

Figure 73: $\quad$ Existing hard-edged podium. By author, 2010.

Figure 74: Podium Edge, 1:100 model. By author, 2010. 
Figure 75: Diagram of before and after podium edge. By author, 2010.

Figure 76: $\quad$ Podium Key Plan. By author, 2010.

Figure 77: 1:250 Working model canopy. By author, 2010.

Figure 78: $\quad$ Podium Floor Plans. By author, 2010.

Figure 79: $\quad$ Lambton to Featherston Link. By author, 2010.

Figure 80: $\quad$ Grey Street Entry. By author, 2010.

Figure 81: Grey Street Park and podium. By author, 2010.

Figure 82: $\quad$ Podium Disintegration detail. By author, 2010.

Figure 83: Central Atrium. By author, 2010.

Figure 84: $\quad$ Existing staked floor plates, 1:100 model. By author, 2010.

Figure 85: Diagrammatic Section of Atrium. By author, 2010.

Figure 86: Before and after floor area calculation. By author, 2010.

Figure 87: Tower Floor Plan. By author, 2010.

Figure 88: Central Atrium Cross Section. By author, 2010.

Figure 89: Natural Ventilation. By author, 2010.

Figure 90: Central Atrium. By author, 2010.

Figure 91: Secondary Atrium. By author, 2010.

Figure 92: $\quad$ 1:250 Model. By author, 2010.

Figure 93: $\quad$ Atria Positioning. By author, 2010. 80

Figure 94: 1:200 Model. By author, 2010.

Figure 95: Secondary atria social space. By author, 2010.

Figure 96: Communicative Façade. By author, 2010.

Figure 97: Existing vs communicative facade. By author, 2010.

Figure 98: Secondary façade detail. By author, 2010.

Figure 99: Façades Patterning system. By author, 2010. 85

Figure 100: Podium façade. By author, 2010.

Figure 101: Office space section. By author, 2010.

\subsection{DISCUSSION / CONCLUSION}

Figure 102: Retroactive corporate identity section. By author, 2010.

Figure 103: $\quad$ Speed theory development. By author, 2010. 


\section{0 inrRoouction}

Corporate identity and architecture are both vital parts of a dynamic and interconnected system. However, there is a contrast within this relationship; corporate identity evolves and corporate architecture is static. The intangible diachronic nature of corporate identity allows it to develop and accommodate change, however corporate architecture is synchronic, and becomes a symbol of a corporation's identity at one point in time, leaving a remnant of what a corporation was. Therefore, it can be hypothesised that existing multistorey administration architecture lacks a synergetic relationship with their corporate inhabitants.

This hypothesis has manifested the research question; How can retrofitting an existing multistorey administration building improve the synergy of corporate identity and corporate architecture? Therefore, the intended outcome of the research will be a unique design process of retrofitting multistorey corporate architecture. A set of parameters will be identified from this thesis that assist in future translation and implementation of corporate identity to existing multistorey architecture through focusing on a synergetic relationship.

To investigate this aim, Chapter 2.0 explains corporate identity through four sections. Key terminology will be defined in the first. The second examines the history of corporate identity and corporate architecture signifying their dynamic relationship. The third section presents translation and implementation strategies, tools and methods. The final section will look at a term developed in the context of this thesis - speed theory - which explores layers of corporate architecture and their diachronic relationships. This chapter concludes by identifying the next step for corporate identity and its relationship with corporate architecture: Retroactive Corporate Identity. In chapter 3.0 and 4.0 a design case study tests the hypothesis through two stages, translation (Chapter 3.0) and implementation (Chapter 4.0). Chapter 3.0 describes the translation process of the selected corporate, Fisher \& Paykel Appliances. Chapter 4.0 analyses the selected building, 215 Lambton Quay and describes the implementation of corporate identity to the existing 
corporate architecture. Chapter 5.0 critiques the design case study within the framework set up by the existing literature. This provides a critical view of the investigation and is once again split into translation and implementation, however culminates by providing an outlook for future research. The thesis is then concluded by presenting significant findings and its relevance to existing literature, architecture and the synergy of corporate identity and corporate architecture. 


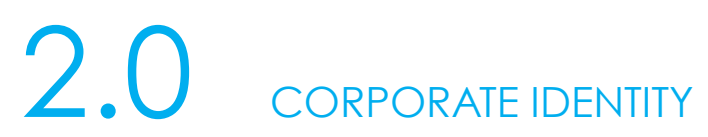

Corporate identity can be, but is not limited to, the culture, image, personality, history, vision and values that a corporation expresses internally and externally whilst partaking in business. It is the first impression that employees, clients and colleagues have when they engage, communicate with, and view a corporation. This chapter explains corporate identity from architectural (architect) and management (corporation) perspectives. Firstly, corporate identity terminology will be defined. Then the history of corporate identity and corporate architecture will be presented. Key strategies, tools and methods that have been developed from analysing corporate identity history will also be examined.

\subsection{DEFINITIONS}

To begin, corporate identity terminology is defined. Identity, corporation, corporate identity and corporate architecture can attract ambiguous connotations and are understood differently by corporations, architects and the public. Therefore, they are clarified here to remove any ambiguity.

\section{IDENTITY}

Identity is the individuality of an entity (Collins English dictionary, 2000). Also it is defined as the expression of the entity's culture, values, history and personality to others through different modes of communication (Messedat,

1. Rowden's definition, presented on the first page of his book, 'The art of identity, creating and managing a successful corporate identity' (2000) is from a marketing and social perspective. This angle of enquiry is helpful to architects as it is way to see how people outside the field of architecture perceive and translate identity. 2005). Interestingly, the origin of identity is derived from the Latin word ident, which means to repeat over and over again (Collins English dictionary, 2000). This dictionary definition of identity will lead you to think there is a strong relationship to identical. Generally this is true, however, the word has attracted another meaning in contemporary society, corporate identity theory to be specific. Mark Rowden' (2000) explains the major benefit of identity is to be seen differently. 
The ultimate identity in the corporate environment is to be seen differently to competitors. Difference is fundamental to becoming visible, however this visibility must influence the surroundings, motivating it to subscribe to your goals. (Rowden, 2000, p. 1)

When Rowden's definition is compared to the first, a dual meaning manifests. Friedman (1998) identifies this dual meaning as, difference versus sameness and that dynamic shifts can occur within individuals or groups. Identical does still have a place in corporate identity theory where consolidation and consistency is required. This is seen within corporations' uniforms or the repetitive features of fast food buildings. However, as Rowden stated, corporations are also seen as individuals and must convey individuality to gain a competitive advantage. Identity has a specific meaning within corporate identity theory and this thesis. Importantly, both definitions discussed will be considered.

\section{CORPORATION}

A corporation is a legal entity that operates independently from its human owner or owners (Black's law dictionary, 2009). This simple law definition is surpassed by their true impact on their surroundings. The size and scale of ambiguous contemporary corporations have grown to a level where it becomes questionable, if they are in control of our society. Therefore, without the comfort of dealing with a person, society is now communicating to corporations that emit a personality. The significance of their identity for the public and themselves is exceedingly important (Kravel, 2008).

\section{CORPORATE IDENTITY}

The amalgamation of corporation and identity forms the crux of this thesis and is fundamental to any corporations' communication to consumers. The term corporate identity was recognised and developed by the College of Design in UIm, Germany, which was founded in the 1950's through the combination of design disciplines (Messedat, 2005, p. 77). Identity and corporation, together, as defined in 1995 by Stadler \& Funck (cited in Messedat 2005):

In economic practice, corporate identity is the strategically planned and operationally activated self-portrayal and behaviour of a business internally and externally, based upon a pre-defined company philosophy, a long term business objective and a defined image, with the aim of bringing all of the company's negotiation instruments into a uniform framework to represent the company internally and externally. (p. 21) 
This management and marketing definition has substantial potential when interpreted as an architectural statement. In their statement, Stadler \& Funck focus on personal aspects of a corporation, the day-to-day interaction of its consortium internally and externally. The potential lies when the architectural representation of the company internally and externally is applied to this definition.

\section{CORPORATE ARCHITECTURE}

Corporate architecture, which can vary from a home office to multistorey office buildings, is the largest physical presence of corporate identity. Whether unintentionally or intentionally, corporate architecture is a statement about a corporation (Knittel-Ammerschuber, 2006, p. 10). Architectural corporate identity is of interest to corporations as employees have a direct and intimate relationship with it, furthermore, the public perceives and judges the building (Knittel-Ammerschuber, 2006, p. 7). However, it is found that corporate architecture is primarily designed to be spatially efficient and entire sectors of corporations think this way and do not understand the potential of architectural expression (Knittel-Ammerschuber, 2006, p. 7) Furthermore, the importance of corporate architecture needs to be strengthened within a corporation's financial structure to allow expression (Messedat, 2005, p. 11).

The definitions above have provided an understanding of terms that are central to this thesis. Identity is defined as a dual meaning that exists within corporate identity theory. Both meanings defined must be considered together within this thesis. Corporations have an identity, however, through this ambiguous term a corporate identity must be extracted and expressed through corporate architecture. The following section on corporate identity history will further define and elaborate the theory of corporate identity and contextualise these definitions.

\subsection{THE FULL CIRCLE OF CORPORATE IDENTITY}

The following section examines the history and development of corporate

2. Vernacular, meaning a native language, is applied within this thesis as a stylistic expression of architecture abiding to the current surrounding architectural language of the time (Collins English dictionary, 2000). Vernacular style is important within corporate architecture as modern corporate architecture strives to be different and not an extension of its surroundings (Ambrose, 2008). identity and its importance for corporations. This discussion will begin with the description of vernacular ${ }^{2}$ corporate identity. Retrospectively, this type of corporate identity has been identified as an early form of corporate architecture. Following this, the influence of the industrial revolution on corporate identity is discussed, as this industrial vernacular style developed the first recognised corporate architecture. Commercial multistorey architecture of the early $20^{\text {th }}$ century is then critiqued as the first prominent, architecturally translated and designed corporate identity. Furthermore, the 
appearance of the corporate design manual in the 1950s will be discussed. This was another fundamental shift towards an increased involvement by corporations' to express their corporate identity through architecture. Postmodernist ideas of metaphor within corporate architecture will also be examined. This architectural style changed the representation of corporate identity, sometimes to a very literal decorated shed or duck (Venturi \& Brown, 1972). Escalation of green identity and sustainability into the vocabulary of corporations is then discussed. This was and still remains to be a major characteristic of corporate identity and enforced the need for corporate responsibility. Finally, contemporary corporate identity will be critiqued along with its significance for future corporate architecture.

\section{VERNACULAR CORPORATE IDENTITY}

A major change in corporate identity, as a theory and practice, was the shift from vernacular corporate identity to designed corporate identity. This also marked the time when corporations discovered that well-designed corporate architecture could be beneficial to their success (Messedat, 2005, p. 29). This vernacular style is explained through corporate architecture of European and colonial New Zealand examples.

The Margarethenhöhe settlement ${ }^{\text {fig. }}$ ") for the Krupp family ${ }^{3}$ is a prevalent European example. A national selection committee chose the young architect Georg Metzendorf to design a residential and factory town for Krupp. His design was heavily influenced and designed in a local German vernacular style (circa 1900). This unified, however not intentionally translated corporate identity is an example of corporations evolving interest in corporate architecture (Messedat, 2005).

At a similar time, comparable, more pure and functional examples of vernacular corporate identity existed. One is the timber mill industry of New Zealand, which set up communities where resources were abundant. (fig. 2) These communities built from the product that was being produced, expressed uniformity through materiality and colonial architectural styles. Therefore, the uniformity within these communities fused architecture with ideals and goals of the company. Vernacular expression of corporate identity, though not intentional, can be identified as an early form of corporate architecture.

3. The Krupp family founded a large business in steel production and manufacture and was based in Essen, Germany. A major goal of the company was to show a commitment to their staff by creating communities around their factories (Messedat, 2005 , p. 29). 
urban consumers wanted (Gartman, 2009, p. 205). David Gartman (2009) identifies the hermetic glass boxes of Mies Van der Rohe and Skidmore, Owings and Merrill(fig.6) as monuments to a technocratic elite. Their shield like façades removed all connection to dirty production techniques, reflecting the superficial corporate environment and the irrationality of consumerism (Gartman, 2009).

Mies Van der Rohe's glass tower of 1957, (fig. 7) designed for liquor producer Seagram, is a symbol of superficiality within this era of corporate architecture. The non-structural, pattern of mullions attempts to replace the true load bearing structure. Gartman also expresses concern that the rational and proportionate presence of this building acts as a sober expression of the liquor producer within (Gartman, 2009).

This new type of corporate architecture placed greater emphasis on the façade. It acted as a barrier, blocking the public from the truth, expressing what the corporation wanted to show (Gartman, 2009, p. 203). Perhaps this untruthful representation of goals and morals reflected corporations' attitudes of the time, therefore implementing a successful translation of corporate identity.

\section{THE CORPORATE DESIGN MANUAL}

The next development in corporate identity theory was the appearance of corporate design manuals. This signalled increased contribution from corporations to translate their image rather than the architect. Arguably a direct influence to this change is Peter Behrens holistic corporate identity implementation for AEG (Knittel-Ammerschuber, 2006, p. 13).

Recognising the potential, the College of Ulm, Germany, combined all disciplines of design to create new key strategies for translating corporate identity during the 1950s. Furthermore, corporations adopted these systematic approaches to incorporate all aspects of communication, logos, packaging, uniforms, signage and architecture (Messedat, 2005, p. 79).

Messedat (2005) gives the example of Olivetti, which implemented two volumes of detailed corporate design guidelines. (fig. 8) Architecturally the manuals lacked complexity, only explaining layouts of signage on façades and shop windows. This was the beginning of the signs (logo) dominance over architecture. It became challenging for architects to provide architectural design input to manual writers (marketers). This progressed translation of corporate identity, however, reduced individual architectural expression of corporate architecture (Messedat, 2005, p. 79).

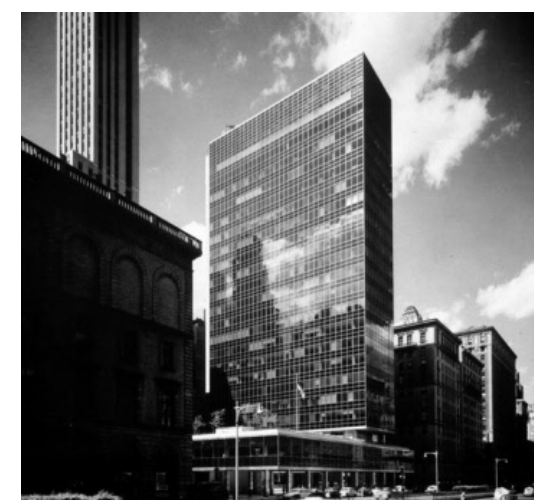

Figure 6. Lever Building, Skidmore Owings \& Merrill, 1952

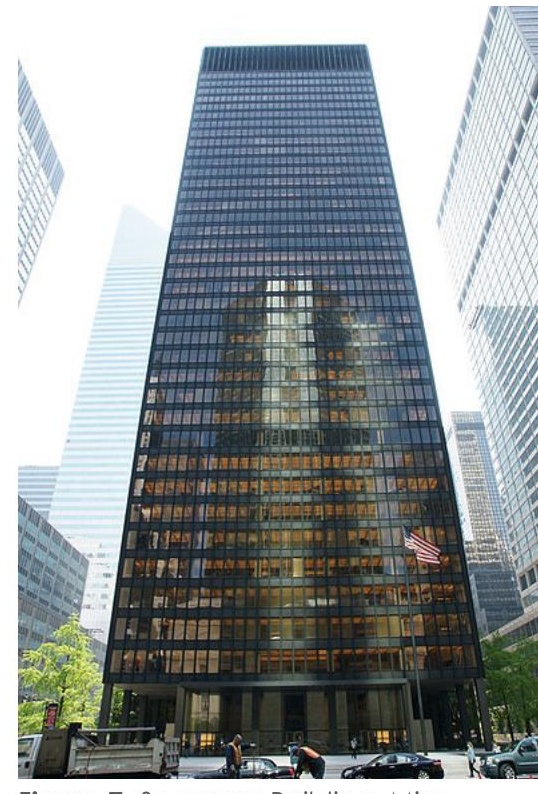

Figure 7. Seagram Building, Mies Van der Rohe, 1957

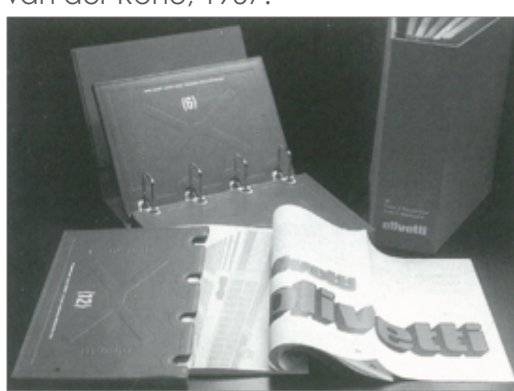

Figure 8. Olivetti Corporate Design manual.

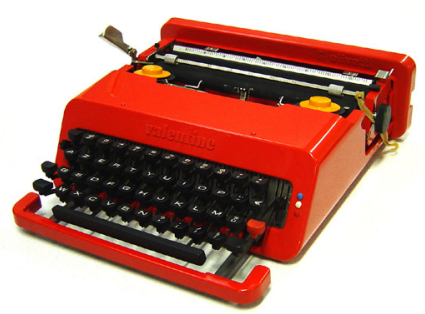

Figure 9. Olivetti Valentine Typewriter, 1969.

7. Olivetti is an Italian technology manufacturer founded in 1908. Originally specialising in typewriters (fig. 9) it now designs and manufactures computers and printers. 


\section{THE METAPHOR}

In response to corporations' weak architectural translation of their identity though design manuals, Post-modern architects attempted to materialise their ideas through metaphor. Invasion of the sign and advertising transformed architecture into a sign itself.
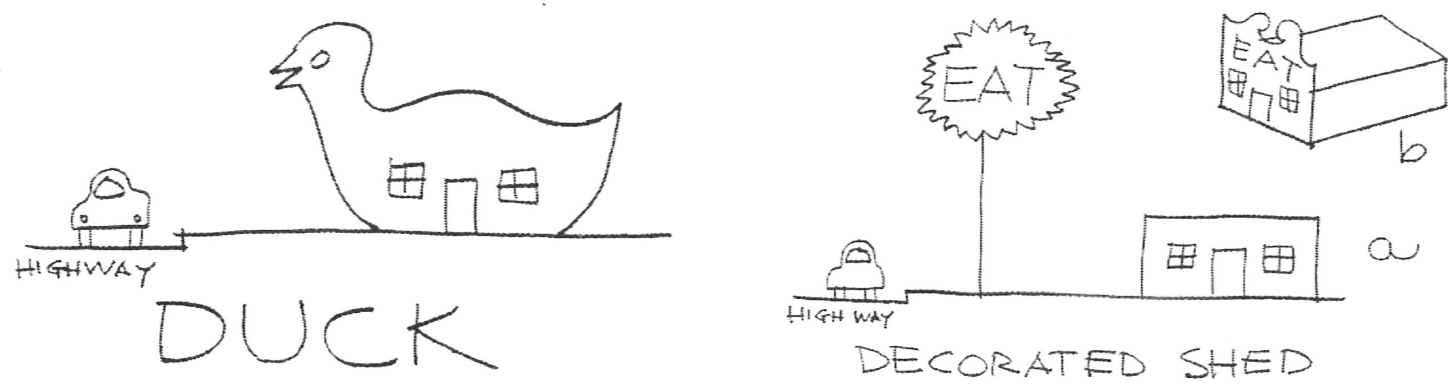

Figure 10. Duck + Decorated Shed, Learning from Las Vegas, 1972.
Robert Venturi and Denise Scott Brown illustrated architecture's struggle to communicate meaning with their study, Learning from Las Vegas (1972). They defined two examples of corporate architecture, the decorated shed and the duck. (fig. 10) The decorated shed was a response for low cost corporate architecture to communicate through signs attached to a building. The duck manifested when a building became the sign. The classic example given is a corporation, serving fried duck, within a building shaped like a duck (Venturi \& Brown, 1972).

Within a later commentary, Charles Jenks (1991, p. 39) states that metaphor in architecture is a verb, an active thought that occurs when we relate architecture to another object or experience. Throughout the Post-modernist era metaphor was explicitly used within corporate architecture. This was also a reaction to the Modernist movement and the struggle to metaphorically analyse the new archetype, creating a lack of connection to consumers.

Chris Abel $^{8}$, critiquing Jenks, identifies that there are positive and negative aspects to Post-modernist use of metaphor. Positive metaphors act as a chain of thought to desires of current society. He gives the example of the Olivetti training centre, Hampshire, England, ${ }^{7}$ designed by James Stirling (1969-72).(Fig. 11) The plastic modular nature of the building created a link to the product (typewriter), (fig. 9) which in turn conjures links to modernity and technology. Abel also identified negative metaphors within the same building. Influenced by personal preconditions, the viewer of the Olivetti building could also translate stacked trash cans. The issue, that Abel identifies, is that positive reactions are created through a developed understanding of architectural representation. Negative reactions are manifested when understanding of metaphorical language is lacking (Abel, 1997, pp. 100-
8. Chris Able's Book Architecture \& Identity (1997) critiques the role of metaphor in changing architectural concepts (Chapter 8). He provides a non post-modernist narrative of Jenks ideas identifying the issues of this era's use of metaphor. 
101). Venturi and Brown's, Jenks' and Abel's statements illustrate that Postmodern metaphorical architecture walks a fine line before becoming a sign. Within corporate architecture this line is often trodden and sign writing on a glass façade (decorated shed) is thought to be more successful than the architecture supporting it (Messedat, 2005, p. 79). The other extreme is when the building becomes the sign (duck). In this situation the metaphor to architecture itself can be lost. There needs to be a balance between the ambiguity of Modernism and the literalism of Post-modern architecture.

\section{GREEN IDENTITY}

In the late $20^{\text {th }}$ century emphasis on society's responsibility to the environment and each other became mainstream. With large groups of people sharing the same goals (including architects) corporations were forced to take responsibility for their actions too. Green identity, also known as but not limited to, sustainability, environmental design and ecological design is a form of corporate (architectural) identity that responded to environmental activism of the 1960s.

Ian McHarg was a founder of the principals of green identity through his manifesto, which presented five approaches to design with nature (1971, pp. 196-197)'. Many subsequent architects, Yeang (1998) and McDonough (2002) to name two, wrote their own manifestos on environmental design. This approach still continues to grow as society recognises the potential of green identity.
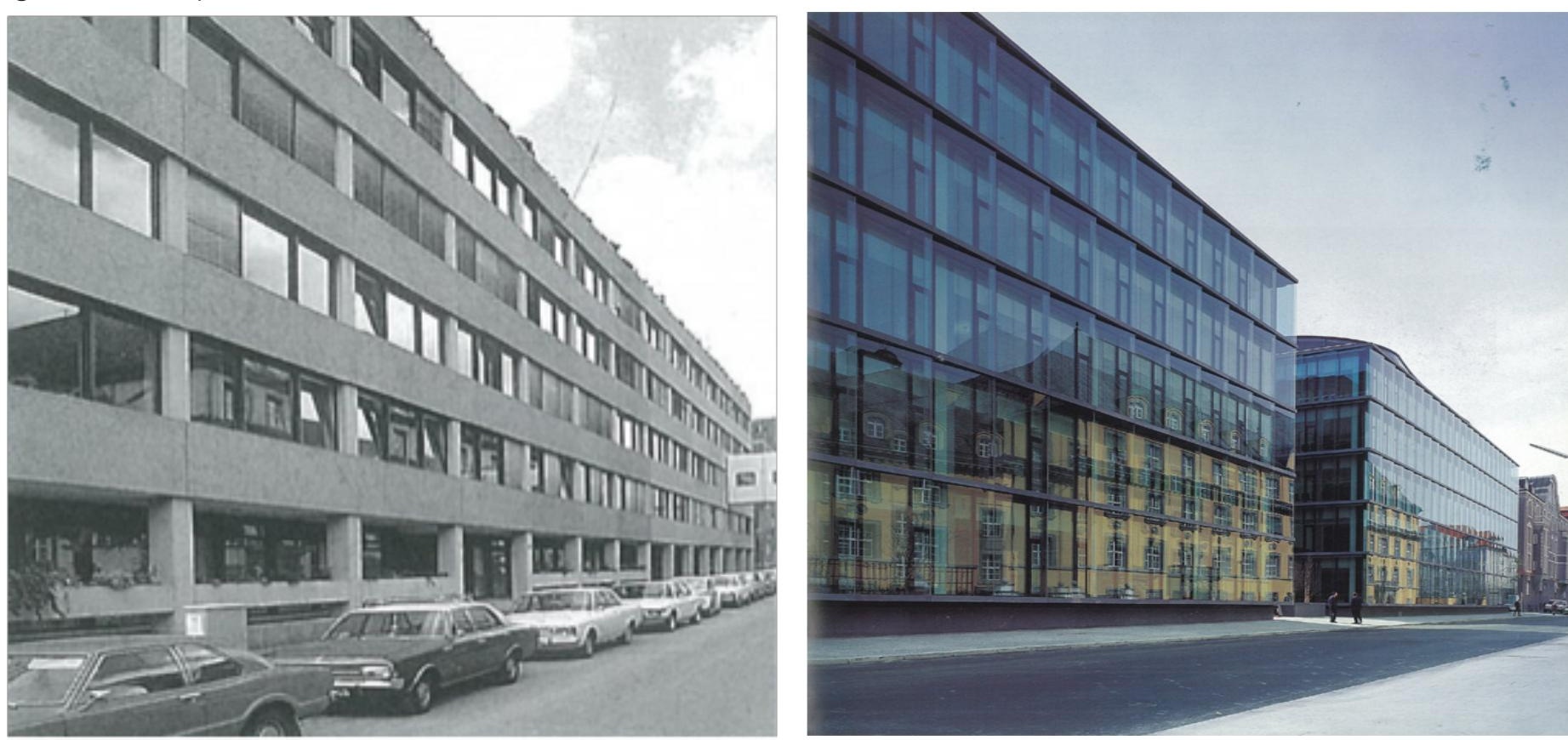

Figure 12. Before (1973) and after (2002) retrofit of an insurance building in Munich, Architects: Baumschlager \& Eberle. The retrofit reused the existing building and now uses $75 \%$ less energy than the existing (Schittich, 2003, pp. 114-123). 
9. McHarg's Model for designing with nature included five criterion:

- Negentropy, the increase in levels of order

- Appreciation, the capacity to transmute energy into information and thence to meaning and to respond to this.

- Symbiosis, the cooperative arrangement that permits increase in levels of order and requires apperception.

- Fitness and fitting, the selection of a fit environment and the adaption of that environment and of the organism, to accomplish a better fitting.

- Presence of health or pathology, the evidence of creative fitting, requiring negentropy, apperception and symbiosis.

McHarg believed his models contained all ecosystems, therefore determining their relative creativity in the biosphere.

10. Summary of Yudelson's Business case (2010, Chapter 2)

Benefits to the building owner:

- Economic and financial benefits; reduced operating and maintenance costs, tax benefits through government incentives.

- Productivity Gains; improved work environment, thermal, lighting.

- Risk Mitigation; less sick staff, reduced insurance, property value increases.

- Health improvements

- More competitive product

Benefits to tenants:

- Public relations and marketing Branding and Positioning a commercial property:

- Recruitment and retention of staff

- Top-line revenue gains through above techniques

Benefits to future financial performance:

- Energy cost reductions

Figure 13. Times Square 1919

compared to Times square 2009.
Recently the power of this movement has made green identity the norm for corporate architecture. However, the goals of running a good business and responsibility of providing a healthy environment still need to be treated equally (Yudelson, 2010). Jerry Yudelson is attempting to draw these, two seemingly polar opposites, together with his book, Greening Existing Buildings (2010). He describes a business case, aimed at corporations, to adhere to green identity and presents benefits to building owners and tenants. ${ }^{10} \mathrm{~A}$ critique of this work, Yudelson admits (pg 87-90), is that there are still limits to implementing mainstream green identity. These include, uneven distribution of benefits between building owners and tenants, and cost of upgrades to existing buildings, which can be higher than standard, non-green, new buildings. The main risk is that some corporations are changing their identity through bells \& whistles (Hosey, 2010). Lance Hosey believes that green identity must come from its origins, a holistic approach to design. This process creates a genuine identity and not, 'the presentation of cheap 'eyewash' showmanship' (Reichardt, Mass, et. al. 2010).

\section{A FUTURE IDENTITY CRISIS}

As illustrated, the speed in which corporations change is increasing, architecture must develop a response to this. Corporate metamorphosis has been implemented in management structure for some time. Used as a tool, it allows corporations to change their corporate structure to suit changing social and financial conditions when necessary (3Deluxe, 2008, p. 149).

Architecturally, corporate metamorphosis attracts a more refined and tangible meaning. It consists of a progressive sub category of corporate design (Circ, 2007), a method of designing expressively and adaptively to suit changes of internal corporate management (3Deluxe, 2008, p. 149). (fig. 14)
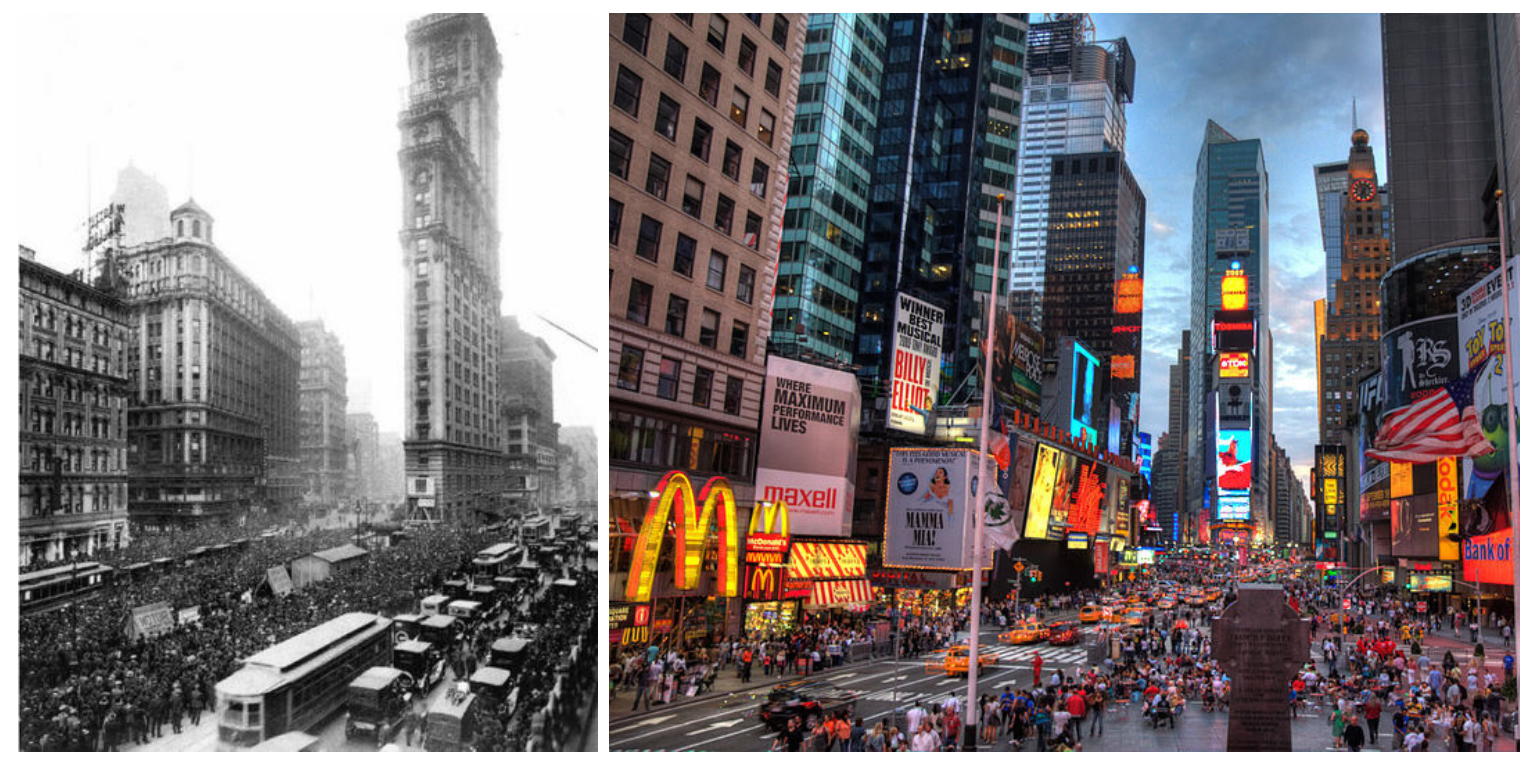


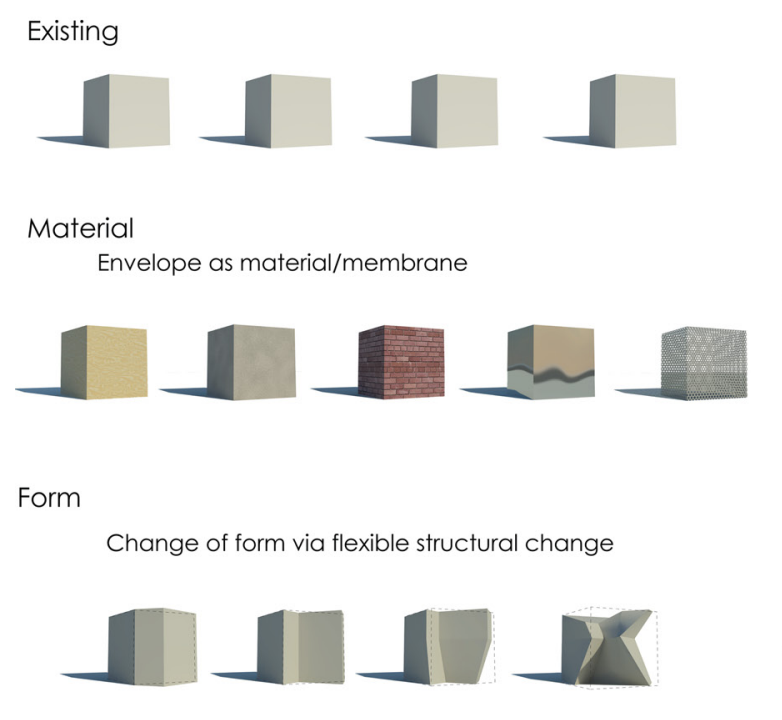

Hybrid
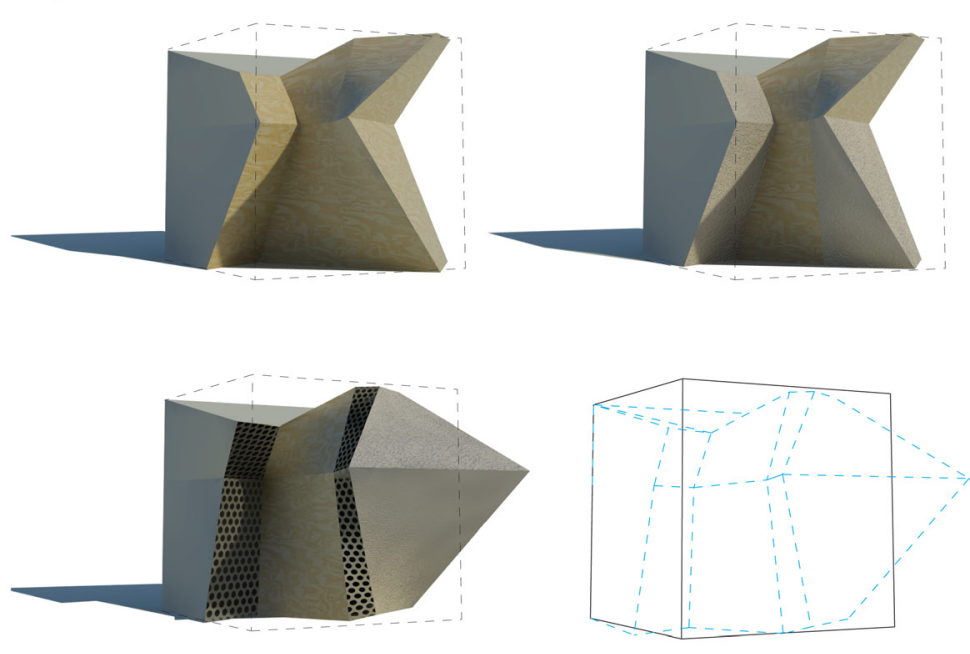

From analysing figure 13 it can be argued that contemporary corporate identity is attempting to deal with this utopian idea of timeless and fluid

Figure 14. Early experimental Interpretation of architectural architecture through media façades. This typology of façade, an adaptive corporate metamorphosis. two-dimensional electronic screen, often is applied to meaningless architectural form. Pop-culture media represented through this grid of electronic pixels, creates no physical connection to a buildings inhabitants. Therefore, another iteration of the corporate shield developed within the early $20^{\text {th }}$ century is recreated.

This chronological description now ends at the point where corporate architecture may recirculate or alternatively, a new type of more genuinely responsive corporate identity may develop. Through this discussion the history of corporate identity has been examined, particularly its relevance to corporate architecture.

\subsection{TRANSLATION + IMPLEMENTATION: STRATEGIES, TOOLS AND METHODS}

In this section, strategies, tools and methods for translating corporate identity and implementing corporate architecture will be presented to sumarise and provide an approach for the design case study. Two seminal texts on corporate architecture are examined. Firstly, Jons Messedat (2005) provides a critical strategic analysis of existing techniques and patterns within corporate architecture. His strategies are seen as an architectural approach attempting to influence corporations. In an advancing and process based method, Susanne Knittle-Ammerschuber (2006) responds to Messedat by elaborating on translation and implementation of corporate identity from a 
Figure 15. (Facing Page)Summary of Jons Messedat's strategies to implement corporate identity (Messedat, 2005, pp. 262-268). management approach. This is the opposite of Messedat as it is attempting to change architecture through management techniques. These two approaches will both be discussed to ascertain which characteristics from each are valid.

\section{STRATEGIC APPROACHES}

Messedat (2005, p. 261) states, 'Architecture can adopt a fundamental and defining role as an overriding design discipline within strategic management'. Furthermore, his approach to illustrating strategies of corporate identity translation is a predominantly superficial analysis. He reflects on his in depth historical research and case studies by presenting seven recurring, corporate identity themes. Figure 15 summarises Messedat's themes comparing their fundamentals, positives and negatives and an example he has presented.

These simplistic themes become ambiguous and remain as an analysis of existing examples rather than a progressive tool for implementing corporate identity. Furthermore, the seven categories provide a multitude of combinations that an architect may attempt to use. It is unfortunate that there is a lack of guidance to which category, or combination of, shall be utilised. Case-by-case assessment of the situation is paramount, however, if a project is client driven how does an architect know if the appropriate strategy is applied? More importantly, how does the architect convince a client to implement a particular strategy if they disagree? These are questions that will be investigated through the design case study.

A systematic scenario for implementing a corporate design system has also been provided by Messedat. He divides this system into four phases; investigation, development, integration and accompaniment. (fig. 16)

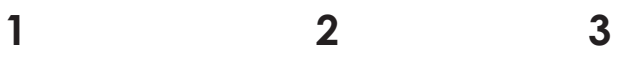

\begin{tabular}{|c|c|c|c|}
\hline Investigation $\rightarrow$ & Development $\rightarrow$ & Integration $\rightarrow$ & Accompaniment \\
\hline $\begin{array}{l}\text { Analyse the } \\
\text { situation at the } \\
\text { outset. Evaluate } \\
\text { the existing visual } \\
\text { characteristics } \\
\text { of the company, } \\
\text { buildings, logos, } \\
\text { stationary etc. }\end{array}$ & $\begin{array}{l}\text { Define the strategy } \\
\text { and goals. The core } \\
\text { values and goals } \\
\text { of the company } \\
\text { need to be fleshed } \\
\text { out and written in } \\
\text { a descriptive way } \\
\text { to orient possible } \\
\text { architectural } \\
\text { directions. }\end{array}$ & $\begin{array}{l}\text { Select the design } \\
\text { team. This can be } \\
\text { done externally, } \\
\text { internally or } \\
\text { through a design } \\
\text { competition. The } \\
\text { designers should } \\
\text { be familiar with } \\
\text { corporate design. }\end{array}$ & $\begin{array}{l}\text { Control and development. } \\
\text { The design team } \\
\text { and the company } \\
\text { representative(s) need } \\
\text { to keep to the original } \\
\text { values but also keep an } \\
\text { open mind to any new } \\
\text { developments that will } \\
\text { keep the company at the } \\
\text { forefront of their field. }\end{array}$ \\
\hline
\end{tabular}

This proposal for the implementation of corporate identity is not too different to any client - architect relationship. Potentially this shortfall is due to Messedat's focus on analysis of existing patterns within corporate architecture.

In a further attempt to clarify strategies, Messedat lists elements of corporate 

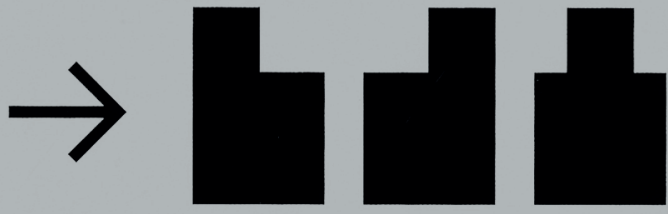

Characterisation by an Architect
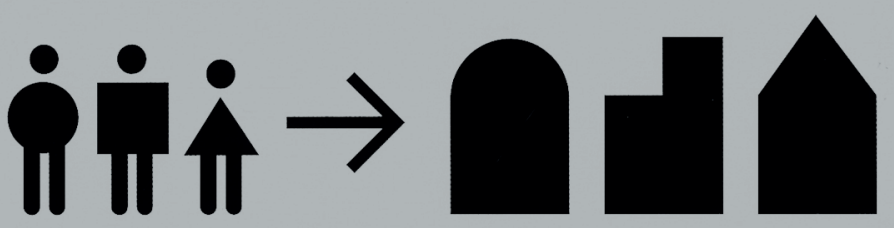

Collaborations with a Variety of Architects
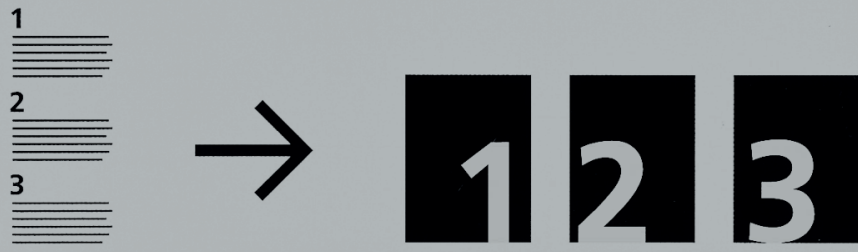

Expression of Corporate Principals
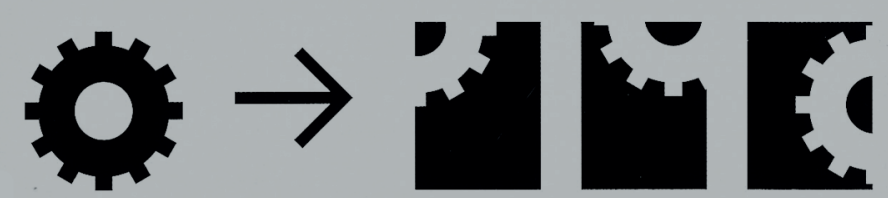

Associations with the Business Content

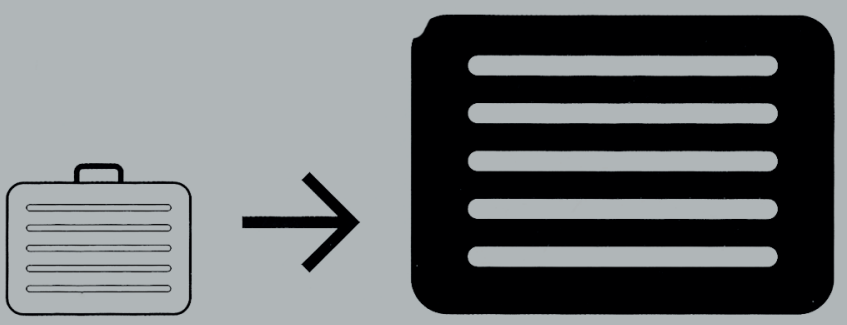

Architecture as a Portrayal of the Product
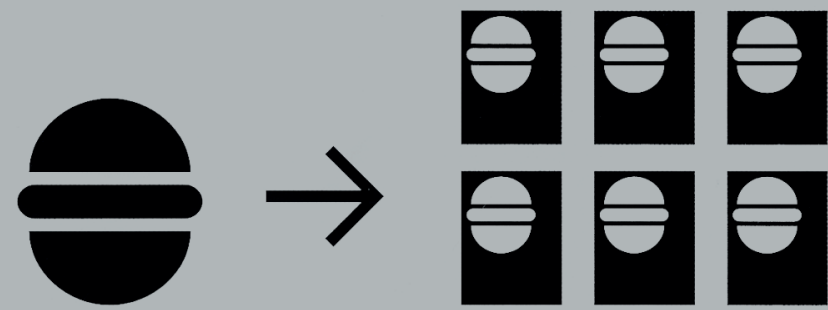

Recognisability through Repetition

\section{BRAND}
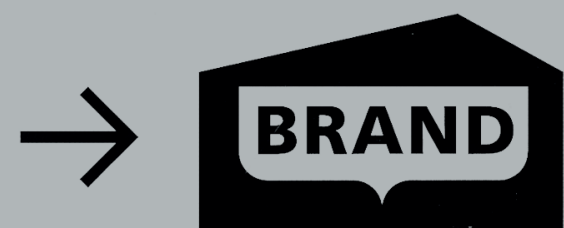

Communication of Brand Contents
+ Consistency of style and communication

_ Architect's personality can override corporate identity

+ Popularity through use of avant-garde designers

- Accumulation of fashionable architectural objects and inconsistency of ideas

+ Opportunity to represent corporate principals and structure

- Corporation must be consistent with their perceived image

+ Strong connection to corporate identity and environment

- Generates static architecture that cannot be adapted

+ Clearly understood advertising and link to product identity

- Can be overdone reducing architectural substance

+ Instant recognisability and connection to brand

_ Architecture becomes secondary and monotonous

+ Creation of experiences to connect consumers to the brand

- The corporate must create and believe in the experience
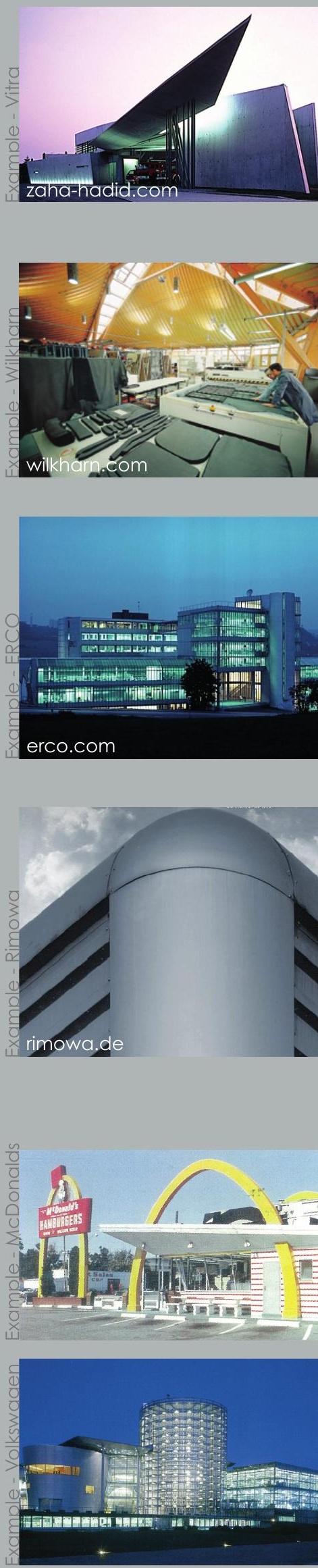
Figure 17. Components of corporate architecture(Messedat, 2005, p. 271).

11. This view of corporate architecture is not new. Chapter 2.4 elaborates on the origins of corporate architecture component analysis and design methods.

12. The goal is to optimally and appropriately represent a business internally and externally with qualitative buildings, spaces, and presentation concepts, which express the content, identity and personality of the company. Ultimately, corporate architecture can make an essential contribution to the economic success and to the culture of a business (Messedat, 2005).

Figure 18. (Facing page) Summary of Susanne KnittleAmmerschuber's strategies to implement corporate identity (Knittel-Ammerschuber, 2006).

architecture; external components (building shell), interior components (Interior design) and fit-out components (furnishings). (fig. 17)

\section{External components}

Building Shell

- Selection of the location in terms of visibility

- Design of the external works and landscaping

- Building Form and Façade

- selection of materials

- Use of colour text and signs

- Day and night appear-

ance through light and

illumination

This breakdown of corporate architecture ${ }^{11}$ provides allusion to a much more detailed corporate identity implementation system. It can be assumed that due to the multiplicity of methodical combinations Messedat has not attempted this. The outlook that Messedat provides, ${ }^{12}$ somewhat similar to the definition of corporate identity, is overshadowed by his identified limits (2005, p. 272). Ultimately it can be concluded that the fluidity of contemporary corporate culture provides corporate architecture with its major contest. How can it respond to the changing nature of business size, technology, goals, methods and image? Perhaps the increasing significance of corporate architecture will help develop a solution. Knittle-Ammerschuber's attempt is discussed in the following section, Management by Architecture.

\section{MANAGEMENT BY ARCHITECTURE}

In a response to Messedat's definitive analysis of existing examples, KnittleAmmerschuber (2006) provides an integrative, management based, design process, also giving examples of component translation and implementation within corporate architecture. She splits her analytical and methodical description into two parts, both focused on management techniques that are aimed at the corporate reader rather than Messedat's architectural targets. The first strategy is Management by Architecture: Methods, which describes the implementation of corporate identity through key business administration design and ordering principals. Secondly, Knittle-Ammerschuber describes Management by Architecture: The Practice. In this section the narrative shifts to explain the process of implementing corporate architecture through an 'architectural process' perspective. Both methods will be presented and discussed, firstly to compare Messedat's strategies and secondly to summarise both authors' ideas and identify gaps and issues within corporate identity theory. The following table(fig.18) analyses Management by Architecture: Methods by identifying the hierarchy of management methods through 
Process of information

and message

communication

exchange

motivation

Strive to increase

productivity

Critically observe facts and data to propose

creativity

unconventional solutions

\section{People}

Architectural language

Productive environment

New incentives from immediate environment

Architectural Flexibility
Architectural hierarchy of structure and spatial mediation Macro to micro levels of transparency

Level of inter-hierarchy concealment

Levels of

Structure

\section{System}

technique +
technology production technology

innovation Emee

Employee
+ freedom

Sequence of functions process to reach business goal

Quality
quality management systems Communication of services + marketing product to consumers
Primary attitude management $\begin{array}{r}\text { towards tasks, services } \\ + \text { employees }\end{array}$

\author{
corporate \\ identity
}

Tool to create corporate image
Technical infrastructure + services

Innovative + creative planning Process based architectural arrangements

Quality of fit to internal + external users Expression of aesthetic brand experience

\section{Planning + design of} work environment

Impressive, memora-

ble, unified experience for consumers + employees
Innovative service integration + technical infrastructure

Novel + unique architectural components Synergy of spatial layout + corporate processes

Usability + durability of architectural systems

Unique components to stimulate interest

Visual representation of management structure + Style

Suitable architectural expression of all visual elements 
to architectural techniques. Four management techniques are presented by Knittle-Ammerschuber and compared to architectural practice and techniques. These methods are attractive as they can be read from a corporate or architectural perspective. However, the translation, based on metaphorical translations of words, can attract very personal interpretations. Therefore, she has attentively reinforced each translation with an example, that through a wider reading of corporate architecture can be seen as the norm. This approach improves both architects' and corporations' understanding of complexities when implementing corporate identity.

The second, process based, strategy is, Management by Architecture: The Practice. Knittle-Ammerschuber warns against the late inclusion of the architect within corporate projects (2006, pp. 138-139). This generally happens when corporations attempt to quantify spatial requirements without an architects' input. The corporation then develops strict design manuals that create issues for an architect to provide quality advice. To avoid this she suggests Degenhard Sommer's 'work phase o' (1993). This strategy involves the corporation consulting an architect at the beginning of an architectural project to develop strong understandings of each other's goals and methods (Knittel-Ammerschuber, 2006, p. 139). Furthermore, When communication begins between the corporation and architect, clear goals need to be defined in the form of a written mission statement, if not done previously. This is the condensed, communicated version of a corporation's goals and aspirations providing an ideal basis for developing architectural concepts (Knittel-Ammerschuber, 2006, p. 140). Once the mission statement is obtained, the ephemeral task of analysis and translation needs to be undertaken. Although the translation process is not clearly defined, KnittleAmmerschuber does provide an insight into the life of the building after the design and construction has been completed. Regular investigation needs to be carried out within the corporation to assess if the culture of the company has changed and the suitability of the architectural environment (2006, p. 155).

Knittle-Ammerschuber's research into corporate identity theory elaborated implementation strategies, tool and methods. However, it has been identified that there are still no developed guidelines to implement corporate architecture. In searching for a strategy within Messedat and KnittleAmmerschuber's texts they both cannot crystallise a method to follow. Instead, possibly because of the diversity of architecture, they can only suggest professional skills of architects be used to translate corporations' identities into architectural form. Therefore, a collaborative approach, using 
Messedat and Knittle-Ammerschuber's techniques, methods and tools will now be discussed to ascertain a holistic approach for the design case study.

\section{STRATEGIC MANAGEMENT BY ARCHITECTURE}

From the investigation of two corporate identity texts, a conclusion about their success and limitations is now presented. This will be used within the design case study, which will also act as an experiment to test limitations of the combined strategies. Firstly, a key issue which can be concluded from discussing both texts, is the lack of developed strategic advice to translate and implement specific corporate identity. Knittle-Ammerschuber has provided an easier way to translate business structure into architectural concepts, however, she concludes her translation strategies by assuming the skill of an architect will deal with particularities. Perhaps for the retention of individuality within corporate architecture, this is beneficial. Furthermore, within the architectural profession creativity is embraced and a rigid set of translation guidelines would possibly stifle further development. Another important issue that both authors foresee, and fail to strategise, is the aspect of time in corporate architecture. As illustrated in section 2.2 corporate culture is, and always will be, in a state of flux. Its intangible state has allowed it to adapt to changes that consumers and other corporations demand. However, in our lifetime, architecture will remain to be a tangible and physical object. Corporations and architects can only prepare for changes based on existing trends. Figure 19 chronologically positions both authors' strategies, techniques and methods along a timeline of a typical corporate building. This diagram illustrates that corporate identity theory does not adequately include the aspect of change within the design phase and after the building is inhabited. It is seen as a utopian idea. To further investigate ideas of time and change in corporate architecture theories of Francis Duffy, Stuart Brand and Smart Architecture Foundation will be presented. This will juxtapose the theoretical translation and implementation with tangible aspects of corporate architecture layers to hypothesise a solution through the design case study.

\subsection{SPEED THEORY - CORPORATE ARCHITECTURE BREAKDOWN}

To further investigate translation and implementation of corporate identity into corporate architecture, components or 'layers' will be discussed. Layers are based on time and are a system of categorising significant elements of corporate architecture. This diachronic, facilities management approach of looking at buildings was founded by Francis Duffy (1990). This section will analyse what I term, Speed Theory ${ }^{13}$ and its development through

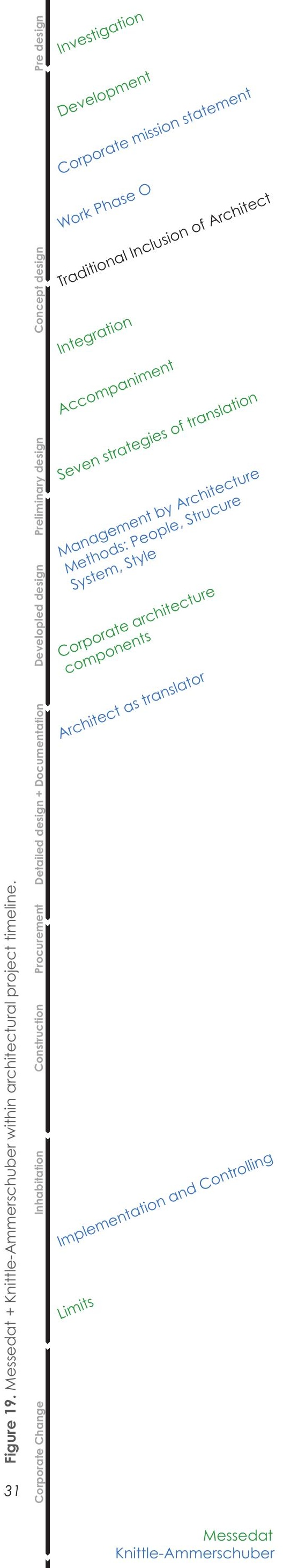


13. Speed theory, within the context of corporate architecture, is the chronological analysis of building layers. Francis Duffy called them Layers of Longevity (1990), Stewart Brand: Shearing Layers of Change (1994), SLA titled their analysis Changing Speeds (2003). The name Speed theory is used to encompass all these theories and their development over time.

14. These three theories were originally juxtaposed diagrammatically in Rethinking Technology: a reader in architectural theory, Edited by William W. Braham, Jonathan A. Hale, and John Stanislav Sadar (2007, p. 438).

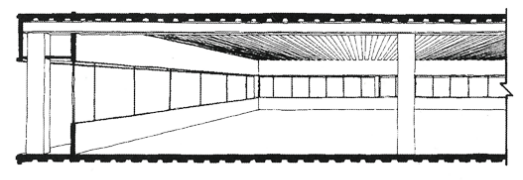

(- The building shell. Lifespan: 50-75 years. Structure, cladding (skin).

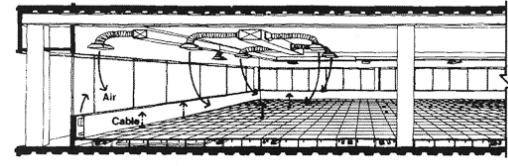

(2) Services. Lifespan: 15 years. Heat, ventilation, light, power

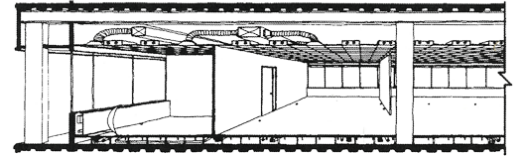

(3) Scenery. Lifespan: 5 years. Fixed interior elements - ceilings, partitions finishes, infomation technology equipment.

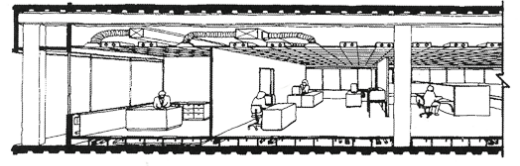

(1) Settings. Day-to-day rearrangement. Office furnishings.

Figure 20. Shell, Services, Scenery and sets.

Figure 21, 22, 23 (Facing Page) Reinterpretation of Duffy, layers of longevity (1990), Brand, Shearing layers of change (1994), and SLA, Changing speeds (2003) as originally juxtaposed in Rethinking Technology, See note 14 investigations of Francis Duffy, Stewart Brand and Smart Architecture Foundation (SLA)..$^{14}$

Measuring Building Performance (1990), is Francis Duffy's attempt to rationalise the importance of facilities management to builders, owners and architects. Duffy, an architect himself, saw limitations in measuring buildings through cubic meters and square areas. Thus, he proposed a more economically viable approach where time should be the main unit of measure. (fig. 20 + Fig 21) In terms of corporate identity, Duffy's theory lacked the inclusion of inhabitants', specifically their image. He explicitly states, 'Understanding what they (buildings) are for - a resource that can be used by organisations and individuals to achieve their goals - is the essence of facilities management' (Duffy, 1990). As explained in section 2.2, by 1990 the image of corporations had already become a major part of what corporate architecture (buildings) is for. Moreover, what Duffy produced is not only a way of analysing the life cycle of a building, but also a way of approaching design. This is evident through the following major iterations of his ideas.

Following Duffy's plea for architects to incorporate 'layers of longevity', Stewart Brand (1994) analysed the potential of speed theory. He expands Duffy's corporate and financial focused layers into more generally applied 'six S's'. (fig. 22) One vital development that Brand makes is that layers are interrelated, therefore if one changes in the design process or after building completion, others are affected. Brand states that his 'layers of change' are different to Duffy's by considering design and construction (design process, translation) as well as life cycle (building behaviour, implementation) (Brand, 1994 , p. 13). This solidified Duffy's ideas as a design system. However, like Duffy, the inhabitant (corporation) is still not visible within speed theory.

SLA's attempt at speed theory (fig. 23) is founded in the recent focus of corporations sustainability, green identity. As a consortium of architects, SLA's self proclaimed mission is to, 'create and discuss concepts and ideas for buildings and cities that combine optimum performance with a minimal use of materials and energy'(SL.A, 2003, p. 171). Approached as a proposition of flexibility within design, SLA has sought to provide a design tool to mediate issues of future change in architecture. Furthermore, they warn against mixing layers, as this will generate issues at interlayer interfaces. However, once again the importance of the inhabitant is still treated as secondary.

From economic origins, this theory has evolved into a design tool. Through these layers, a multiplicity of design relationships can be foreseen and interface issues predicted. This becomes an advantageous approach, 

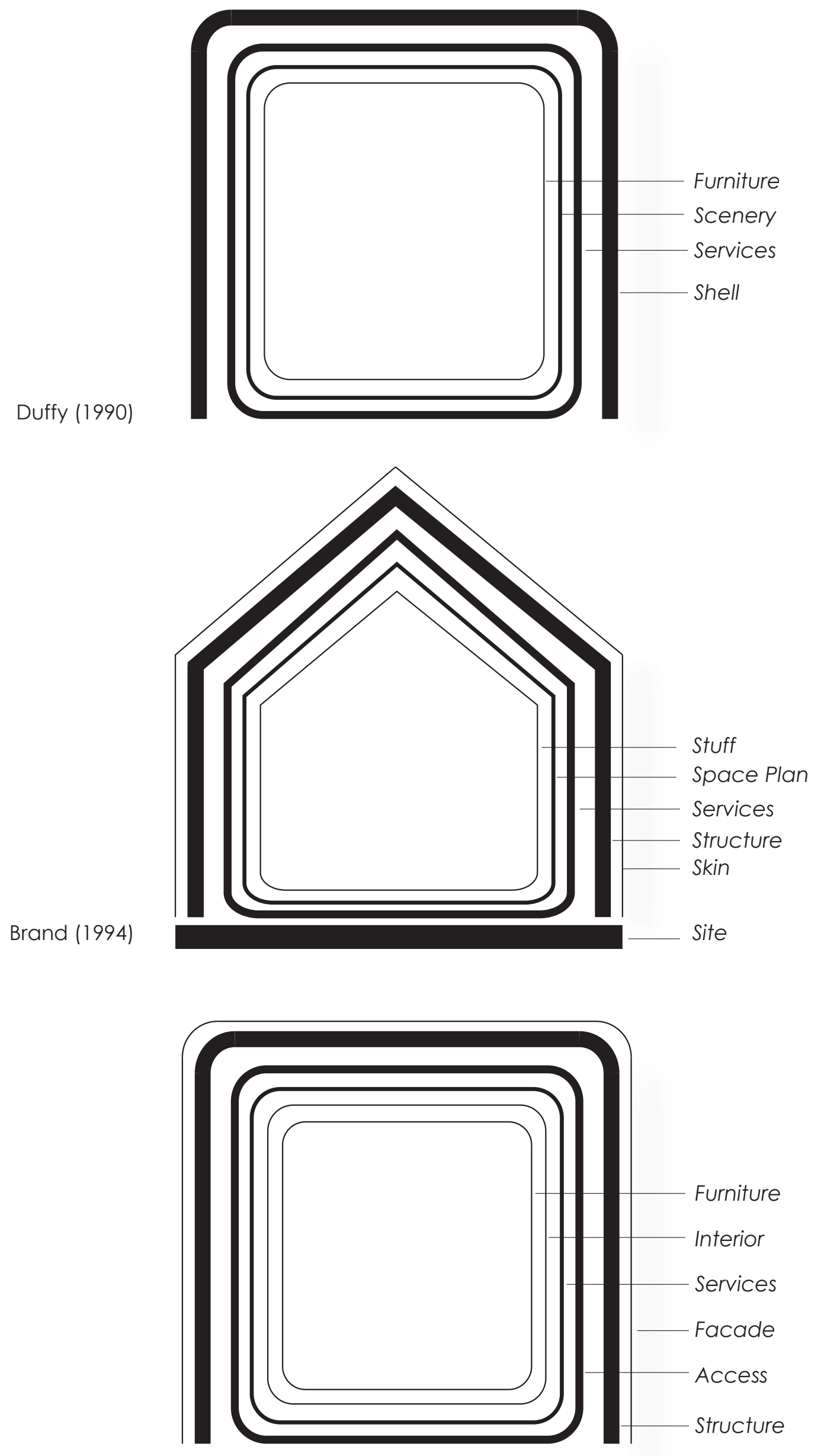
especially if flexibility or future change is necessary, which has been illustrated in section 2.2. However, throughout the three iterations of speed theory, corporations' representation within the diagrams remains absent. This way of analysing and designing corporate architecture could be further improved with the inclusion of previously discussed corporate identity theory and practice. This will be proposed in the following section then tested within the design case study.

\subsection{RETROACTIVE CORPORATE IDENTITY}

The development of corporate identity theory can be concluded to provide an opportunity for a new interpretation of corporate architecture. This involves developing existing strategies to translate corporate identity into layers of corporate architecture to address issues of change. To reach this conclusion meanings and terms central to this thesis have been defined. The history of corporate identity and corporate architecture was described and analysed, identifying issues and innovations that have developed over the last century. Contemporary strategies, tools and methods of Messedat and Knittle-Ammerschuber have been discussed. Iterations of speed theory was then systematically analysed to identify translatable components of corporate architecture and systems to consider change. To explore the above information and improve the synergy of corporate identity and corporate architecture, the design case study will test translation and implementation techniques, through speed theory, with concentration on the identified issue of flexibility. This will manifest through a multistorey corporate architecture retrofit, with the implementation of a corporations identity.

\subsection{REFERENCES}

3Deluxe. (2008). 3deluxe: transdiciplinary approaches to design. Netherlands: Frame Publishers.

Abel, C. (1997). Architecture and identity: towards a global eco-culture. Oxford: Architectural Press.

AEG. (2010). AEG History. Retrieved 16/11, 2010, from http://www.aeg. com/node367.asp.

Ambrose, G. (2008). The visual dictionary of architecture. New York: AVA Publishing SA.

Black's law dictionary. (2009). St. Paul, MN: West.

Brand, S. (1994). How buildings learn: what happens after they're built. London: Phoenix Illustrated.

Circ. (2007). Essay. Retrieved from http://corporate-lexicon.com/pdfs/Essay_english.pdf. 
Collins English dictionary. (2000). London: Collins.

Duffy, F. (1990). Measuring Building Performance. Facilities, 8(5), 17-20.

Ford Motor Company. (1915). Ford Factory Facts. from http://www.mtfca. com/books/15_factory.htm.

Friedman, S. S. (1998). Mappings: feminism and the cultural geographys of encounter. Princeton, N.J: Princeton University Press.

Gartman, D. (2009). From autos to architecture: Fordism and architectural aesthetics in the twentieth century. New York: Princeton Architectural Press.

Hosey, L. (2010). Gizmo green: sustainable design deserves more than bells and whistles. Architect, 99, 29.

Jencks, C. (1991). The language of post-modern architecture. New York: Rizzoli.

Knittel-Ammerschuber, S. (2006). Architecture of success: building strategies and business. Boston, MA: Birkhäuser.

Kravel, J. (2008). Corporate buildings. Barcelona, Spain: Links.

McDonough, W. (2002). Cradle to cradle: remaking the way we make things. New York: North Point Press.

McHarg, I. L. (1971). Design with nature. New York: Doubleday/Natural History Press.

Messedat, J. (2005). Corporate architecture: Development, concepts, strategies. Ludwigsburg: AV Edition.

Reichardt, J., Mass, B., et. al. (2010). Aesthetic and Efficiency. Retrieved 6 May, 2010, from http://www.r-m-a-architekten.de/index_e.html.

Rowden, M. (2000). The art of identity: creating and managing a successful corporate identity. Aldershot: Gower.

Schittich, C. (2003). Insurance Building in Munich. In C. Schittich (Ed.), In detail: Building in existing fabric: refurbishment, extensions, new design (pp. 114-123). Boston: Birkhäuser.

SL.A. (2003). Smart architecture. Rotterdam: 010 Publishers.

Sommer, D. (1993). Industriebau: Die Vision Der Lean Company: Praxisreport. Verlag AG: Birkhäuser.

Venturi, R., \& Brown, D. S. (1972). Learning from Las Vegas. New York: Routledge.

William W. Braham, J. A. H., and John Stanislav Sadar (Eds). (2007). Rethinking technology: a reader in architectural theory. New York: Routledge.

Yeang, K. (1998). Bioclimatic skyscrapers. London: Ellipsis.

Yudelson, J. (2010). Greening existing buildings. New York: McGraw-Hill. 


\section{0}

The design case study, termed; Retroactive Corporate Identity, is split into translation and implementation. These two areas of corporate identity theory, identified in chapter 2.0, are vital to the manifestation of corporate architecture. The aim of this chapter is to discuss translation of the selected corporation, to develop an architectural mission statement. Firstly, the selection of Fisher \& Paykel Appliances Holdings Limited (FPA) is explained. This is followed by an analysis of the corporation, starting with a historical description to ascertain founding characteristics of their current corporate identity. To aid translation, two corporate mission statements have been examined to identify significant characteristics and extract architectural concepts that exist within both. This analysis culminates in an architectural mission statement, a declaration of driving concepts that is then applied in the second stage of the design case study, implementation (chapter 4.0).

\subsection{CORPORATION SELECTION}

Ultimately, in the context of advancing translation and implementation strategies that have been discussed, the selected corporation can be seen as interchangeable. However, due to the nature of research and for the purpose of this design case study, a corporation was chosen. Below are the basic parameters that were initially used for selection:

- The corporation is to be of a scale to occupy a multistorey office tower.

- The corporation needs to be renowned, therefore, providing extensive marketing material and independent commentary to analyse.

- The corporation must already occupy one or more multistorey buildings, or show interest in doing so.

- They shall produce tangible products, to allow translation of physical concepts as well as intangible characteristics.

- Have potential to show interest in undertaking an innovative project. 
Fisher \& Paykel Appliances Holdings Limited (FPA) was deemed to fit these parameters, therefore, selected. FPA are of a scale to occupy a multistorey office building with approximately $300+$ New Zealand based administration, design and research staff. They are well-known, with extensive historical, marketing and independent information sources. They currently occupy a large amount of real estate of factory typology containing both administration and manufacturing facilities. FPA also produce tangible appliances used within residential architecture, furthermore, their creative and innovative history makes them a perfect candidate for this design case study. The selection of FPA provided a corporation, with a suitable identity, to translate and implement within the design case study.

\subsection{FISHER \& PAYKEL - THE CORPORATE IDENTITY}

After selection, FPA's history has been examined. This analyses their corporate identity development by discussing the foundation of the company, what they produce, their current corporate architecture and the corporate structure of the company.

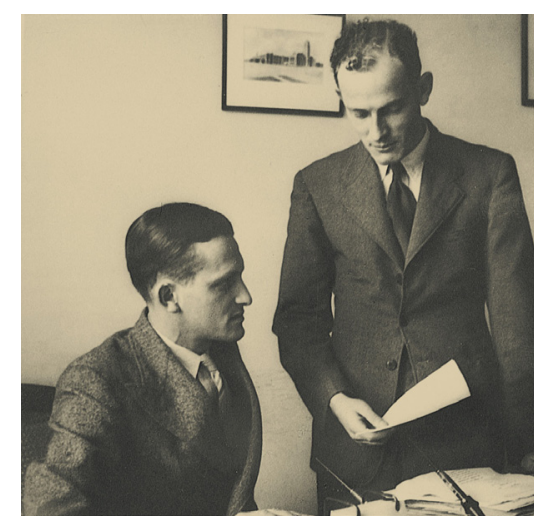

Figure 24. Fisher \& Paykel founders, Woolf Fisher (left) and Maurice Paykel (right).

Figure 25. Position of FPA offices and factories.

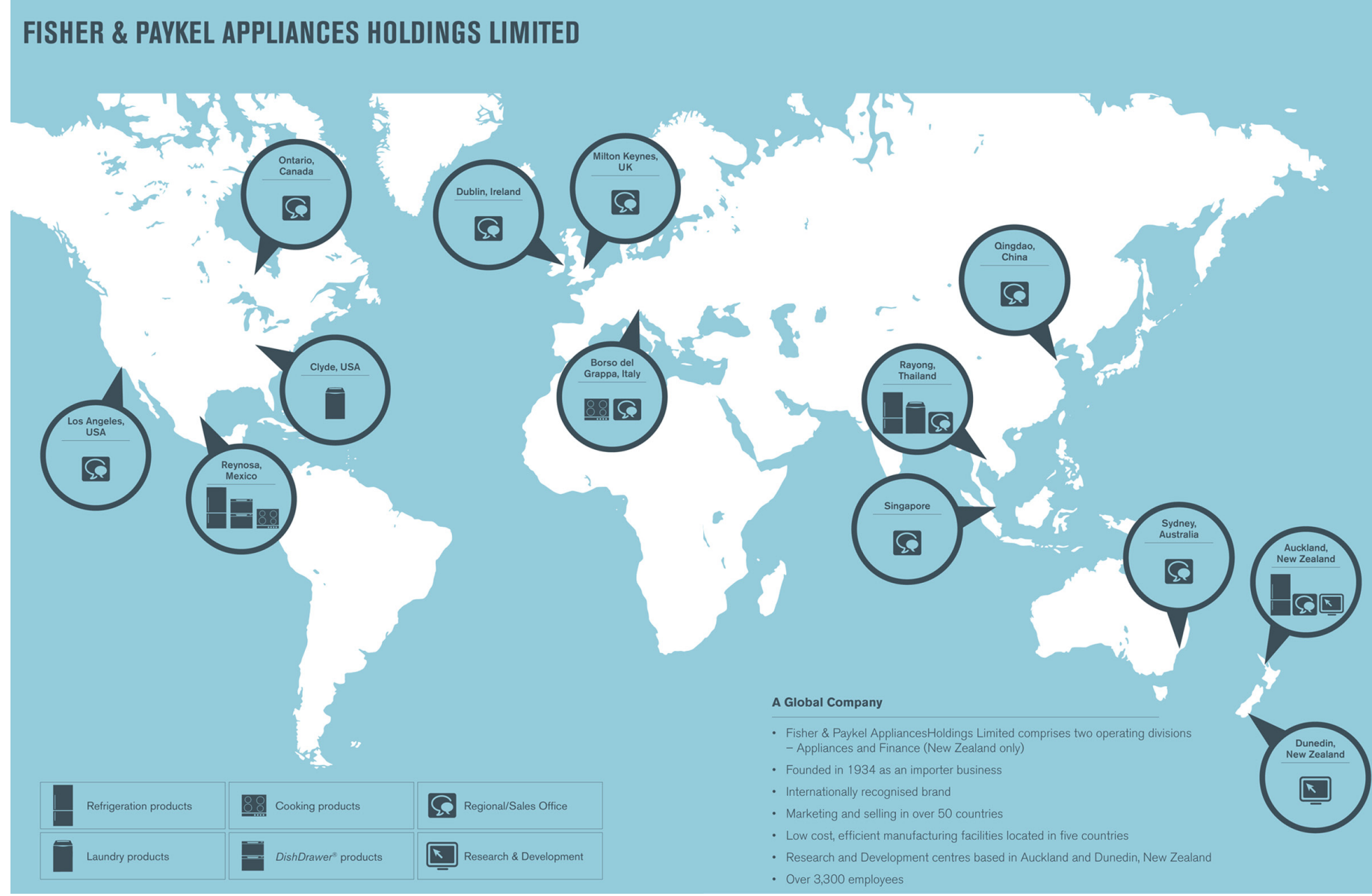



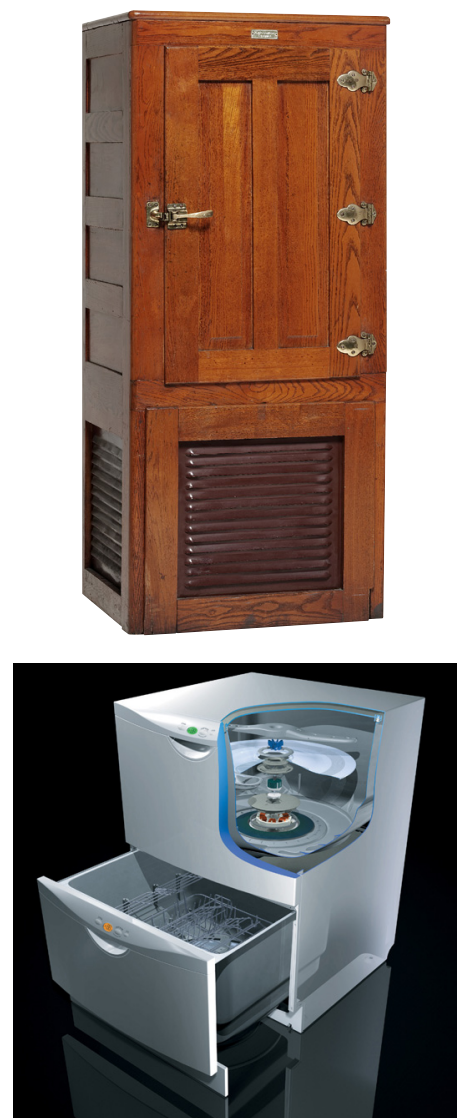

Figure 26. FPA products, Fridge (1930), Double Dish Drawer (1997).

Figure 27. Carlaw Park Lane Factory.
Maurice Paykel and Woolf Fisher (fig. 24) formed FPA in 1934 as an importing and distribution business of home appliances. In 1938, FPA developed into a licensed manufacturer of washing machines when import restrictions were introduced. This forced them to develop their own innovations for manufacturing home appliances, which are now sold in over eighty countries

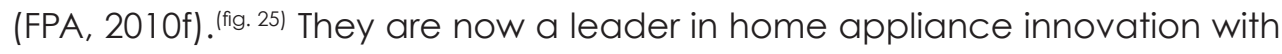
key product developments(fig. 26) including: the introduction of electronic appliance control in 1985, the launch of the smart drive washing machine in 1991, also in 1997 the double dish-drawer was released and more recently a drawer based refrigerator (FPA, 2010f). The latest product innovation is a refrigerator compressor that uses $30 \%$ less energy than conventional technology (FPA, 15 September 2010). Through this extensive corporate and product history, based in New Zealand, they have recently launched into international manufacturing markets. Manufacturing in New Zealand is becoming financially unviable, however the quality management and design that has founded the company's identity has been heavily influenced by its New Zealand location. 
FPA's core business management and research and development (R\&D) departments have been based in New Zealand since the founding of the company. ${ }^{\text {(fig. }}$ 27) Their public corporate architecture started with a showroom on Queen Street, Auckland to sell imported appliances. From there, FPA expanded to large administration, R\&D, and manufacturing plants in East Tamaki, Auckland and Mosgiel, Dunedin (FPA, 2010f). However, over the last 20 years they have constantly expanded manufacturing facilities in other countries in search for affordable labour and central global distribution points. This global redistribution has forced the closure of the manufacturing plant in Dunedin (2008) and, it can be assumed the inevitable closure of the East Tamaki plant. Administration and R\&D do still remain in both Auckland and Dunedin. (fig. $28+$ fig. 29) In both locations the large factories are flanked by domestic style and scale office space. Specifically, the East Tamaki plant currently occupies over $35000 \mathrm{~m}^{2}$ split into $25000 \mathrm{~m}^{2}$ of factory space and $10900 \mathrm{~m}^{2}$ of administration, management and research and development areas. ${ }^{15}$ Mason \& Wales architects were presented with the following design brief in 1991 for the construction of the East Tamaki offices (Barry, 1991):

1. Integrate all functions at one site.

2. Link all existing buildings onsite.

3. Provide single storey construction to remove hierarchical divisions inherent in multistorey construction.

4. Provide an open plan office environment to break down physical barriers.

5. Visually and functionally link all management and manufacturing functions on site.

6. Provide a cafeteria for to serve both office and factory staff.

7. Provide high-tech information/communications/environmental systems with maximum flexibility.

8. Architectural appearance shall be low-key, simple, without extravagance, and without display to the street.

9. Construction shall be simple and cost effective.

This ambiguous design brief addresses simple issues leaving the architect's to perceive what these statements mean. Number eight, which omits architectural expression to the public, presents a significant issue with this brief. Perhaps, the industrial location of these factories and lack of consumer interaction allow FPA to dismiss the need for complex architectural expression. Through the next two examples of corporate architecture it is obvious that FPA is beginning use it as a tool for expression.
15. Calculated from a scaled copy of the floor plan. (fig. 28) 

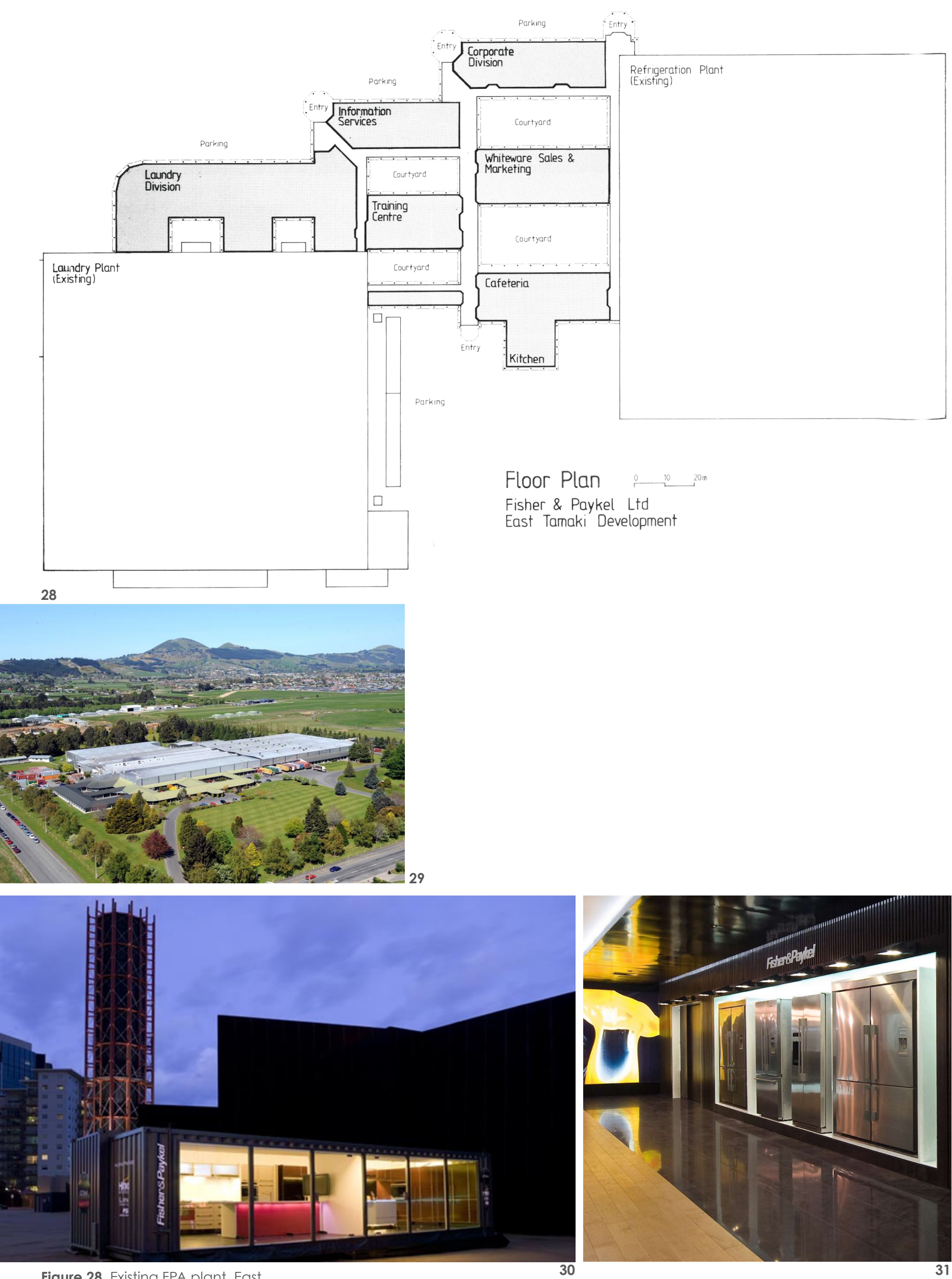

Figure 28. Existing FPA plant, East Tamaki Auckland, Original Plan.

Figure 29. Dunedin Plant.

Figure 30. Project Ironside.

Figure 31. Fisher \& Paykel Experi-

ence Centre, Hangzhou, China. 
Project Ironside, (ifi. 30) a portable exhibition, is used to display what FPA see today's kitchen and tomorrows kitchen (Sheppard, 2009). Two kitchens, of different quality, are installed within a shipping container that can be transported, expanded and used where FPA see fit (Davies, 2008). This dynamic form of corporate architecture is uninhabited creating a major link between the product and consumer treating the relationship to the company as secondary. Another new, but similar, architectural concept is the Fisher \& PaykelExperience Centre, located in a luxury shopping mall in Hangzhou, China, opened on 23 May 2010. FPA are planning to implement three more of these (permanent versions of Project Ironside) experience centers (FPA, 2010a) aiming to increase awareness of products within the China Market (FPA, 2010e). These two innovative and tangible marketing strategies are a new move for FPA showing their developing commitment to corporate architecture. It can be concluded that the current structure of FPA is going through a major change with the movement of manufacturing offshore. Furthermore, the current typology of the factory and management is horizontal, therefore, with the removal of manufacturing, FPA have the opportunity to move to a more visible urban location creating a necessity for corporate identity translation and implementation. These existing architectural implementations will be revisited in chapter 4.0.

\subsection{CORPORATE MISSION STATEMENT}

Translation of corporate identity begins with a corporations mission statement which provides an ideal basis for developing architectural concepts (KnittelAmmerschuber, 2006, p. 140). This section discusses two of FPA's mission statements comparing aims to develop an understanding of, firstly, what the underlying identity of the corporation is, and secondly, if any trends are developing to identify change. Before the comparison is described, an approach against Knittle-Ammerschuber's advice is worth mentioning. This was the communicative disconnection to the corporation. Avoidance of personal contact was important, as development of the architectural mission statement was preferably only to be influenced by available marketing material. Marketing communicates corporate identity information about a corporation without direct interpretation from individual employees. Also, the approach through an 'outsider's eye' is similar to that of a consumer and removes any corporate bias. Furthermore, the issue of a strict, spatially driven, corporate design manual is avoided. As mentioned, this can force the architect to retrospectively apply identity based concepts to a defined and inflexible programme (Knittel-Ammerschuber, 2006). 


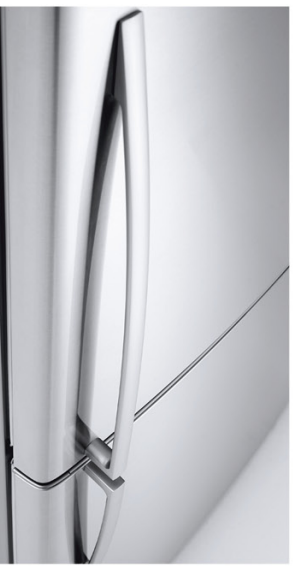

Syle is about desirability, it reflects the way in which we do things. It's not only the way we design our products; it's the way in which we evolve in response to change.

\section{Style}

Figure 32. DNA Mission statement. 16. DNA within FPA's mission statement attempts to relate to the biological meaning of DNA, which is the genetic makeup of a human, which define ones identity (Collins English dictionary, 2000).

Figure 33. Experience Mission statement, Heart \& Soul.

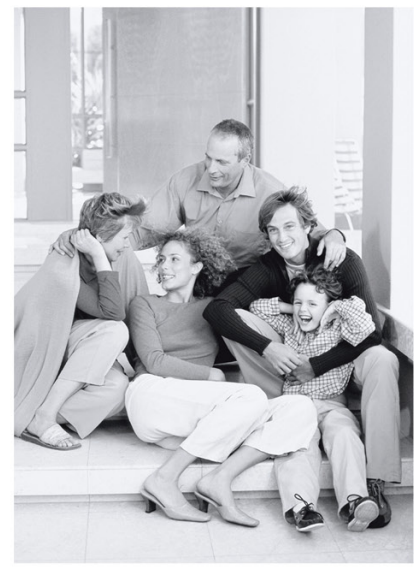

Integrity is about building relationships with our customers, it reflects the way we go about our business; the trust behind our reputation; the way in which we build our values.

\section{Integrity}

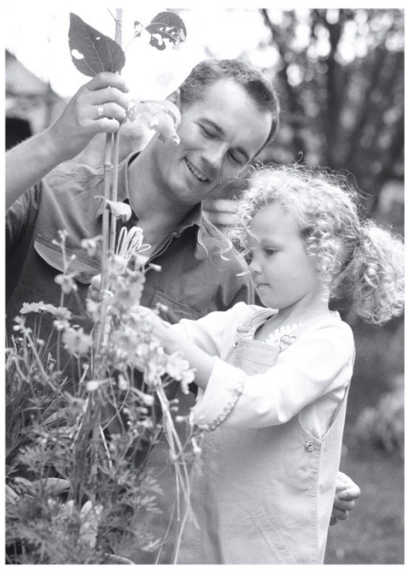

Care reflects how we look after all with whom we come in contact; our respect for the environment; and the way in which our people go about their roles.

\section{Care}

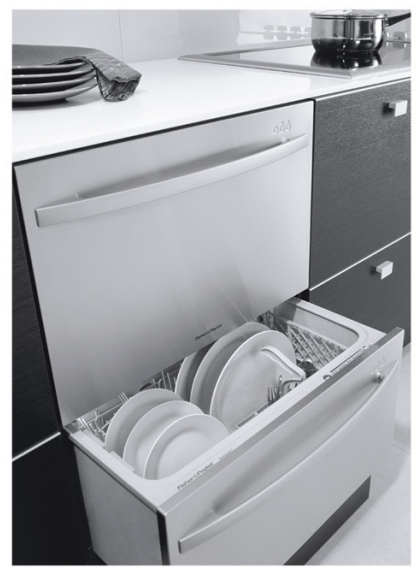

Innovation is our heart; we are innovative in all that we do, from the big ideas through to the detail.

Innovation

The first mission statement, circa 2005, is based on DNA ${ }^{16}$ (FPA, 2010b). (fig. 32) This presents the company as a personal, unique, professional and human collective that consumers can relate to and trust. Presentation of DNA was also used to inspire employees. The key words feature on walls of the East Tamaki headquarters to remind employees of the corporations mission (Revington, 2005). Four key words; Style, Integrity, care and Innovation make up the mission statement. These are supplemented with a small explanatory statement that signify the use of 'we', directly referencing the relationship between the corporation and the consumer. The importance of this will become evident in the following paragraph. This campaign worked well as economic success was achieved over its existence. However, after the 2008 global recession and closure of the Mosgiel factory FPA's corporate identity was damaged (NZPA, 2008).

\title{
Fisher\&Paykel
}

\begin{abstract}
EXPERIENCE > Heart \& Soul :
\end{abstract}
EXPERIENCE

Heart \& Soul

Sense \& Simplicity

Passion \& Performance

Today \& Tomorrow

\section{Heart \& Soul}

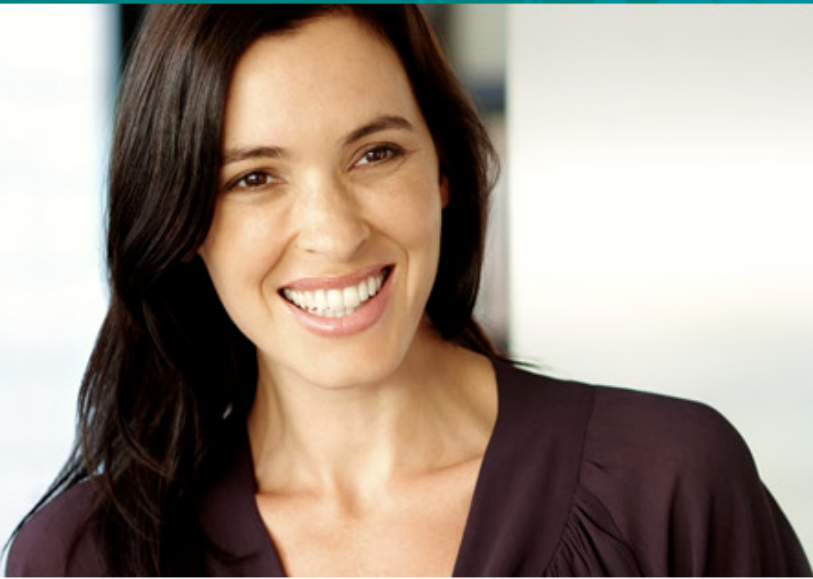


To mediate identity damage of the recession and Mosgiel closure, the second mission statement is assumed to be a tactic to regain consumer confidence. This mission statement is based on experience ${ }^{\text {(fig. 33) }}$ and once again there are four categories: Heart \& Soul, Sense \& Simplicity, Passion \& Performance and Today \& Tomorrow (FPA, 2010c). In relation to the DNA mission statement, the significant pronoun was changed from we to you, with the product making a promise to consumers, or you, and not the corporation, previously we (New Zealand Trade \& Enterprise, 2009).

Through identifying the two mission statements the comparative analysis is now discussed. The DNA and Experience mission statement key words linked as follows: (fig. 34) Style is related to Passion \& Performance as both are talking about image and longevity. Integrity parallels Heart \& Soul as it is representing the core relationship between the product (corporation) and the consumer. Care is communicating the same message as Today \& Tomorrow through a promise that FPA will, 'take care of the details' (FPA, 2010c). Innovation is similar to Sense \& Simplicity as they both state the company or product is leading technology and provides the consumer with a new and unique experience.

$\begin{array}{lll}\text { Style } & \rightarrow & \text { Passion \& Performance } \\ \text { Integrity } & \rightarrow & \text { Heart \& Soul } \\ \text { Care } & \rightarrow & \text { Today \& Tomorrow } \\ \text { Innovation } & \rightarrow & \text { Sense \& Simplicity }\end{array}$

Interestingly, the explicit mention of the environment does not appear in the Experience mission statement. In the DNA mission statement FPA stated that, 'Care reflects how we look after all with whom we come in contact; our respect for the environment; and the way in which our people go about their roles'(FPA, 2010b). Conversely, environment does appear in separate sections of marketing material. This separation may be a technique to emphasise commitment to the environment through specific documentation. Otherwise, the lack of any mention could be a sign that FPA see sustainability as the status quo and, or an added specification to the products.

Both campaigns have had mixed results through the recession and manufacturing closures, generally FPA have managed to regain a positive corporate identity within New Zealand. Recently they topped the 2010 Readers Digest most trusted brands survey in the white-ware category backing up the previous three years (FPA, 2010d). However, another 18000 
person Consumer New Zealand survey has put FPA behind in reliability and quality (Johnston, 2010). This is possibly caused from manufacturing teething problems in new countries. Therefore, it can be further concluded that FPA are a corporation that need an official translation and implementation of corporate identity through an architectural mission statement.

\subsection{ARCHITECTURAL MISSION STATEMENT}

Two FPA mission statements have been obtained and analysed. This section discusses the ephemeral task of corporate identity translation into an architectural mission statement. Whilst referring to the strategies, tools and methods provided in chapter 2.0, they will influence, however, not constrain this new mission statement. Firstly, the general translation will be discussed, which is based on Messedat's seven categories of translation. To further develop the process, Knittle-Ammerschuber's management approaches are used, furthermore, speed theory is used to separate architectural elements for translation. This process ultimately culminates in an architectural mission statement, specific to FPA that is used for the task of implementation (Chapter 4.0).

For general translation a combination of three translation categories' was identified to align with FPA's mission statement and history. Each strategy by itself is limited so by using a combination the process was open to change without being too ambiguous. The three translation strategies used are below:

- Expression of corporate principals, the most intangible of Messedat's strategies, was chosen as FPA has a developed history and defined principals. Their creative background and flat management hierarchy need spaces that nourish a highly supportive, communicative and open space.

- Secondly, associations with the business content is considered as FPA produce tangible objects and design products for everyday living, therefore the building will be treated as a product; a product for corporate identity communication to employees and public, and a tool for a productive work environment.

- Communication of brand contents, which Messedat (2005, p. 268) describes as portraying an experience, adheres well to FPA's experience mission statement. Therefore, the experience mission statement shall be implemented throughout the design case study providing the opportunity to architecturally express the experience of FPA. 
As mentioned, this general approach provides a basic system to translate characteristics of corporate identity, however for detailed translation of architectural elements a further developed system was needed. Thus, a translation matrix (fig 35) was created using a combination of the general translation (above), Knittle-Ammerschuber's Management by Architecture and speed theory's chronological architecture breakdown. This combined both areas of architecture and management and juxtaposes them within the same table, along side the corporate mission statements of FPA. The management and speed theory elements of the matrix are as follows:

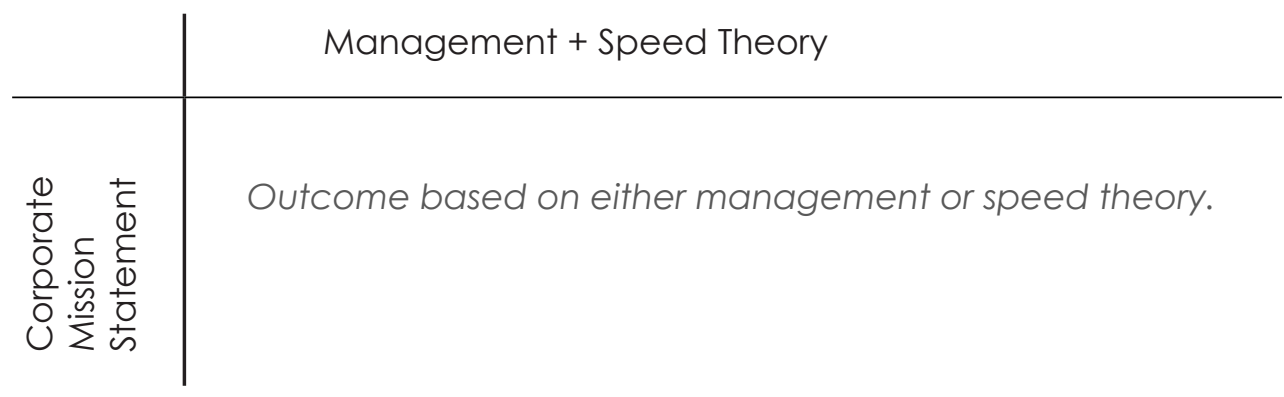

- Architectural Elements

Main elements of the building that need to be considered, speed theory.

- Architectural Process

The consideration of design process. Particularly, which elements influence and consider each other.

- Spatial Use

The use of space and intersections between different programmes of varying sales.

- Spatial Layout

The layout of spaces to provide complimenting and contrasting areas of overlap to express or suppress spatial use relationships.

- Construction Process

The way in which elements are constructed and connected to work with surrounding space.

- Construction Details The detail of connections and construction to express construction process.

- Corporation Use How the corporation will use the space, functionally and visually in relation to achieving their mission statement. 
Figure 36. Architectural mission statement matrix example (See appendix 6.2 for full matrix).
When put along side the existing corporate mission statements that have been analysed; the comparison of both mission statements and the architectural translation can be systematically created.

\begin{tabular}{|c|c|c|}
\hline Original Mission & Current Mission & Architectural Elements \\
\hline Statement $\rightarrow$ & Statement $\rightarrow$ & \\
\hline Integrity $\rightarrow$ & Heart + Soul $\rightarrow$ & \\
\hline $\begin{array}{l}\text { is about building relationships } \\
\text { with our customers, it reflects } \\
\text { the way we go about our } \\
\text { business; the trust behind our } \\
\text { reputation; the way in which } \\
\text { we build our values. }\end{array}$ & $\begin{array}{l}\text { Your kitchen is more than just a room; it } \\
\text { is the heart and soul of your home. It's } \\
\text { a space where you can share delight; } \\
\text { fulfil a passion and taste the best } \\
\text { life has to offer. Creating a feast for } \\
\text { family and friends is one of life's daily } \\
\text { rituals and simple pleasures. From our } \\
\text { perspective food needs to be more } \\
\text { than just fuel, it needs to be delicious } \\
\text { as well. Each of our products has been } \\
\text { designed to bring out the chef in you, } \\
\text { by making cooking easier, more enjoy- } \\
\text { able. This is what drives us to do what } \\
\text { we do - creating experiences that } \\
\text { enhance the time we spend together. }\end{array}$ & $\begin{array}{l}\text { Fixed elements } \\
\text { (Structural) to be exposed } \\
\text { and used as a feature. }\end{array}$ \\
\hline
\end{tabular}

This example shows Integrity, and Heart and Soul translated into a way to implement structural elements. By working through this table, specific architectural implementations were committed, then used to create the final architectural mission statement in the form of previous FPA mission statements to ensure the four areas are implemented. (fig ${ }^{37)}$

The four areas ascertained by comparing FPA's two mission statements have been translated into specific architectural statements to create the architectural mission statement. The conclusive finding is that the building shall be treated as a product, for FPA to implement its corporate and architectural mission statements. Based on the strategies, tools and methods presented in chapter 2.0, and the discussed combination a much more developed and dynamic system was created to provide an approach that creates a strong synergy to the corporation for the use within corporate identity implementation. 


\section{DNA Mission Statement $\rightarrow$}

Experience Mission Statement $\rightarrow$

Sense + Simplicity $\rightarrow$
Architectural Mission

statement

\section{$\rightarrow$ Innovative} Communication

is about desirability, it reflects the way in which we do things. It's not only the way we design our products; it's the way in which we evolve in response to change.

We understand that our lives are becoming more complex. We believe in technology that is both leading edge and the same time human. This approach has led to the development of refrigerators that think for themselves to keep food fresher, and cookers so smart they help clean themselves. Whether it's washing machines that use half the water you normally use or dishwashers designed to wash as well as store your dishes - above all we believe in insight led design that is tailored to peoples changing needs around the world.

\begin{tabular}{ll}
\hline Integrity $\rightarrow$ & Heart + Soul $\rightarrow$ \\
is about building relationships with our & your kitchen is more than just a room; it is the heart and soul \\
customers, it reflects the way we go about & of your home. It's a space where you can share delight; fulfil \\
our business; the trust behind our reputation; & a passion and taste the best life has to offer. Creating a feast \\
the way in which we build our values. & for family and friends is one of life's daily rituals and simple \\
pleasures. From our perspective food needs to be more than & just fuel, it needs to be delicious as well. Each of our products \\
& has been designed to bring out the chef in you, by making \\
& cooking easier, more enjoyable. This is what drives us to do \\
& what we do - creating experiences that enhance the time \\
& we spend together.
\end{tabular}

\section{Care $\rightarrow$}

\section{Today + Tomorrow $\rightarrow$}

Behind every product is a story, and that story begins with you. Your kitchen is an expression of who you are, how you cook, and how you enjoy food with others. Our passion is cre ating better experiences that put the joy of food at the centre of your life. Eat, share, live life - we'll take care of details.

after all with wh ment; and the way in which our people go about their roles.

\section{Innovation $\rightarrow$}

\section{Passion + Performance $\rightarrow$}

\section{$\rightarrow$ Sensitive Relationships}

A complex arrangement of spaces that work together to enhance relationships and express ideas of change and innovation.

\section{$\rightarrow$ Respectful Planning}

A product that respects its current and future surroundings, inhabitants and their goals.

$\rightarrow$ Harnessing Potential

is our heart; we are innovative in all that we do, from the big ideas through to the detail.

Food is theatre. From mid week convenience to gourme weekends each meal is a performance and the kitchen is your stage. Celebrating great food and cooking from around the world is the show, from the soft crust of a freshly baked baguette to the comforting fragrance of Vietnamese pho - variety is the spice of life. Just as we are seeking quality and variety in our food, we desire the same of our kitchens, we are looking for unique appliances that combine innovation with reliability and performance. Savour the taste of your next meal in tomorrow's kitchen.
A building that harnesses the inhabitant's performance building productivity and potential of ideas and products.

Figure 37. Final Architectural mission statement. 


\subsection{REFERENCES}

Barry, R. (1991). Industrial: Fisher and Paykel, East Tamaki. Architecture New Zealand(September/October), 44-47.

Collins English dictionary. (2000). London: Collins.

Davies, P. (2008). Project Ironside. Artichoke(25), 59-60.

FPA. (15 September 2010). Fisher \& Paykel Appliances reveals refrigeration compressor technology set to revolutionise energy consumption. Retrieved 27 Nov 2010, 2010, from http://www.fisherpaykel.co.nz/ pressroom/downloads/Compressor\%20release\%20-\%20FPA\%20Press\%20 Room.pdf.

FPA. (2010a). 2010 Annual Report: Fisher \& Paykel.

FPA. (2010b). About Us. Retrieved 11/08, 2010, from http://imagebank. fisherpaykel.com/indexMain.cfm?page=1234AB99-C1C0-45FB-848C1DFA47916F40.

FPA. (2010c). Experience. Retrieved 10/08, 2010, from http://www. fisherpaykel.co.nz/global/experience/index.cfm.

FPA. (2010d). Fisher \& Paykel voted New Zealand's most trusted whiteware brand. Retrieved from http://www.fisherpaykel.co.nz/pressroom/ downloads/fisher\%20and\%20paykel\%20tops\%20most\%20trusted\%20 brand\%20survey.pdf.

FPA. (2010e). FPA Stock Exchange Release ASX/NZX, chairman and managing director \& ceo's address to shareholders. Retrieved 27 Nov 2010, 2010, from http://www.fisherpaykel.co.nz/global/investors/InvestorsPDFs/Announcements/04\%20Chairman\%20and\%20Managing\%20 Director\%20\&\%20CEO's\%20Address\%20to\%20Shareholders.pdf.

FPA. (2010f). Our Story. Retrieved 03/06, 2010, from http://www.fisherpaykel. com/global/company/who_we_are.cfm.

Johnston, M. (2010, 10/5/2010). Survey reveals NZ's best and worst home appliances. New Zealand Herald. Retrieved from http://www.nzherald. co.nz/nz/news/article.cfm?c_id=1 \&objectid=10643928.

Knittel-Ammerschuber, S. (2006). Architecture of success: building strategies and business. Boston, MA: Birkhäuser. 
Messedat, J. (2005). Corporate architecture: Development, concepts, strategies. Ludwigsburg: AV Edition.

New Zealand Trade \& Enterprise. (2009). CookSurface Typifies F\&P Design Approach. Retrieved 12/8, 2010, from http://www.betterbydesign.org.nz/ news-and-resources/design-news/news-details?objld=da9d2603-acaa4b0a-9847-cedc9e7ec7f5

NZPA. (2008, 17/04/2010). Fisher \& Paykel move 'damages iconic brand'. New Zealand Herald.

Revington, M. (2005). Ideas Inc. Retrieved 11/08, 2010, from http://unlimited. co.nz/unlimited.nsf/growth/ideas-inc-p2.

Sheppard, G. (2009). Fisher \& Paykel looks towards the future with Ironside. Retrieved 09/08, 2010, from http://www.current.com.au/2009/04/27/article/ IJEHVBACNO.html. 


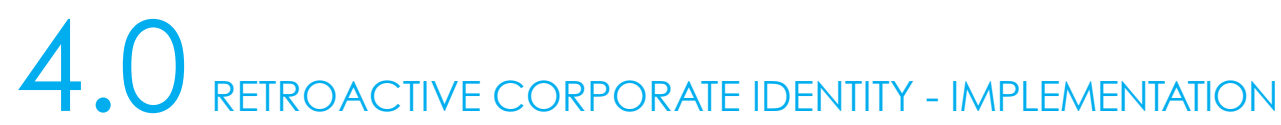

The architectural mission statement for FPA has been developed, completing the translation stage of the design case study. This chapter will now discuss the implementation stage. As mentioned, to explore the strategies, tools and methods a retrofit of an existing building is the focus of the design case study, furthermore to reiterate, a retrofit has been chosen to test the issue of time and change and the implications for corporate identity's synergy with corporate architecture. To begin implementation, the selection of a site and building is discussed. Then, the selected building is also categorically analysed, in cohesion to speed theory, to provide a descriptive breakdown. The general implementation of the architectural mission statement is then described in response to the context of the site and building. Furthermore, five original implementation methods are presented as the culmination of the corporate identity translation in chapter 3.0 and the process of implementing corporate architecture.

\subsection{THE EXISTING CORPORATE ARCHITECTURE - 215 LAMBTON QUAY}

This first section describes the selection process and architectural characteristics of the existing corporate architecture for implementation of the architectural mission statement. Existing context is influential to the outcome of the design case study and this analysis will provide an understanding of how to apply FPA's corporate identity. Firstly site selection will be discussed.

\section{SITE SELECTION}

The site selection was undertaken through a variety of methods with the architectural mission statement created in chapter 3.0 influential to all. The methods were the selection of a city, then the selection of a building.

As illustrated, (fig. 38) Wellington was chosen as the city for the design case study to be implemented. The current exodus of manufacturing to overseas locations leaving current factories redundant was highly influential to this 
17. This survey was undertaken by observing Wellington commercial real estate listings and completed and current construction projects. This was completed in May 2010.

18. The computer was the first point of call to understand the building. This is due to the speed in which the building can be reconstructed and the multiple viewpoints and interpretations that can be represented in, or close to, real time.
19. The 1:100 model was an excellent way to discover the scale of the building, especially the size of the typical office floor plates. The unique shape of the floor plates was difficult to work with, as they did not adhere to the conventional office tower. The model helped to see the positives and negatives of this arrangement.

20. 1:250 and 1:200 physical models that were used later in the design process accompany the computer and 1:100 model. decision. This situation removes the attachment to commercial lots of South Auckland and Dunedin. Also a highly receptive environment was needed. These two characteristics lead to the decision of Wellington. The cultural and creative background of this city is seen as a major advantage, therefore the reception of this project is likely to be higher than other New Zealand cities.

To select a specific site a survey of real estate ${ }^{17}$ was undertaken. Due to the dynamic movements of large corporations around Wellington city there are currently multiple vacant, or soon to be vacant, buildings available. Suitable buildings were selected on the premise that they were; a multistorey administration tower, have high pedestrian exposure and have a floor area of, or close to $11000 \mathrm{~m}^{2}$. which as mentioned, is approximately the space that FPA's non-manufacturing departments currently inhabit. Figure 39 illustrates suitable real estate availability and current corporation relocations in Wellington city. This active situation can be attributed to increased government spending influenced by the global recession and global and local trends in corporation consolidation to increase inter-department communication (IRD, 2007). From the available buildings illustrated, 215 Lambton Quay was selected. (fig. 40, 41, 42)

The following analysis of the building will rationalise this decision, also providing necessary contextual information for implementation of the architectural mission statement. To adhere to speed theory, the site, structure, circulation, envelope and fit out will be discussed separately. Each Layer has been investigated through multiple media. Firstly, the initial information was gathered from city archives, which consisted of plans, sections, elevations and details from the original consent drawings lodged by Peddle Thorpe Architects on 18 December 1978. These were then used to create a 3D computer model to understand the buildings layers and their interface with each other in real time ${ }^{18}$. The 3D model was used to create a 1:100 physical model, which helped experience the construction and makeup in a tangible way and also developed a greater understanding of the scale of the building and relationship of spaces. ${ }^{19}$ These methods of investigation are used to illustrate the following layer breakdown of the building ${ }^{20}$ that begins with a general description of the building history. 

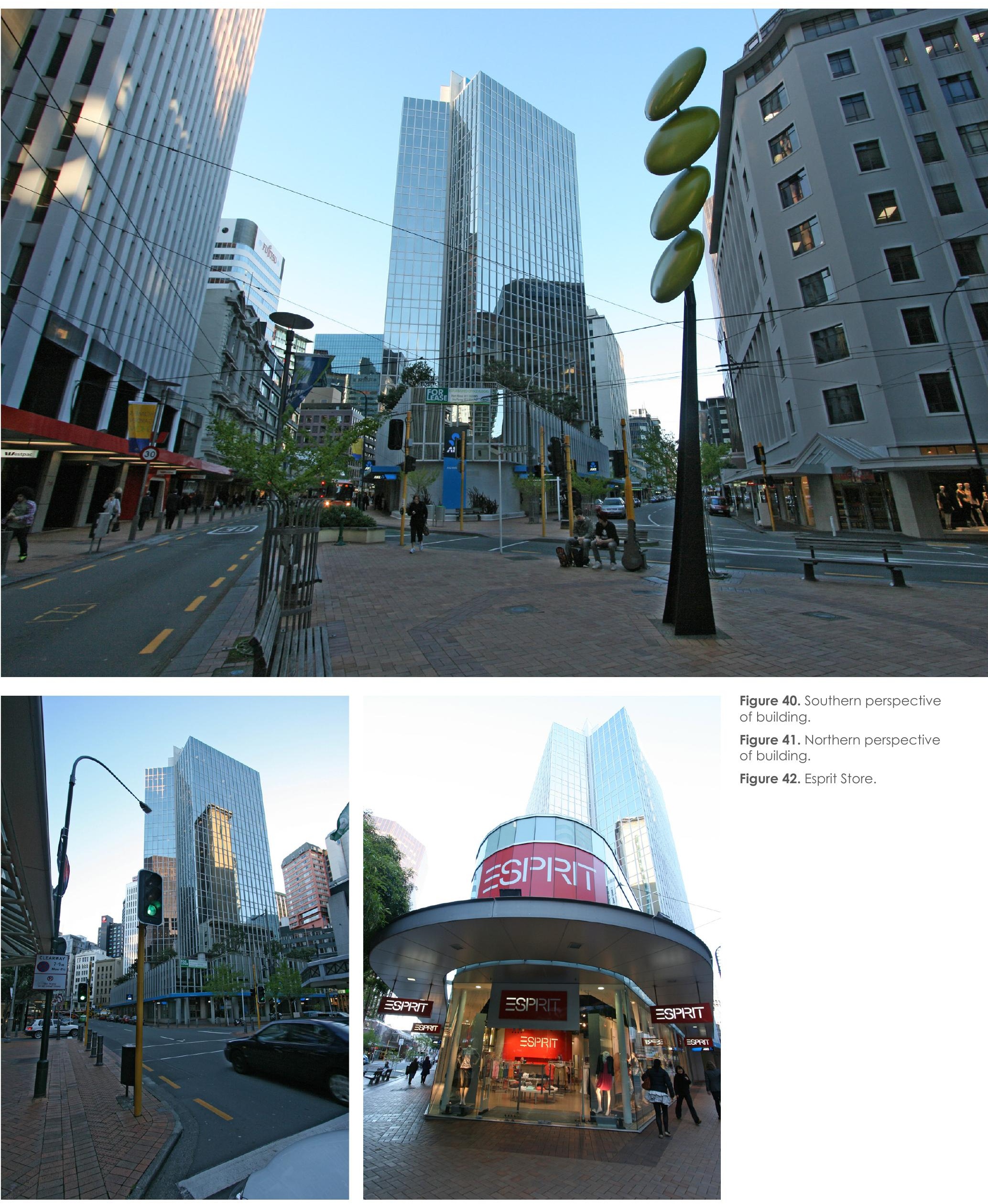

Figure 40. Southern perspective of building.

Figure 41. Northern perspective of building.

Figure 42. Esprit Store. 


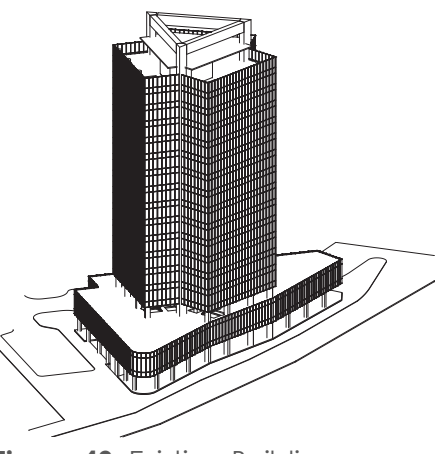

Figure 43. Existing Building.

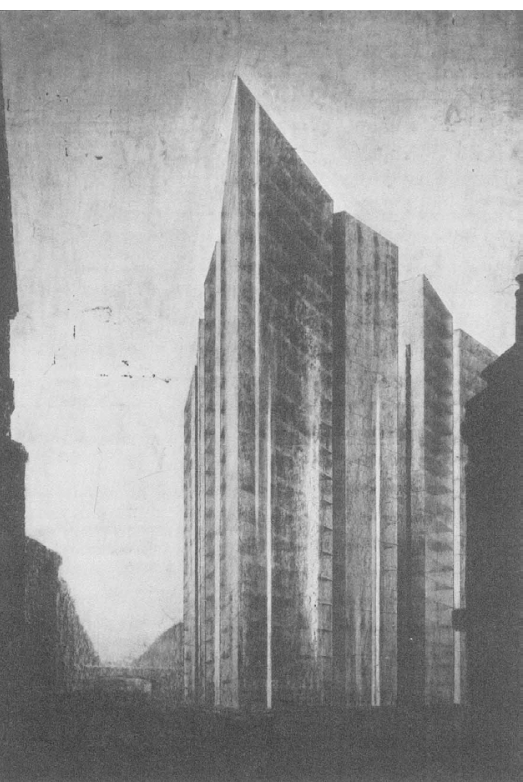

Figure 44. Presentation Perspective, Friedrichstrasse Skyscraper, Berlin, 1921, Mies Van der Rohe.

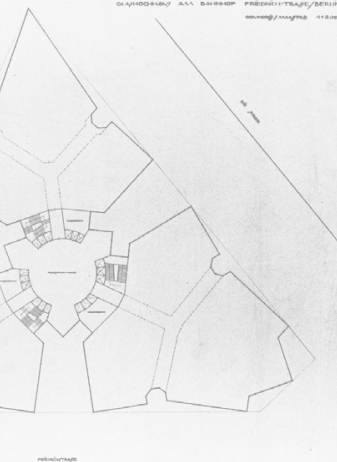

Figure 45. Typical Floor Plan, Friedrichstrasse Skyscraper, Berlin, 1921, Mies Van der Rohe.

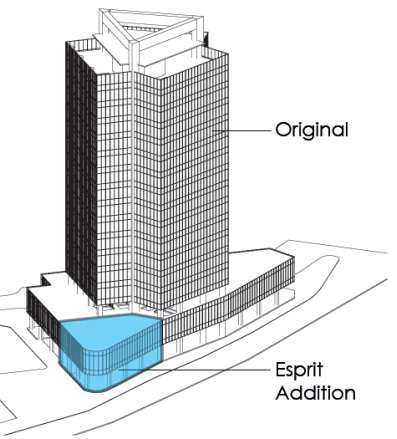

Figure 46. Building evolution.

\section{THE BUILDING}

Australia and New Zealand Banking Group (ANZ) opened the building in 1983 as the head office for ANZ Banking Group (New Zealand) Ltd (ANZ, 2010). This building manifested in the typical style of office towers at the time, based on the tower and podium typology with a consistent glass curtain wall corporate veil. As an overall design, the most unique aspect influenced by the large triangular island site, is shape of the tower. Reminiscent of Mies Van der Rohe's 1921 Berlin Tower, (fig. 44 + fig. 45) the plan has been triangulated to provide high floor areas whilst integrating daylight within internal spaces (Drexler \& Schulze, 1986). Unfortunately, the podium does not share this innovative approach and is built to the constraints of the site boundary. Originally the podium had a recess on the northwest corner. That has since been filled with the Esprit concept store. (fig. 42+ fig. 46) This addition is much more transparent than the existing podium, however it repeats the curtain wall pattern establishing a strong connection to the existing building. The specific speed theory layers of the building are now presented. 


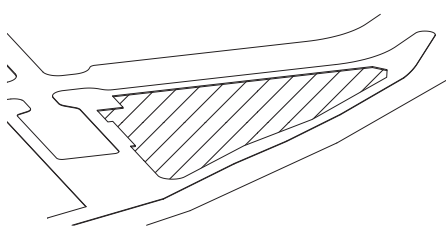

Figure 47. Existing Site.

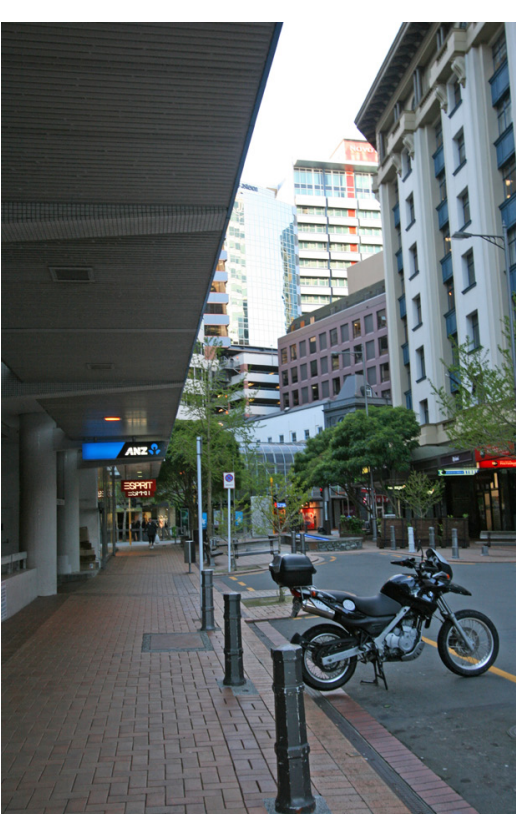

SITE

The slowest layer, site, along the Golden Mile is historically significant with links to the original Wellington beach front. (fig. ${ }^{48)}$ The site now exists as a main urban link from the city to the current waterfront.(fig. 49) Other urban links are; Featherston Street, which borders the eastern boundary and provides high vehicular exposure and a developing retail market. Lambton Quay, on the western boundary, is popular for pedestrian traffic attracted by a high exposure retail environment and commercial workplaces. Grey Street borders the northern boundary, a cul-de-sac street terminates half way for a small park at the Lambton Quay end. (fig. 50 + fig. 51) This street is currently used for parking and provides access to the small basement level of the building. The park is popular however lacks direct sunlightf(ig. 52) and a strong connection to the building. Also the cul-de-sac dominates the space making the park a thoroughfare or temporary stopover rather than a destination itself. It can be concluded that the Lambton and Featherston edges have potential to link together with the park as a focal point to reduce the solidity and island effect of the site.

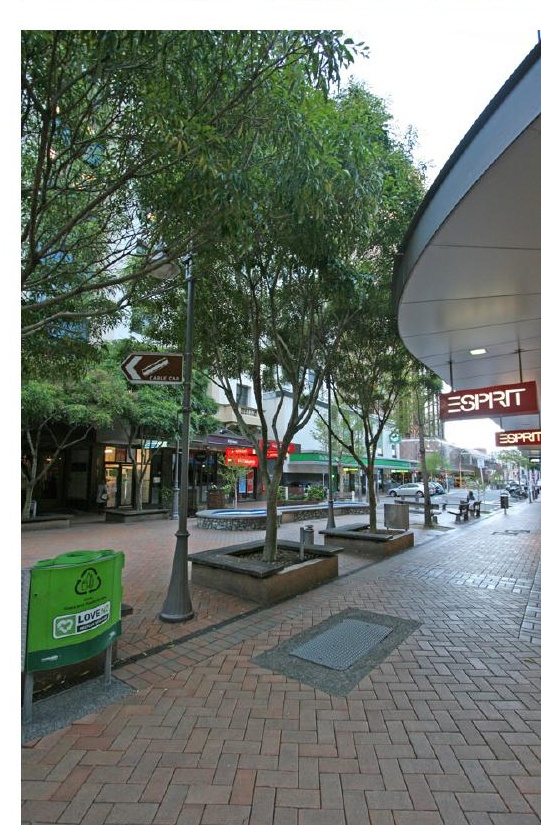

Figure 48. Wellington waterfront history (over).

Figure 49. Urban Links (over).

Figure 50. Grey Street Park, Eastern End.

Figure 51. Grey Street Park, Western End.

Figure 52. Sunlight Study (over). 



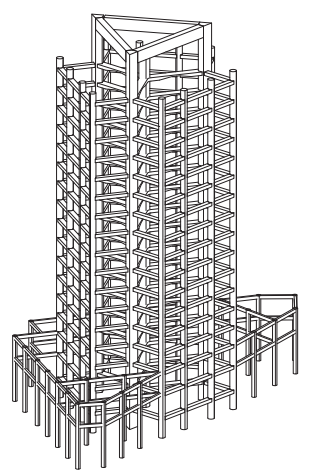

Figure 53. Structure.

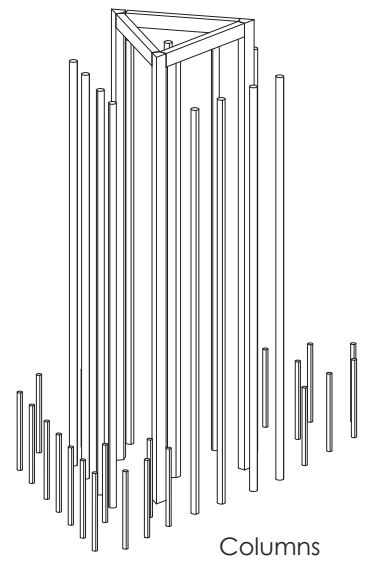

Figure 54. Structural System.

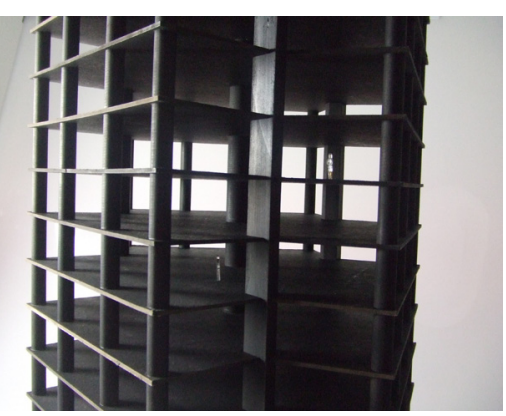

Figure 55. Stacked Floor Plates, 1:100 Model.
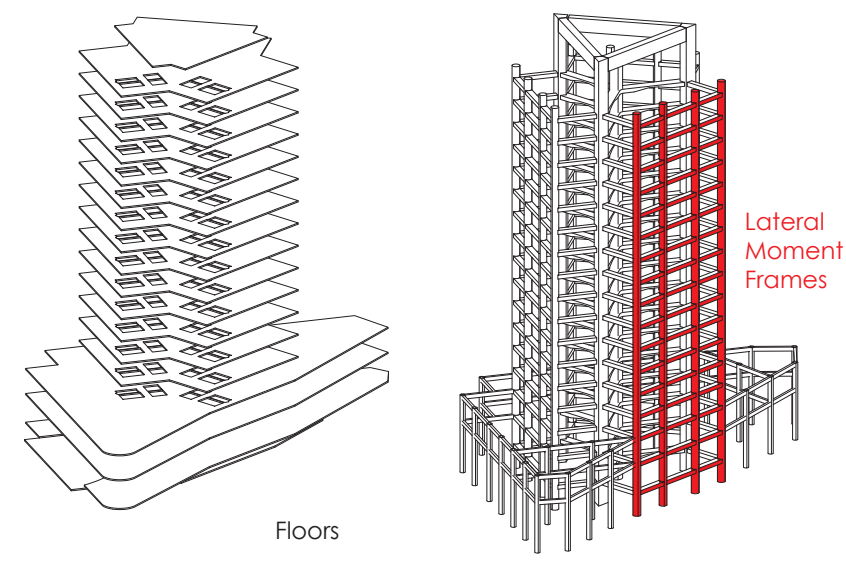

STRUCTURE

The second layer of speed theory, structure, solves the unusual plan of the tower with a simple structural solution. ${ }^{\text {(fig. }}{ }^{54)}$ Three reinforced concrete moment frames flank the wings of the tower floor plate and brace lateral loads of the podium and tower. The triangle columns support the intersection of the wings and resist gravity the loads of the floor. The remaining structure resists gravity loads through the precast floor, in-situ beams and internal insitu columns. The internal structure is very minimal allowing an open floor plate only interrupted by one, two-metre diameter central column. Also the core of the building is not structural and is located in the northwest corner of the tower. This simple, post and beam structure, typical of most flexible office towers, will provide freedom to link spaces and work with the implementation of the architectural mission statement. 


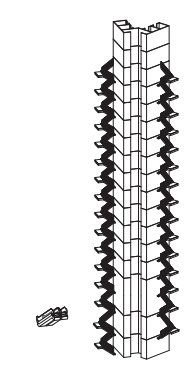

Figure 56. Circulation.
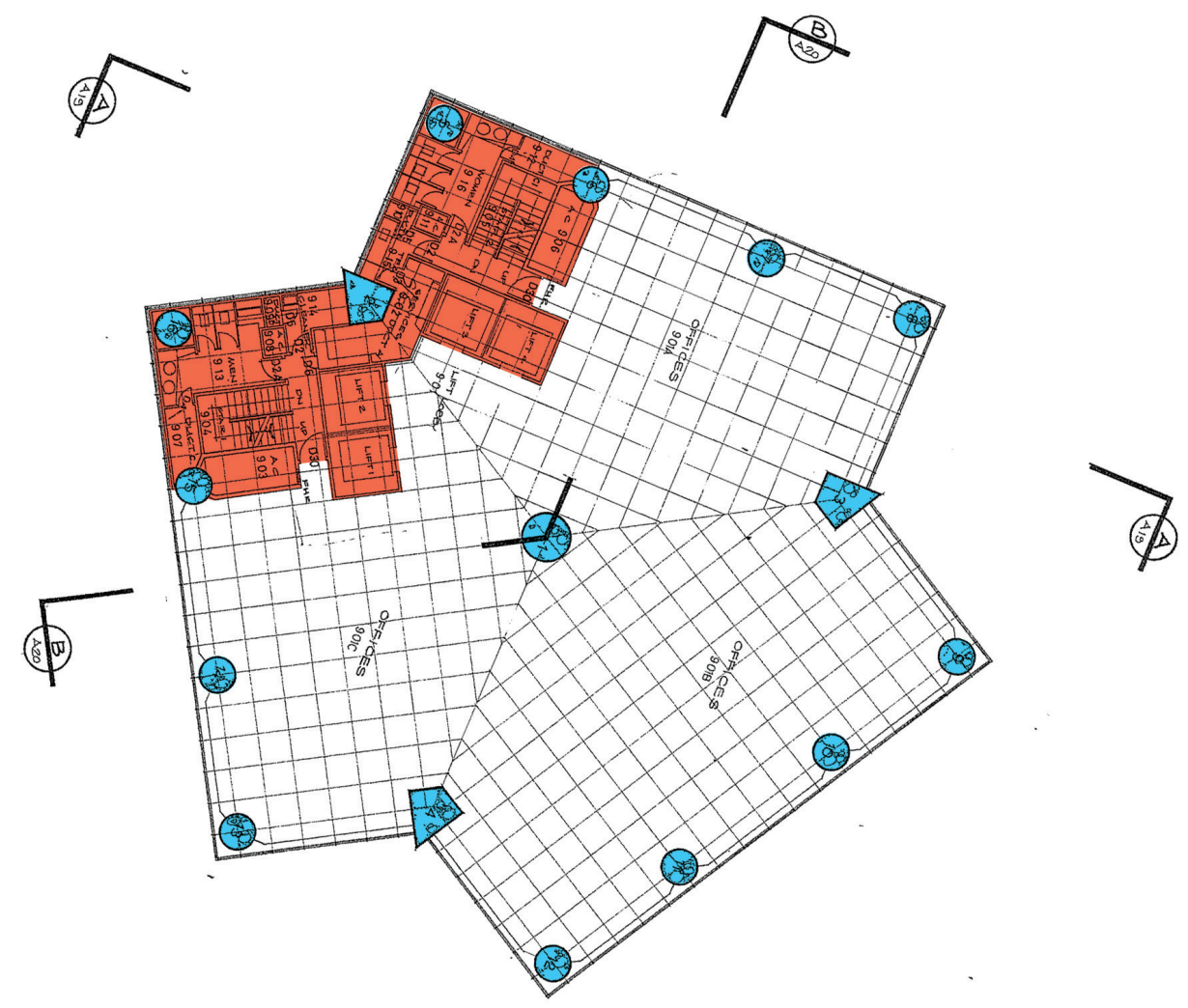

CIRCULATION

Circulation, which is strongly determined by structure, consists of four lifts Figure 57. Typical Floor Plan. and two concrete stairwells. (ifg. ${ }^{57)}$ There is also an escalator from the ground floor to the first floor of the podium. The restricted and contained circulation creates cellular spaces reducing the possibility of inter-floor communication. However, as mentioned, the non structural nature of the core allows flexibility when working with this layer. 


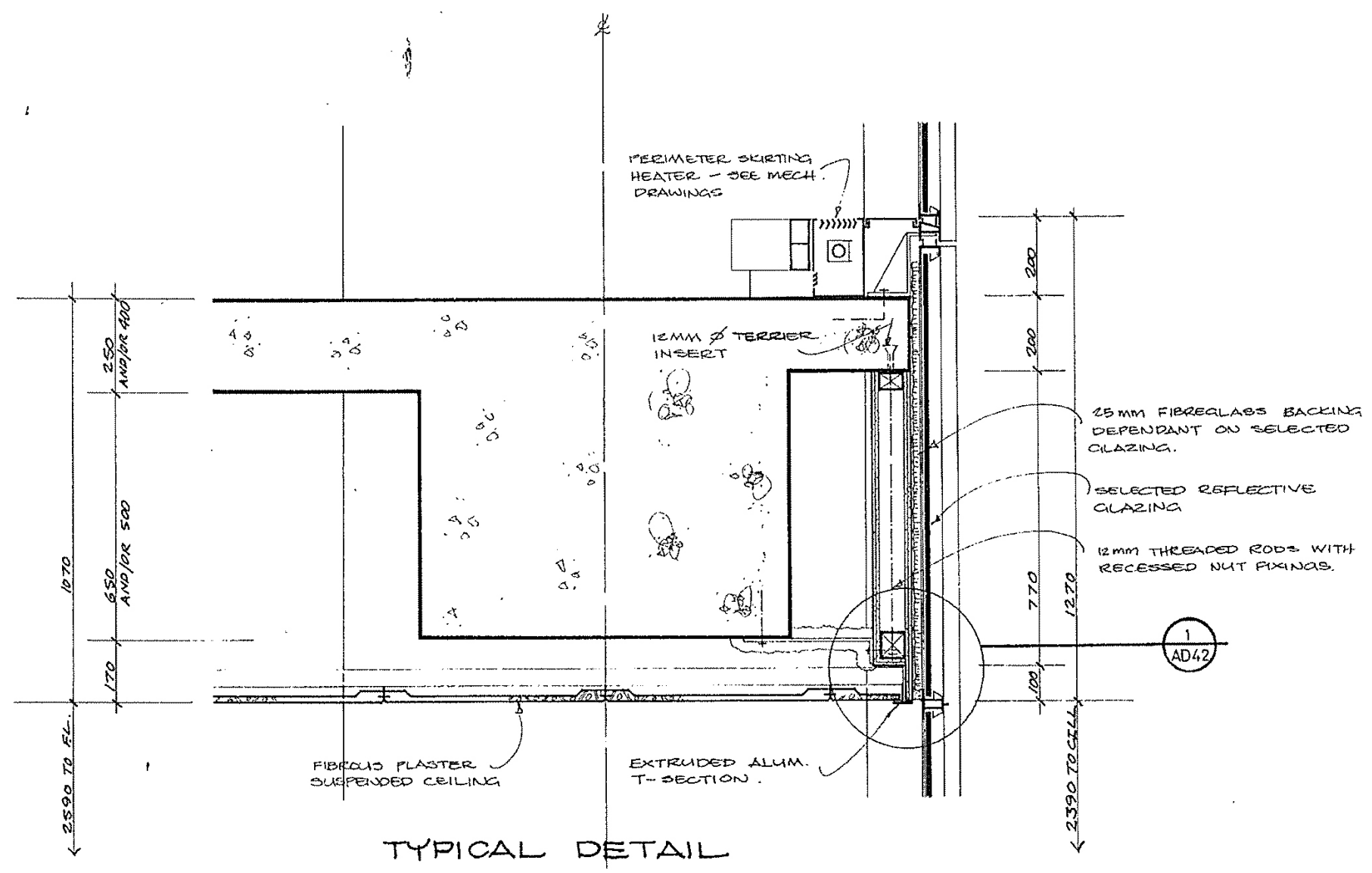

FITOUT

Internal spaces are where corporations partake in business, the importance

Figure 61. Typical Spandrel.

of this layer to others is often overlooked. Currently the fit out consists of a suspended ceiling and office furniture defines space within the large floor plate. The environmental control of internal space is also included within the fit out. HVAC systems, located on floors 3, 16 and 17 track through service ducts then into the ceiling, supplemented by skirting heating systems that run around the perimeter of the wall floor intersection. 
Tower

Product for work and innovation

Work Space

Circulation

Social Space

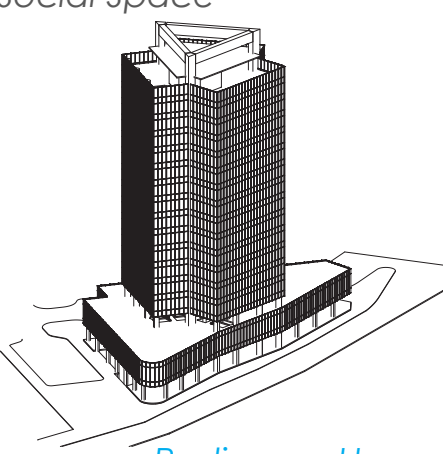

Podium as Home Place of corporate public interaction Experience centre

Pantry

Kitchen

Figure 62. Holistic implementation of Architectural Mission statement.

Figure 63. (facing Page) Implementation Key.
The speed theory analysis of the existing building has presented its history and design. The site has been identified as an important part of the urban milieu that currently does not link into existing facilities well. Structurally, the building is unique, however it provides opportunities for modification through its simplistic solution. Circulation throughout the building is also very hierarchical allowing no visual links between floors and spaces. Currently there is a lack of communication from the internal to external spaces. The envelope is an important element and needs to integrate with the structure and interior fit out, which also needs to be improved to work with the surrounding layers. The following section will describe the techniques used in this case study to synergise FPA's architectural mission statement to the selected building, 215 Lambton Quay.

\subsection{IMPLEMENTATION}

This design case study has been consolidated with the combination of corporate identity theory, FPA's architectural mission statement, and the analysis of the selected existing building. The general application of the architectural mission statement will be discussed along with five implementation techniques that have been developed to communicate FPA's corporate identity. These categories are urban integration, podium disintegration, central atrium, secondary atria and the communicative façade.

The general implementation approach is based on Messedat's three categories of translation used to initially translate FPA's corporate mission statements. Once again, these are: the expression of corporate principals, association with business content and communication of brand contents. These three combine to provide overriding concepts that have been applied to this particular building developing into the idea of treating the building as a product and also as a home. The building typology complimented this statement allowing separate, but supplementary, treatments of the tower

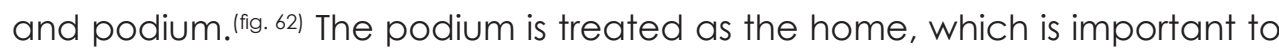
the experience mission statement. It becomes the area of corporate and public interaction and is treated as a space that translates the experience of FPA. The tower becomes a product for work and innovation. It must provide a productive workspace that implements communication within the building and to the urban milieu. The specific applications of this approach developed by investigating the issues identified in section 4.1 via a speed theory analysis will now be discussed. 


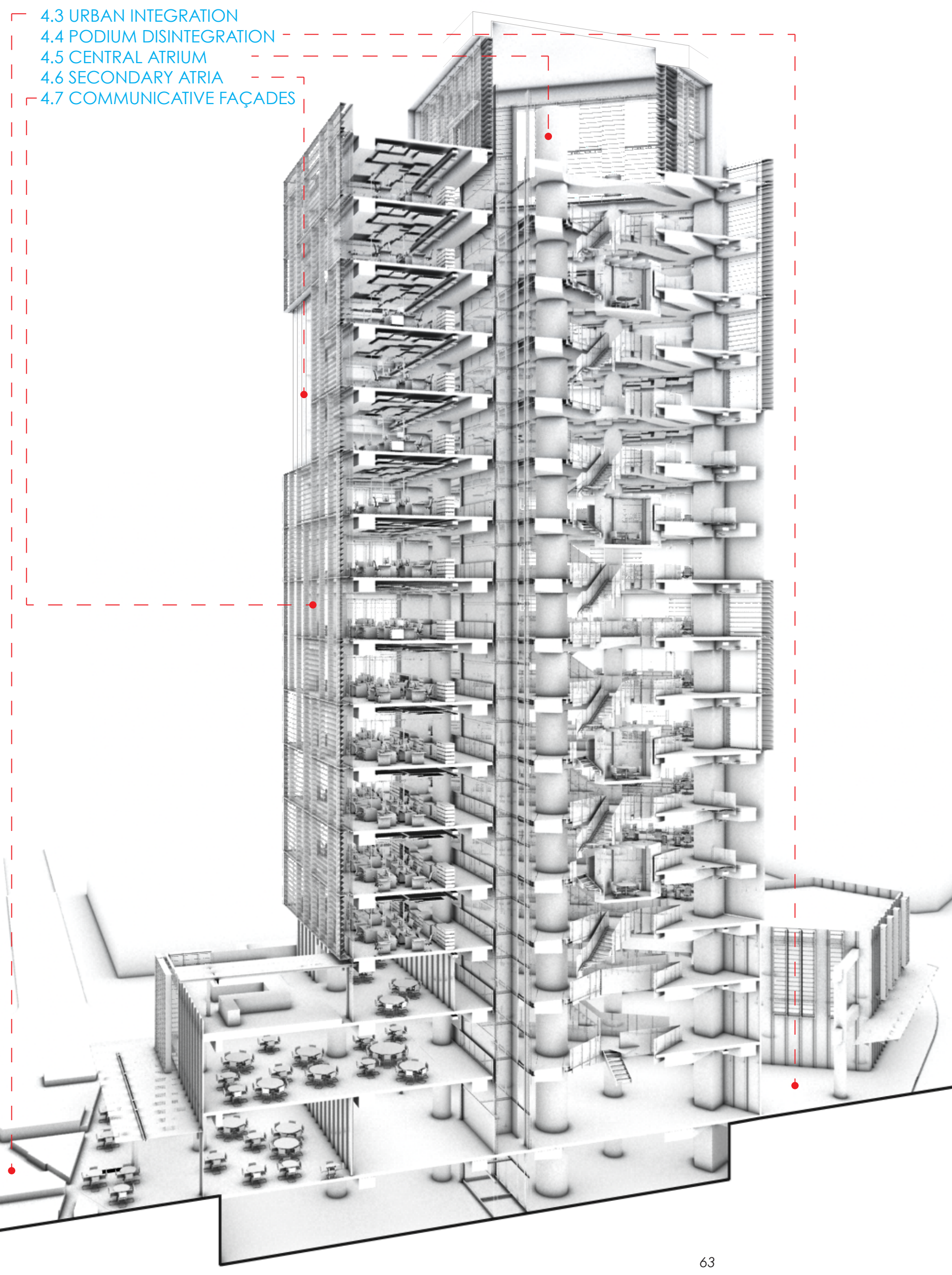




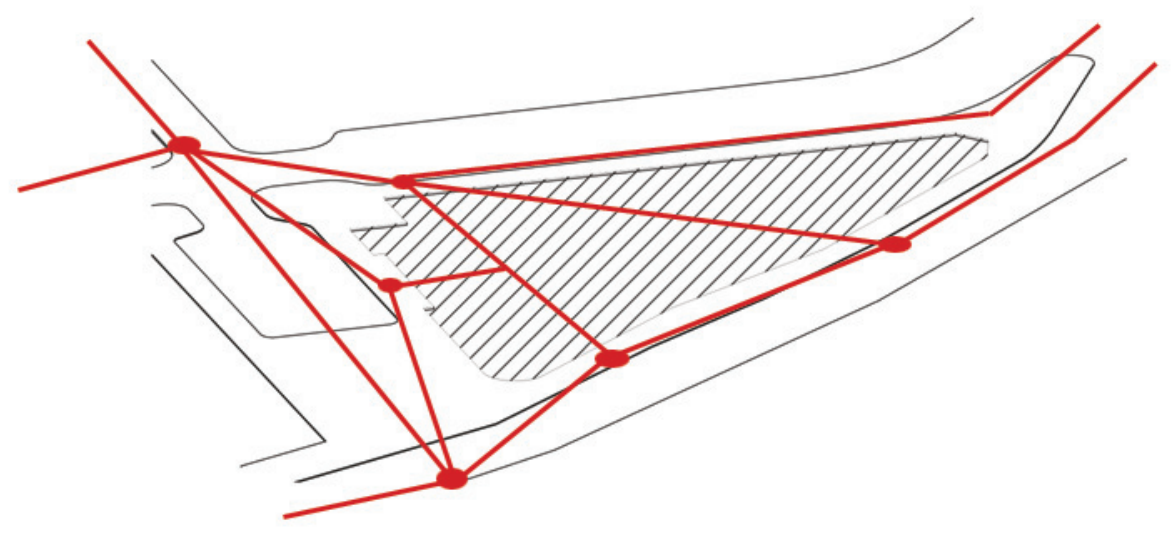

\subsection{URBAN INTEGRATION}

Figure 64. Urban Integration.

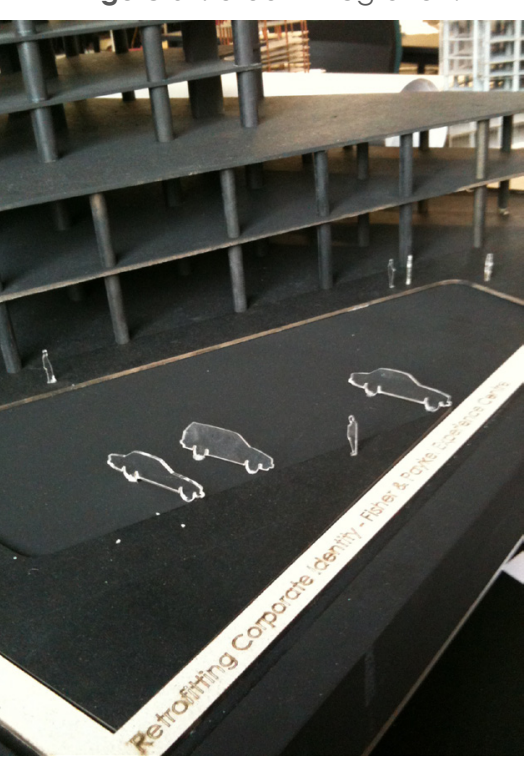

Figure 65. Existing Park, 1:100 Model.

Facing Page

Figure 66. Park Sketch Plan.

Figure 67. Image of Park, 1:200 Model.

Figure 68. Park Plan.
As identified, the site lacks connections to important urban spaces and the solidity of the podium reduces flow through the site. Also, the Grey Street Park has been identified as a major feature that has potential to increase connection of the building to the urban milieu. On an urban scale, the site, along with the park can act as a link between Lambton Quay and the developing retail scene of Featherston Street also linking the Terrace through to Queens Wharf on the waterfront. A park redesign and podium disintegration have been implemented to improve this link. A description of the park will follow and the podium disintegration will be described separately in the next section.

Issues identified with the Grey Street Park are; the lack of involvement with the podium and dominance of vehicular activity over static and slow pedestrian movement. These issues create a major separation between the public space and the building. Firstly, to integrate the park into the podium the parking and vehicular access has been removed to create a stronger gesture of pedestrian space. 


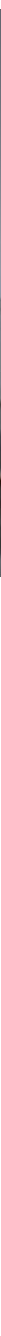

2.Raised Lawn

5.Entertainment decking

1.Existing Footpath

3.Raised communal gardens

4. Concrete path

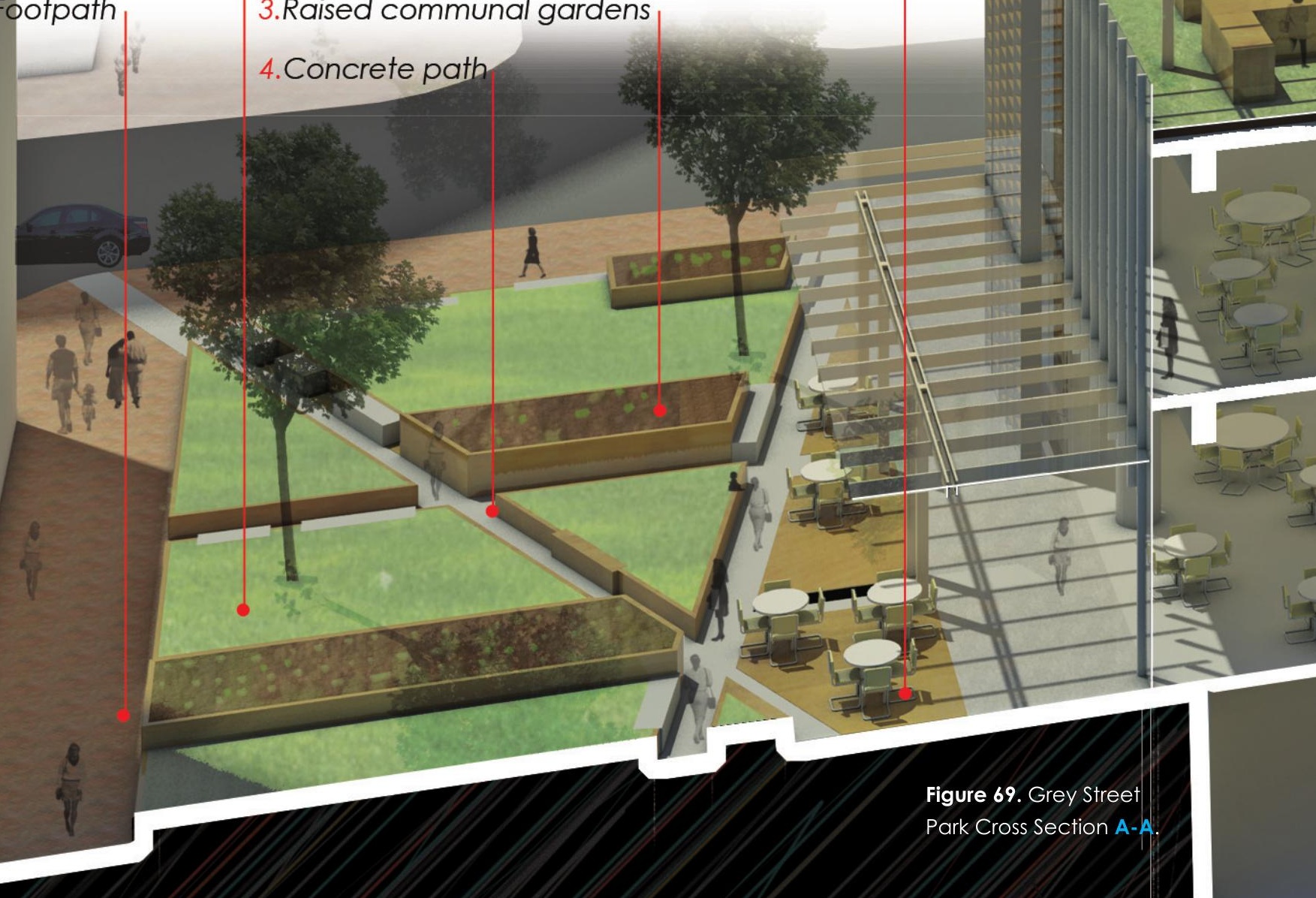




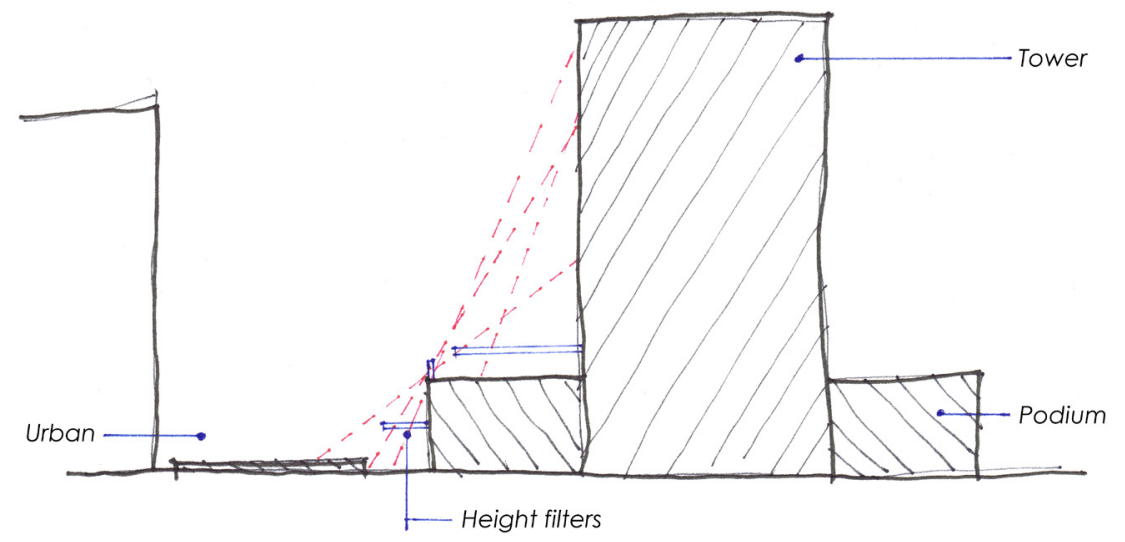

Figure 70.Scale reduction features.
Secondly, to adhere to FPA's architectural mission statement the park is acting as a lawn and an extension of the podium as home to complement surrounding amenities. Raised gardens and paths dissect the main gesture of the park, a lawn. The existing footpath on the northern side of the space has been knitted into the park with its texture being intersected by the new paths. (fig. 68) The north and south edges of the park also include timber decking for immediate dinning spaces to inhabit. This signifies the deck of the domestic yard and links the adjacent entertainment facilities. The edges of the paths, reminiscent of the clothesline path, are scattered with seats. Within the varied islands of grass, raised gardens are planted with seasonal vegetables and herbs to reinforce the domesticity of the space and to compliment surrounding food suppliers. Existing trees will be kept as they reduce the immediate scale of the podium and surrounding buildings. (fig 70 ) Smaller citrus and feijoa trees are also planted to provide pockets of private and sheltered space. The Podium disintegration will now be presented which will elaborate on the functions that the park and surrounding space will link into. 
math dot $1, x^{2}$. $x^{2}-1 y^{2}-2 x$ a

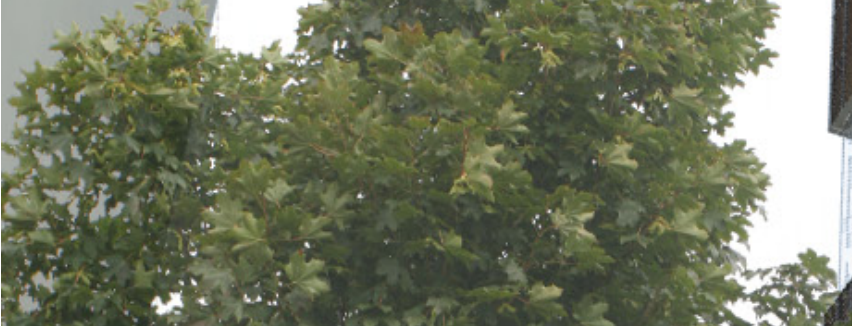

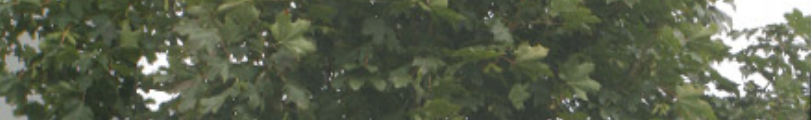

$\operatorname{lin}^{2} t$

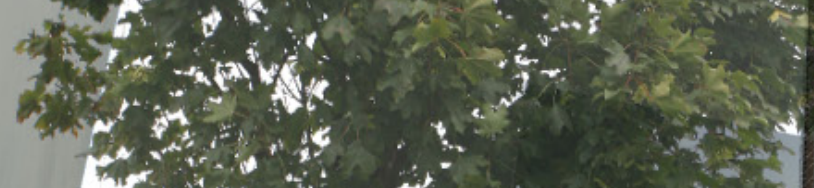

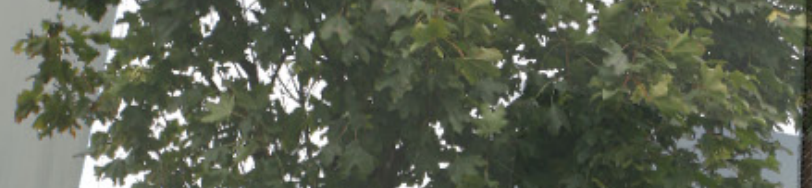

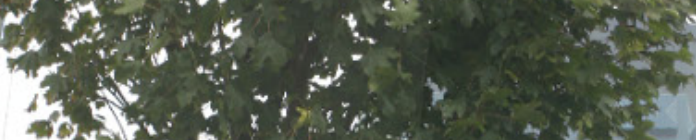
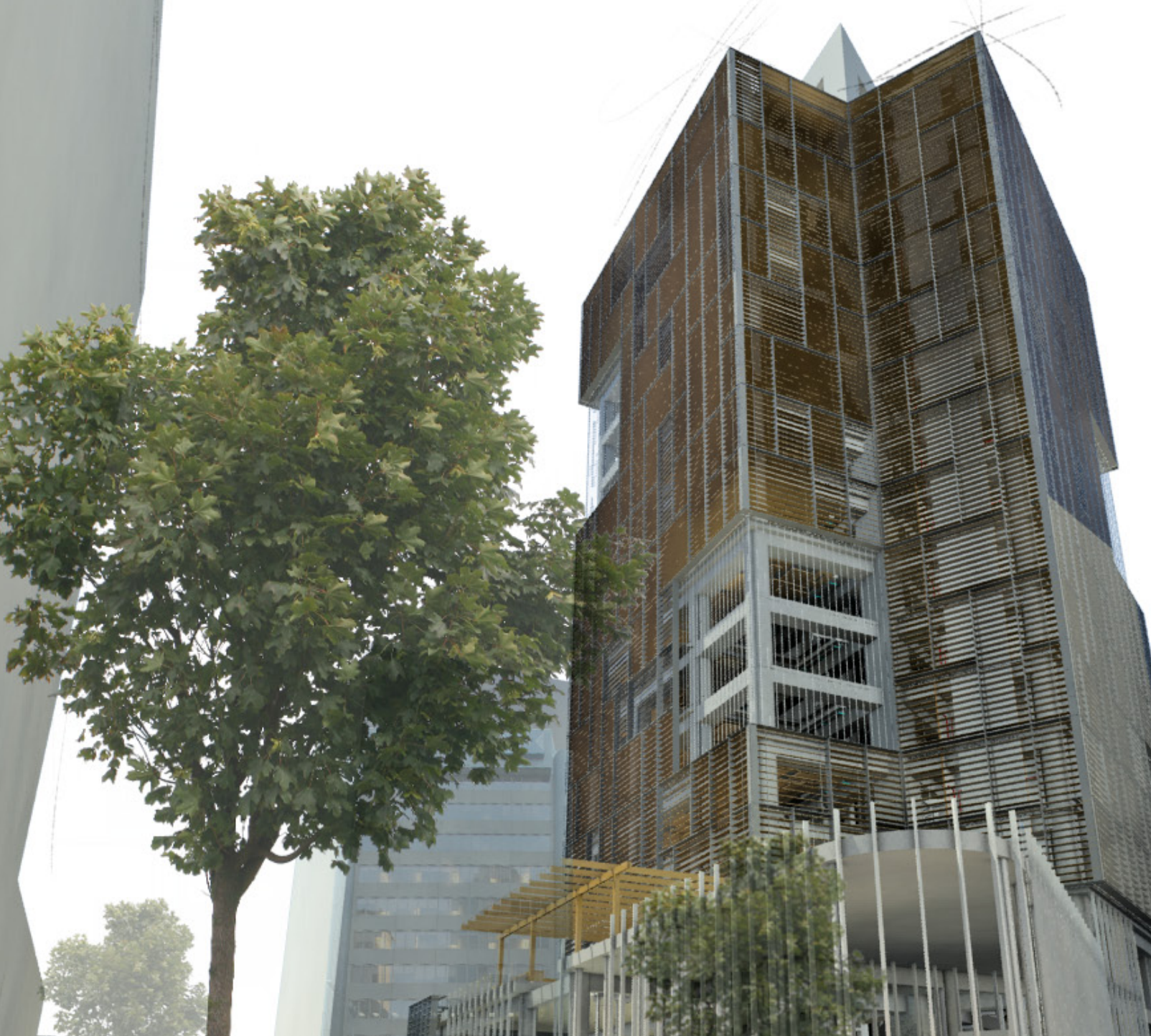


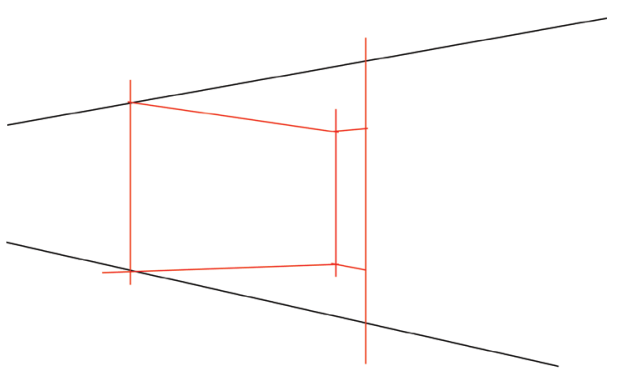

Figure 75. Diagram of before and after podium edge.

with FPA and their products similar to the Hangzhou Experience Centre, China. This is achieved through the idea of home and the manifestation of the kitchen, a drop in cooking school. ${ }^{21}$ Furthermore, FPA can use this facility to test prototypes within the school allowing real time public reaction and research.

The second area of the podium is based on the domestic pantry, which occupies the existing Esprit store. Moore Wilsons Fresh ${ }^{22}$ was chosen to occupy this space. Their quality artisan market culture fits well with FPA and the idea of pantry. The open and exposed corner provides an active edge to the podium drawing people into the park and the podium is made much more porous by inserting large operable openings allowing fruit and vegetable stalls to be extended into the outdoor space.

The third activity area of the podium is based on domestic entertainment areas of home. To bring temporary pedestrians to the podium and park a café or casual food and beverage provider occupies the lower floor. The upper floor is occupied by a formal dinning experience. In good weather an extension of the park is created onto the northern green roof of the podium which also provides the conference centre access to entertain colleagues and clients.

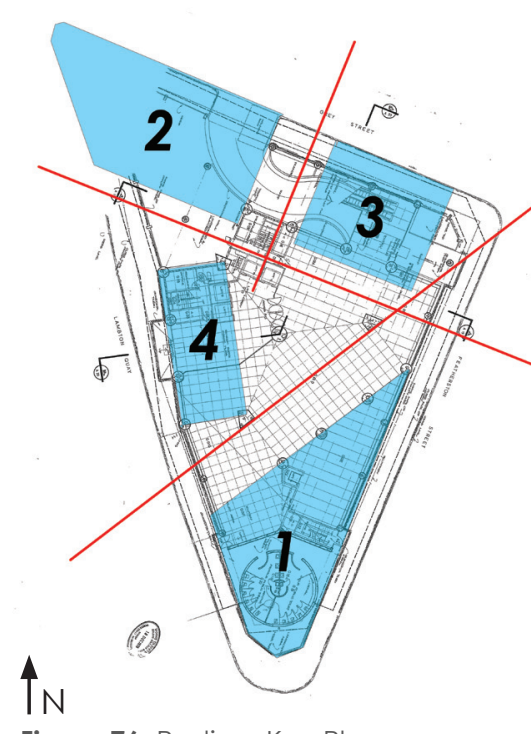

Figure 76. Podium Key Plan.

21. Since FPA are not providing a person-to-person service this programme was created to implement interactivity. NZ Masterchef, a televised cooking competition, used Fisher \& Paykel products throughout the series. Also FPA are starting to sponsor cooking schools throughout Australia. This successful marketing can be translated to the cooking school where the public can drop in and learn to cook a meal with guest chefs.

22. Moore Wilsons are a Wellington based food and goods wholesaler that was established in 1918.

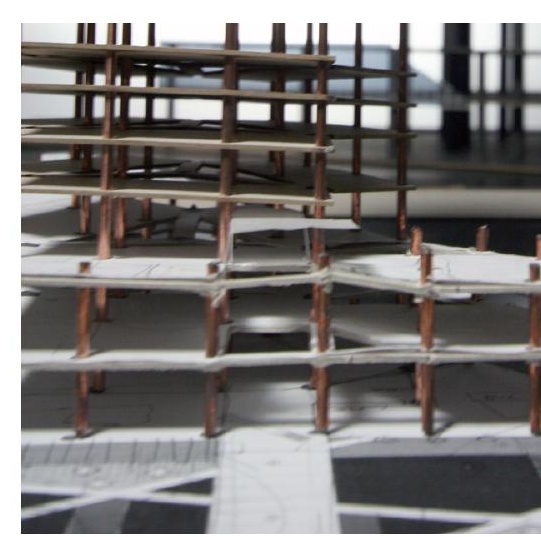

Figure 77. 1:250 Working model canopy. 


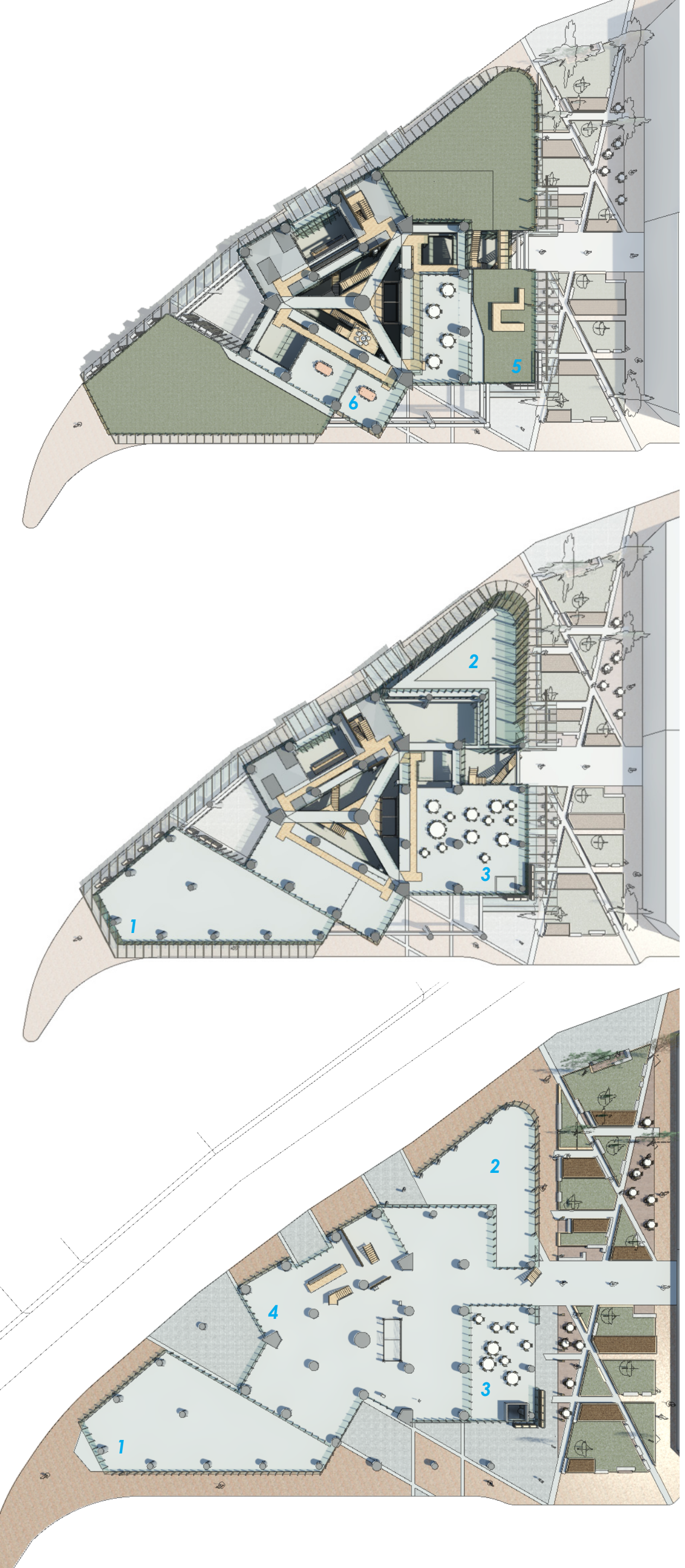





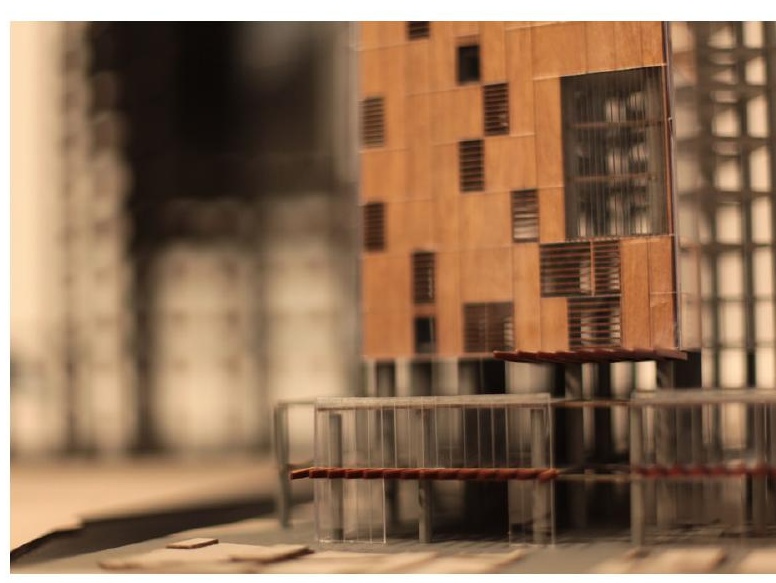

Architecturally, the podium disintegration is achieved through the removal of the floors back to the limit of the tower form. The structural beams and columns are left to provide a reminder of the existing structure and to frame secondary public space created. This secondary space also acts as a buffer to internal spaces of the podium and an area of transition from the street. Furthermore, where the tower is exposed at street level, something that did not happen beforehand, a stronger physical link to the tower is created. These techniques address FPA's mission statement by exposing the existing structure, linking into the existing urban fabric, communicating experience through the podium and finally, creating a product for FPA to interact with the public.

Figure 81. Grey Street Park and Podium, 1:200 Model.

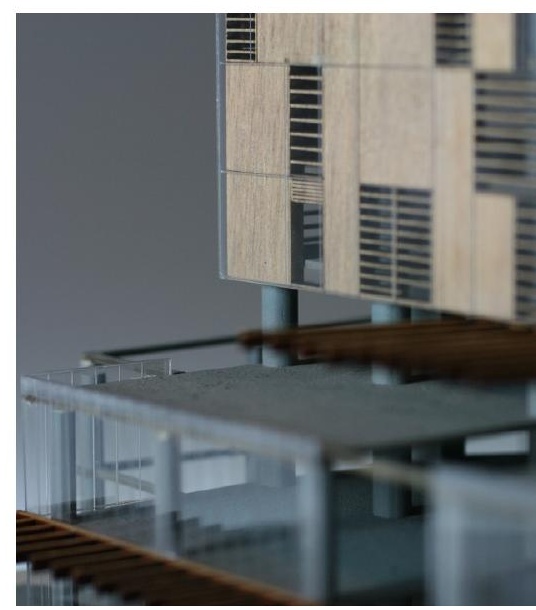

Figure 82. Podium Disintegration detail, 1:200 Model. 


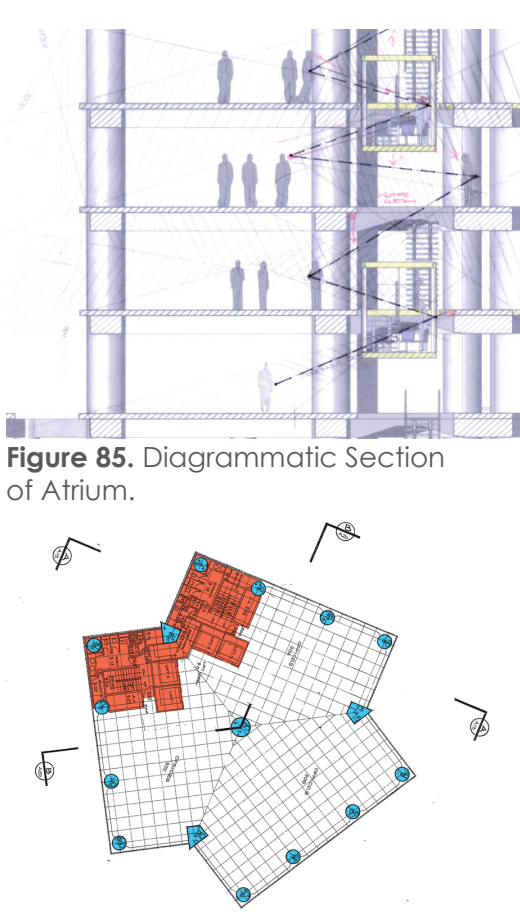

Existing

Floor Plate $=\quad 658.0 \mathrm{~m}^{2}$

Circulation $=43.8 \mathrm{~m}^{2}$

Amenities $=\quad 69.0 \mathrm{~m}^{2}$

Total Usable $=\quad 545 \mathrm{~m}^{2}$

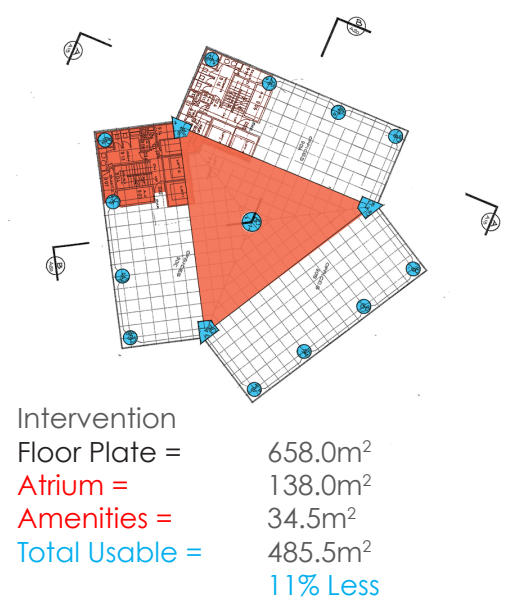

Figure 86. Before and after floor area calculation.

23. Through analysis of the original building drawings the core was deemed to be non-structural. This may not be the case for all office towers, which may use the core as bracing.

24. By shifting the core from the northwest corner to the centre of the floor plate allowed it to be integrated with the atrium. This only reduced the floor plates usable area by $11 \%$. This is a small loss of space for a major intervention into the floor area. 


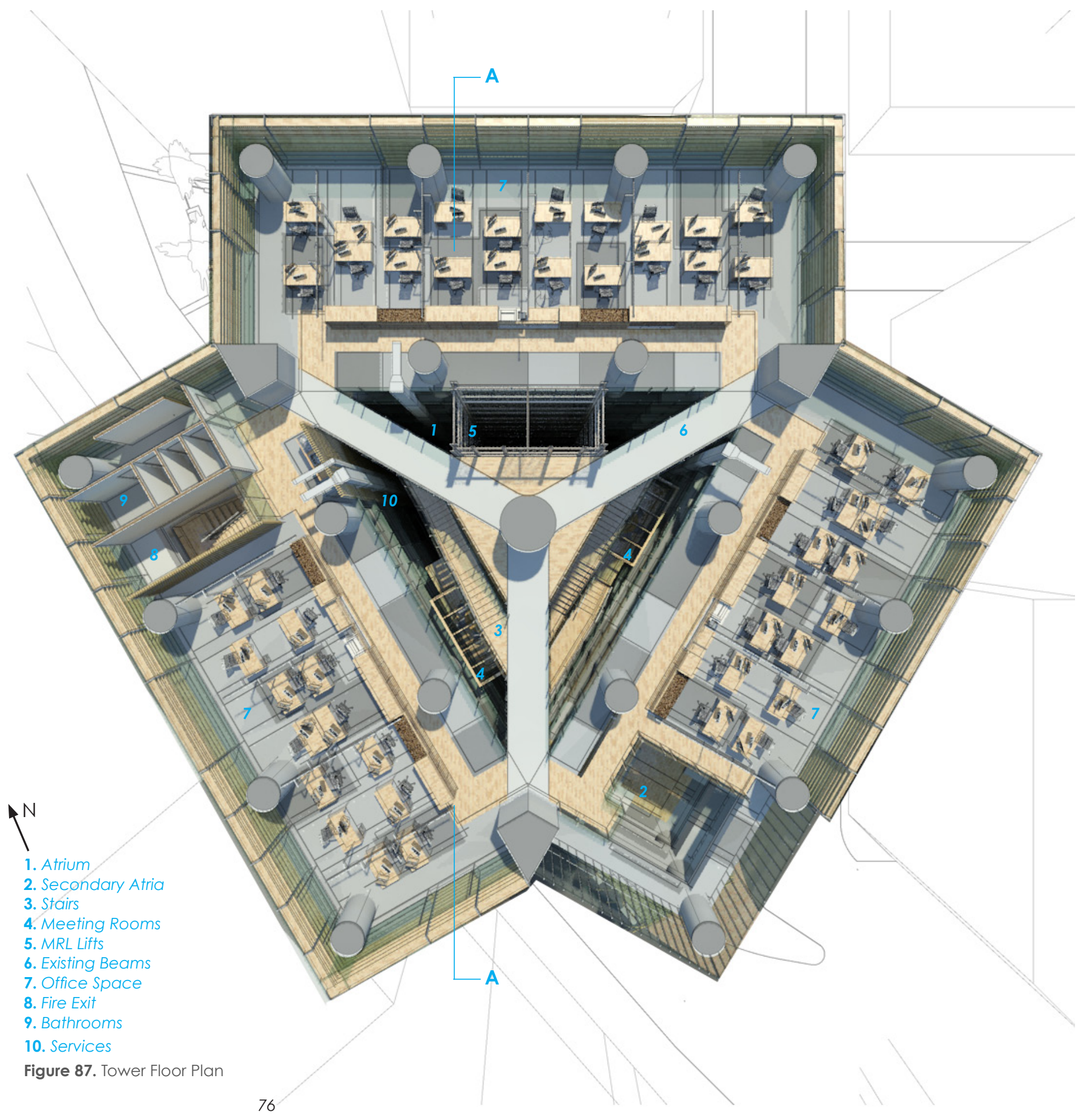


Figure 88. Central Atrium Cross Section A-A

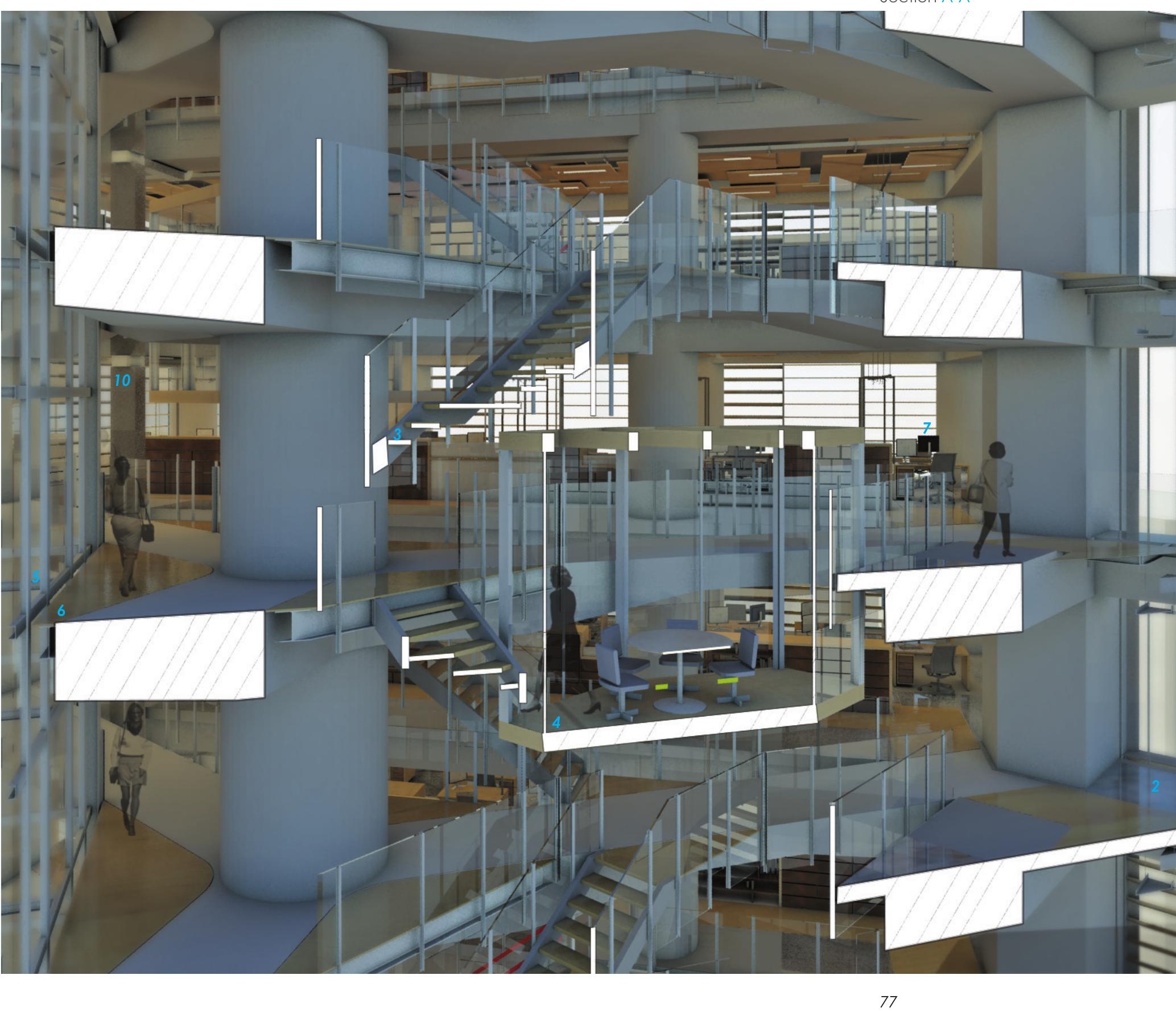




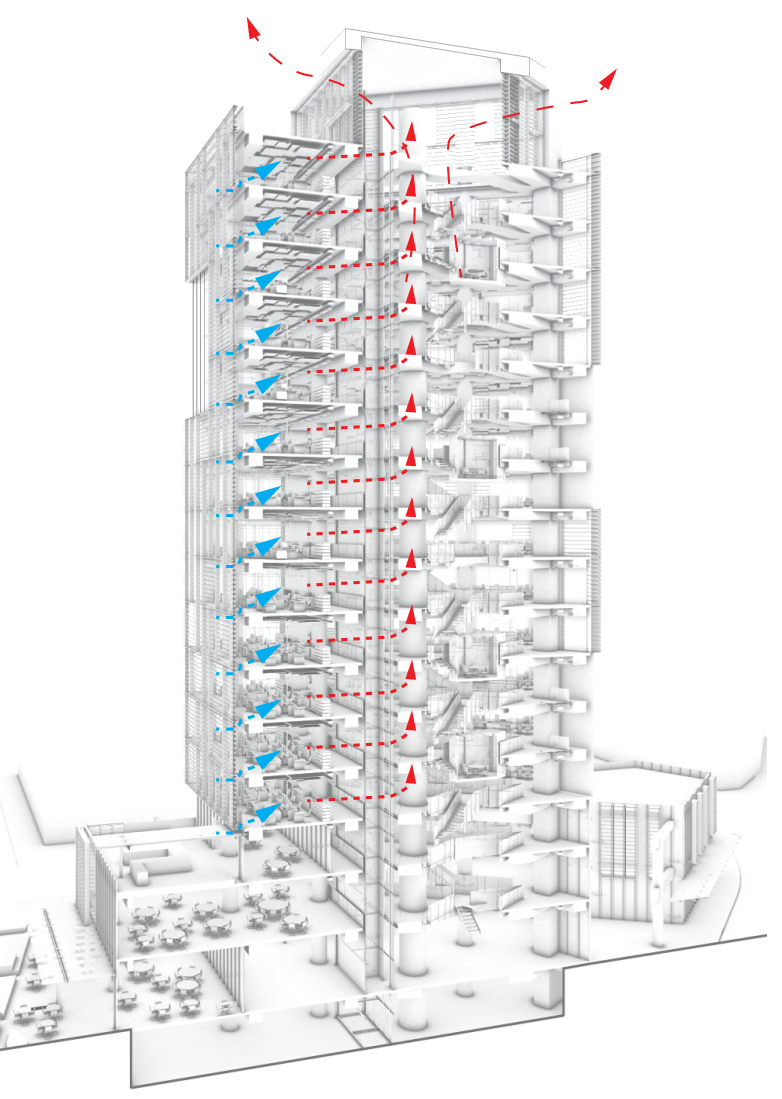

Figure 89. Natural Ventilation.

A supplementary benefit is that the atrium also provides major advantages for a quality internal environment. The open space allows natural ventilation to be used via the stack effect. The façade, described later, will allow air to enter and move across the office space into the atrium. The buoyancy of the hotter air will force it to rise to the top of the atrium where it can escape through controlled openings. Another feature, which deals with the issue of future change, is the freedom of service routing within the atrium. Services are also exposed to express the idea of the building as a product on an aesthetic level. These techniques address FPA's architectural mission statement by exposing the existing structure, linking spaces enhancing communication and social encounters. The complimentary secondary atria will now be discussed, including their relationship to adjacent office space and central atrium. 


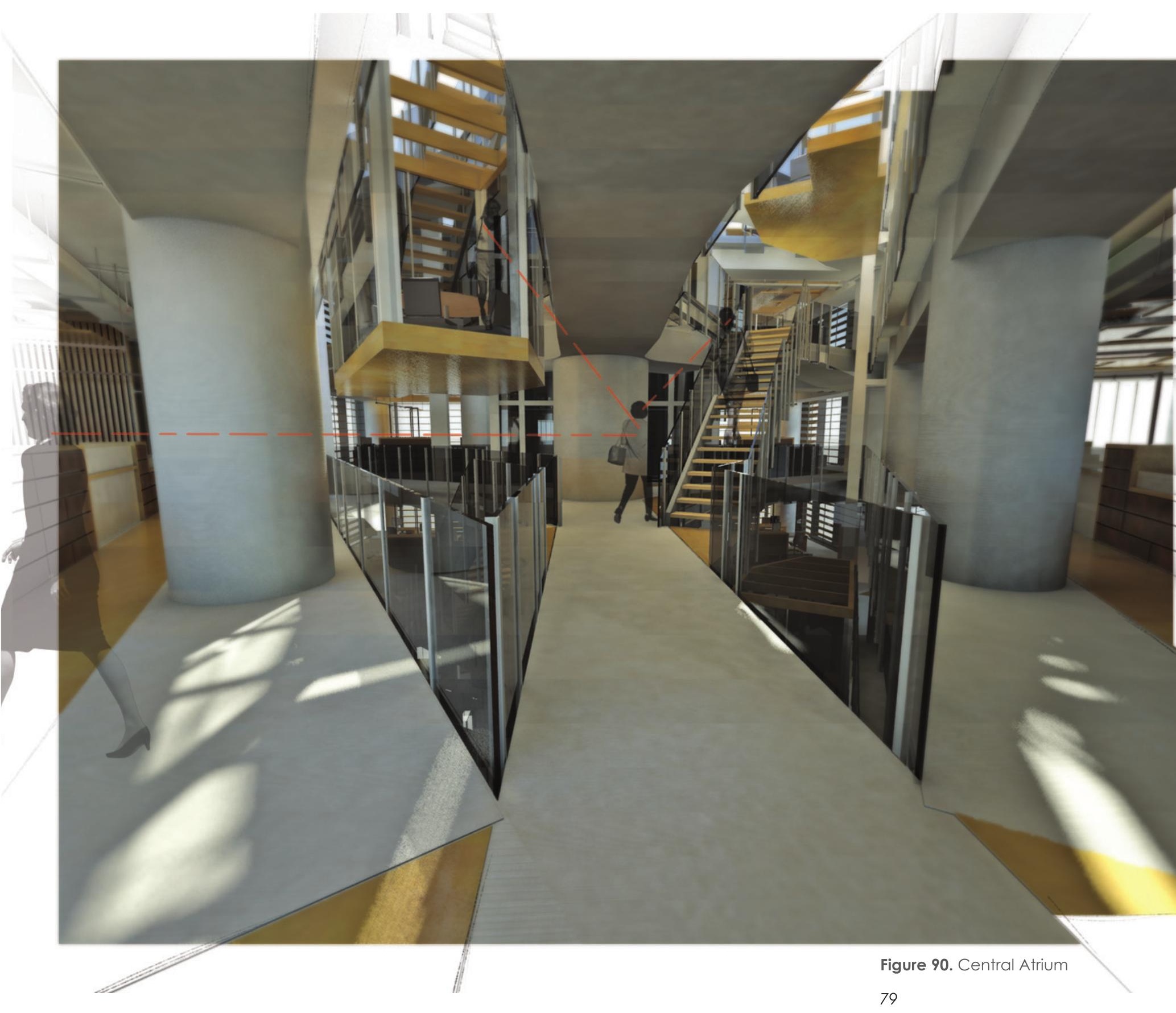




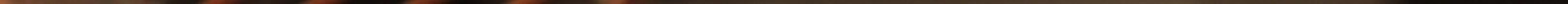




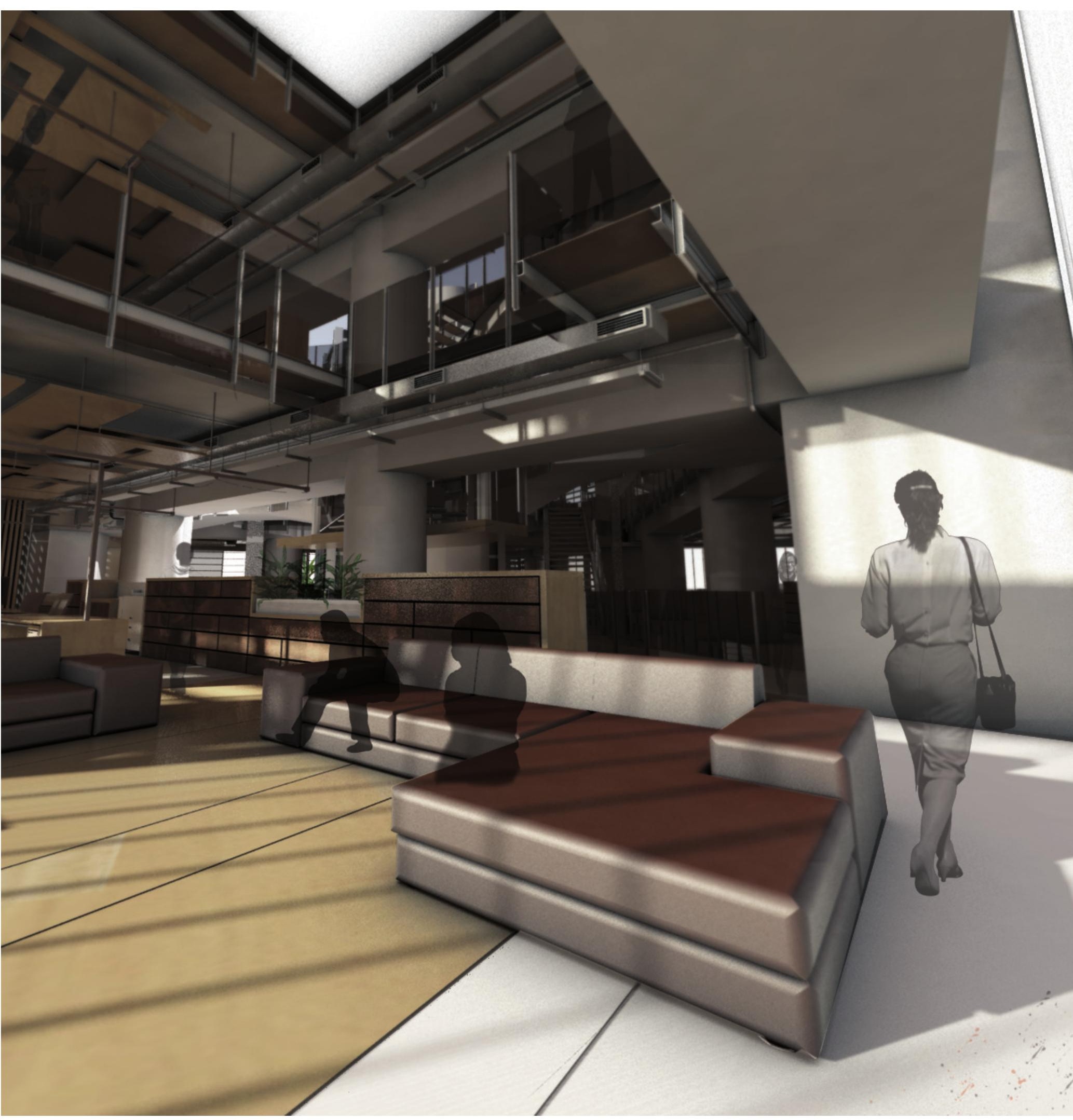



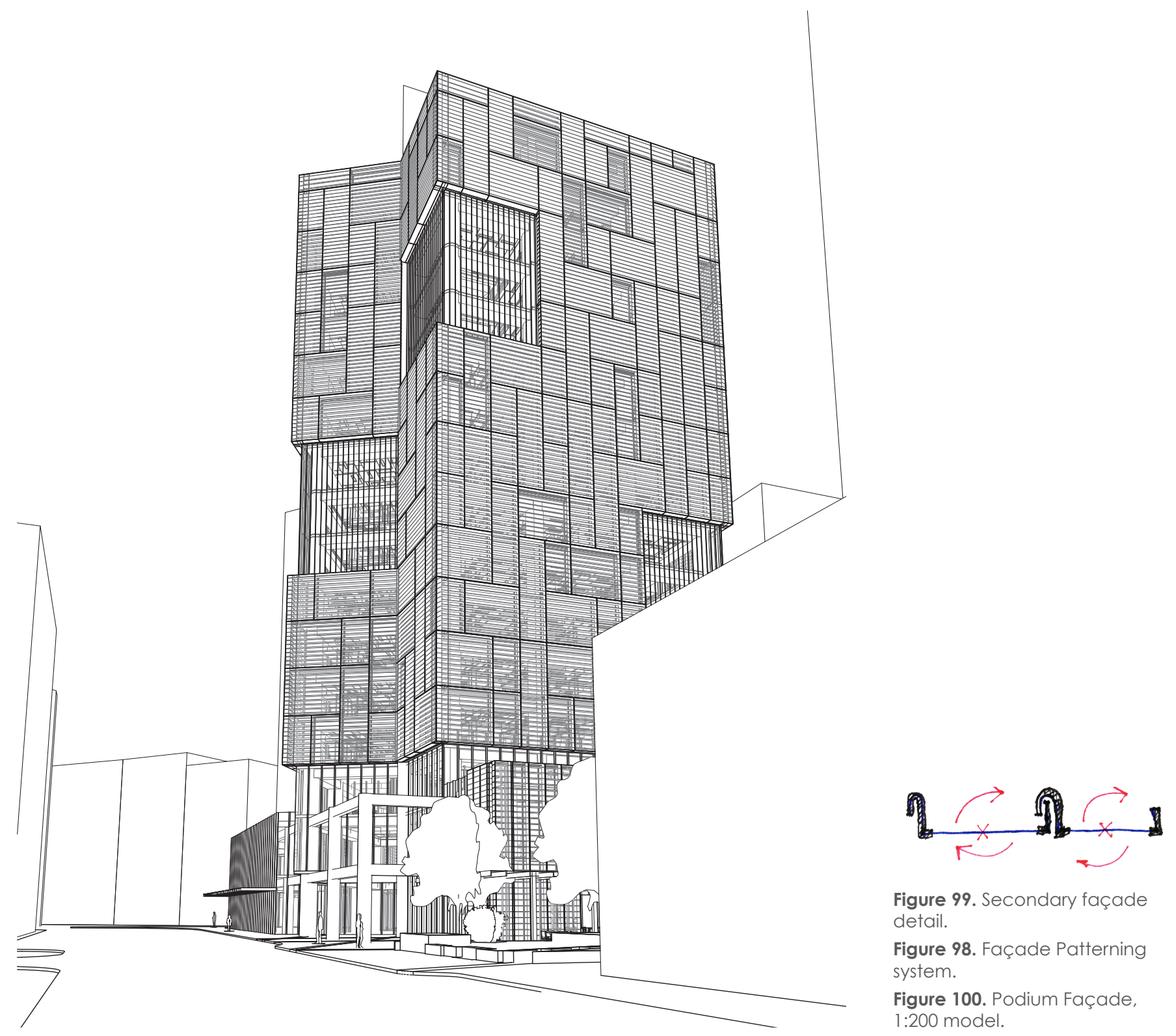

Figure 99. Secondary façade detail.

Figure 98. Façade Patterning system.

Figure 100. Podium Façade, 1:200 model.

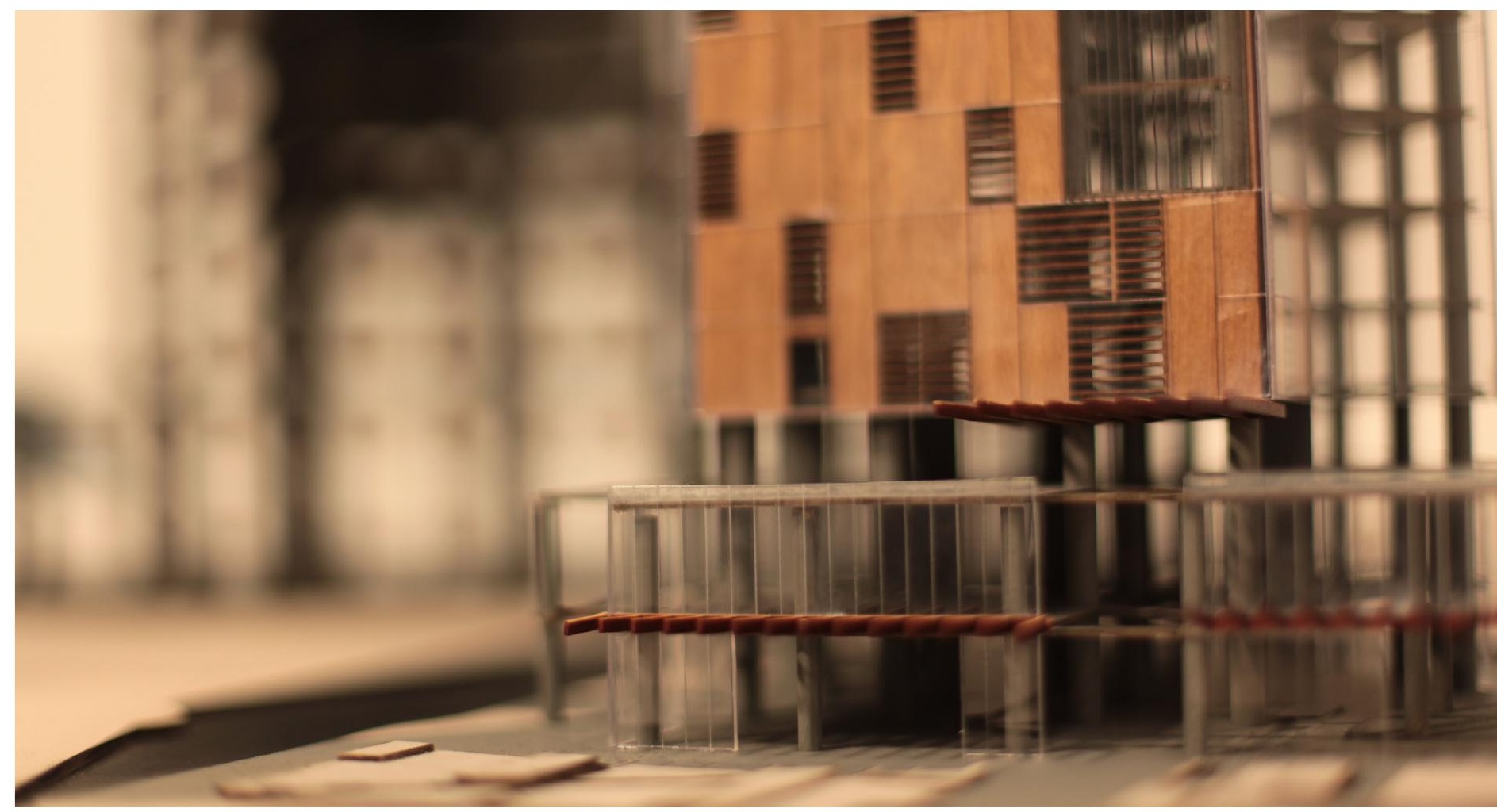




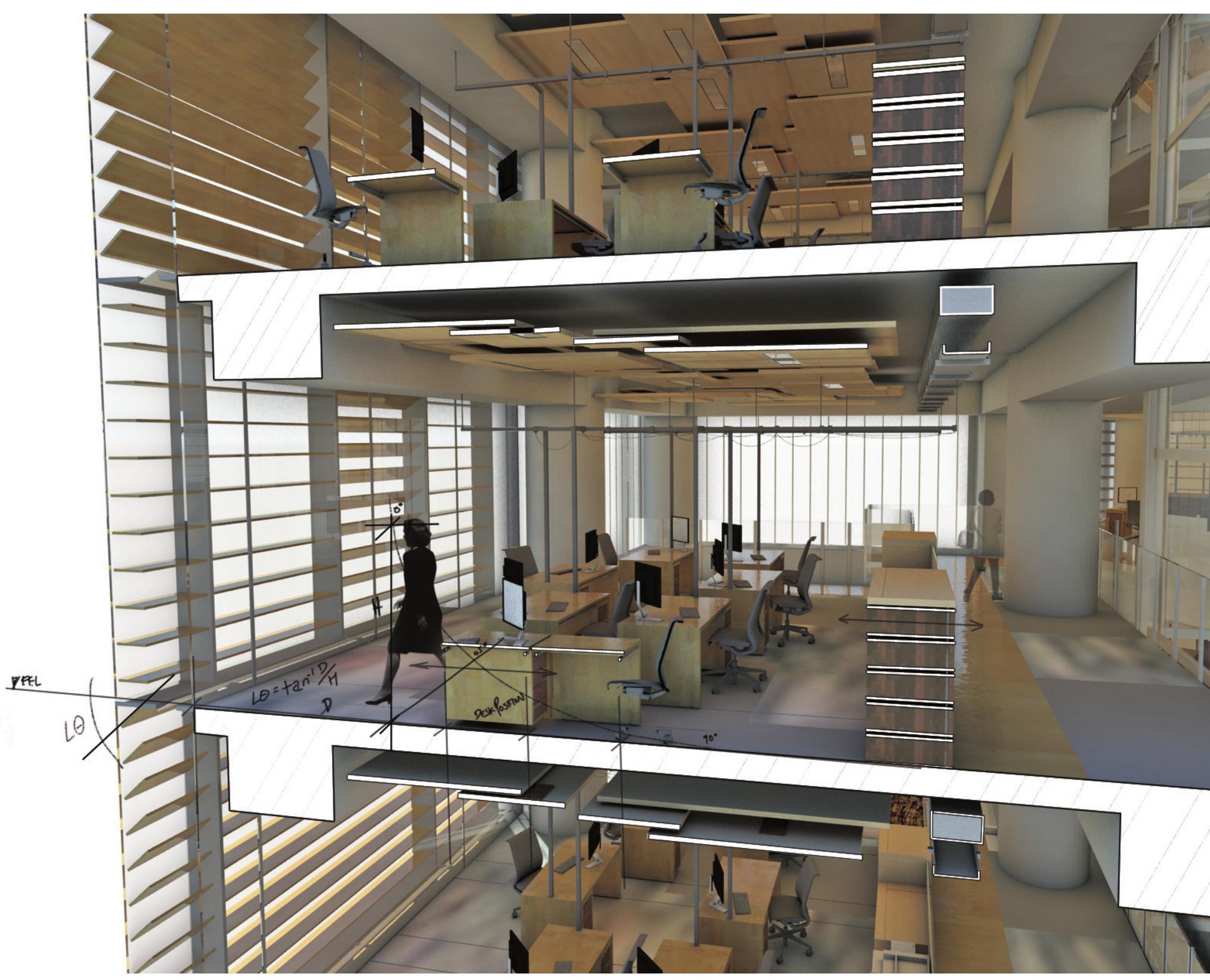

Figure 101. Office Space Section. 
into the office space when further away ${ }^{27}{ }^{28}$. The louver system will also be controlled by a building management system ${ }^{29}$ to increase the efficiency of the louvers and block out heat. Desks also allow informal meeting space to be created when two or more desks are brought together ${ }^{30}$. (fig. 101)

The patterning of the tower façade is designed to remove hierarchy inherent within multistorey buildings. The restriction of any continuous vertical or horizontal line removes the typical pattern of multistorey façades. (fig. 98) Also, by adjusting the vertical span of patterning from one level, to two, the larger scale secondary atrium façades are mediated. The secondary tower façades, relative to the secondary atria, are more transparent providing an outdoor experience allowing greater access to direct sunlight. The vertical glass louver system ${ }^{31}$ spans from the bottom to the top of the secondary atria expressing the void and existing structure. This transparency also creates a link to the similar transparency of the podium and adjacent park, signalling that leisure activities are also taking place within.

The third façade, implemented on the podium consists of a transparent curtain wall system with the inclusion of large openable doors for the entertainment areas and thoroughfares. Service areas for back of house functions are clad in the louver system to link the podium to the tower and provide privacy.

Via the general implication technique, guided by Messedat's three categories, five separate implementations were developed to express FPA's architectural mission statement. The Urban integration, podium disintegration, central atrium, secondary atria and communicative façade will now be discussed along with the translation techniques to asses the significance of this thesis for the synergy of corporate identity and corporate architecture.
27. The louvers are controlled by electric servo-motors and are linked into the desk track to calculate its position. Overrides are built into each desk and an overall building management system. This is to prevent overheating from the low eastern and western sun where horizontal louvers will need to be closed. To allow daylight into the space when low sun angles are present the louvers are perforated. This will turn the closed louvers into a translucent mesh allowing some visibility to the outside. Once the sun has increased altitude the louvers will return to normal operation.

28. Artificial lighting has also been considered. It will also be controlled by the position of the desk and levels given by sensors. This is to maintain a comfortable level of light if natural daylight does not suffice.

29. A building management system controls all electronic environmental systems within a building. This includes lighting, HVAC, natural ventilation openings, fire, doors and the louvers. It will be implemented so all systems work in unison to increase energy efficiency and internal comfort levels.

30. The timber desks are fully adjustable to allow personalisation of the workspace. The drawers are double sided and slide on two rails to allow the use of both sides of the desk.

31. These vertical glass louvers can be opened by rotation. This will allow increased cooling and fresh air of needed and can provide a high porosity opening to create an outdoor space out of the secondary atria.

\subsection{REFERENCES}

ANZ. (2010). Our Company. Retrieved 09/11, 2010, from http://www.anz. co.nz/about-us/our-company/anz-new-zealand/brands/anz/.

Drexler, A., \& Schulze, F. (Eds.). (1986). The Mies van der Rohe Archive (Vol. 1). New York: Garland Pub.

IRD. (2007). Wellington Inland Revenue staff to centralise. Retrieved 3/6, 2010, from http://www.ird.govt.nz/aboutir/media-centre/media-releases/2007/media-release-2007-10-20.html.

Knittel-Ammerschuber, S. (2006). Architecture of success: building strategies and business. Boston, MA: Birkhäuser. 


\section{0}

This chapter will discuss the ramifications of this thesis for existing and future literature and research. To reiterate, two areas of focus became evident through the review of prominent theory and the design case study. These are the translation of corporate identity to corporate architecture concepts and the implementation of corporate identity to corporate architecture. Firstly, the process of corporate identity translation is discussed through the analysis of Messedat and Knittle-Ammerschuber's text and speed theory in chapter 2.0. The application of these texts in chapter 3.0 to translate FPA's corporate identity has developed and provided new interpretations of their use. Secondly, the implementation of Messedat and Knittle-Ammerschuber's texts with the integration of speed theory and its five applications to 215 Lambton quay is examined. Limitations that were discovered are then presented to identify outstanding issues that have not been investigated allowing suggestion of further research. These points will then be concluded, summarising the significance of this thesis. 


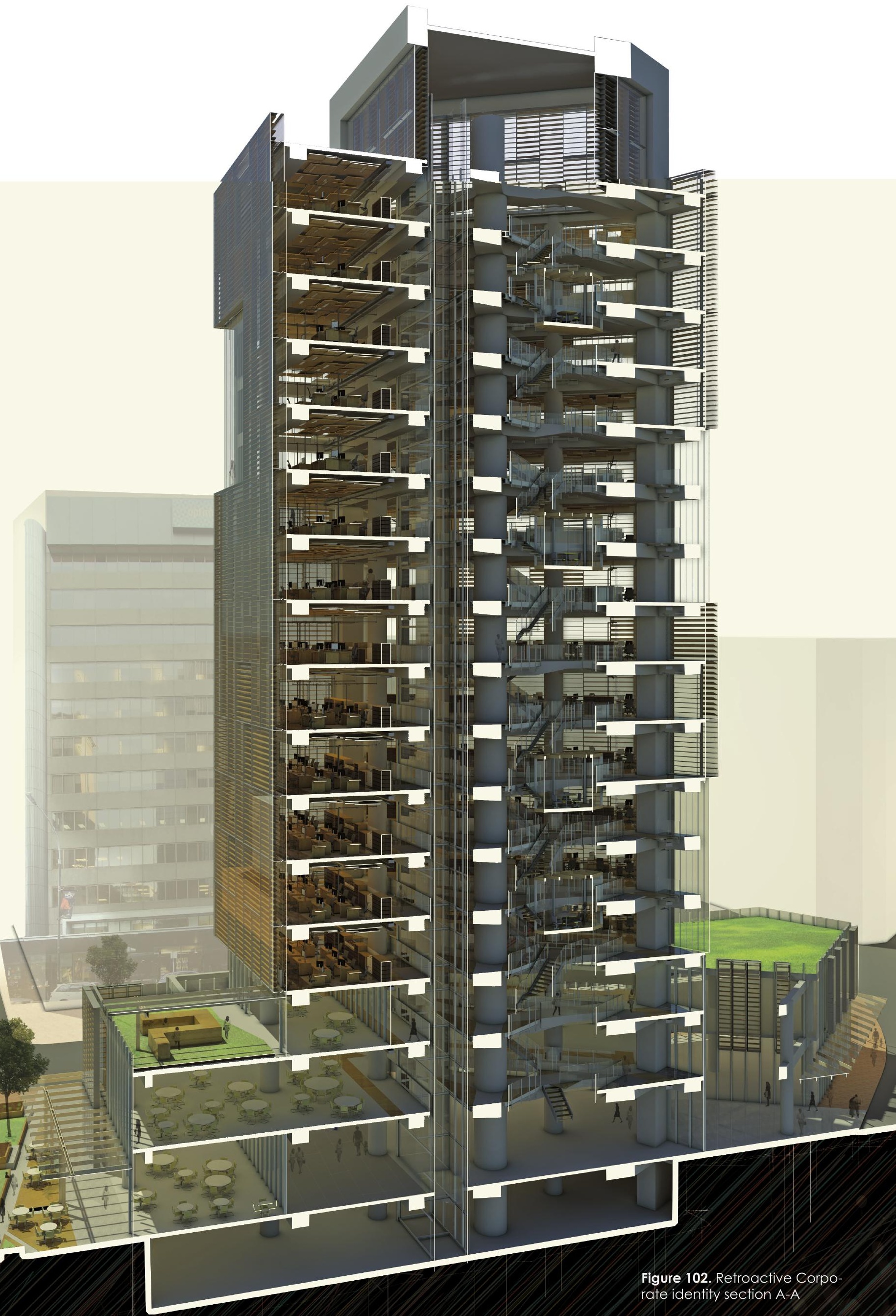




\subsection{CORPORATE IDENTITY TO CORPORATE ARCHITECTURE}

For corporate identity to manifest within corporate architecture, the process of corporate identity translation was examined. This led to the use and critique of corporate identity history, strategies, tools and methods and speed theory to translate FPA's corporate identity into conceptual ideas for the implementation of corporate architecture. This section will chronologically present the process of investigation, refreshing the existing theory, the use or response to the theory and a discussion of its implementation.

Firstly, the historical analysis of FPA was undertaken. This was not suggested by existing literature, however, was necessary to ascertain a background of the corporation. Furthermore, this uncovered the history of the corporation and identified their current, architectural and commercial situation. This initial step is important for the next to be understood. Secondly, mission statements were ascertained and compared to understand what the underlying characteristics of the corporation is and, if any trends are developing to identify future change. Knittle-Ammerschuber stated that the mission statement is vital to the success of corporate identity translation (2006, p. 140). This approach was informative, however it was improved by the inclusion of a mission statement comparison. Knittle-Ammerschuber's suggestion to analyse one mission statement does not consider the changing nature of corporate identity, which is a key area that this thesis is addressing. The comparison of two FPA mission statements proved to be beneficial as links between past and present mission statements were identified. Comfort could be taken in the knowledge that vital, recurring, goals and characteristics of the corporation are committed to the new idea of an 'Architectural mission statement'. Messedat and Knittle-Ammerschuber hint towards techniques and existing translation techniques, however do not state the need for it to be committed to form similar to a corporate mission statement. The holistic approaches of Messedat and Knittle-Ammerschuber were used as an initial approach, however lacked depth in actual guidance for the process of translation. The value of developing an architectural mission statement is, that if directly translated from the corporations, the corporation can still understand it. Furthermore, it becomes a much more powerful tool for the architect, aiding implementation of corporate identity. As this process was not developed within existing theory, speed theory, another prominent interpretation of corporate architecture was used. This chronological analysis of corporate architecture, turned design tool, was used to consolidate the idea of time within the architectural mission statement. It also allowed each element of corporate architecture to be 


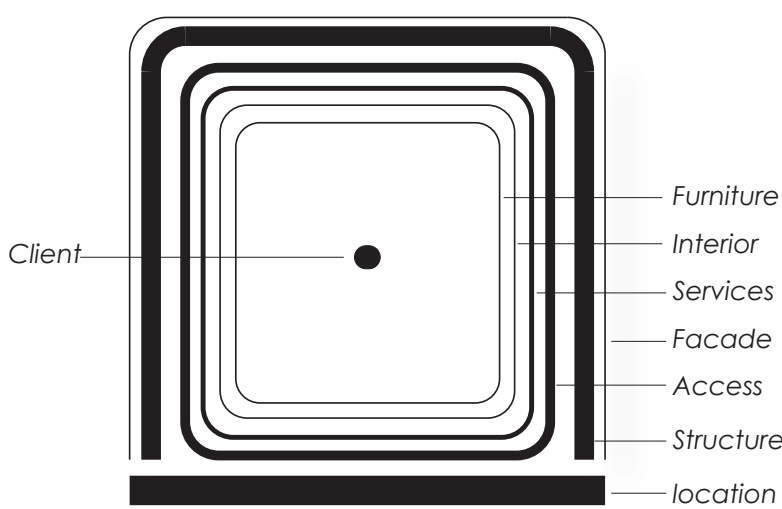

Client Intergration

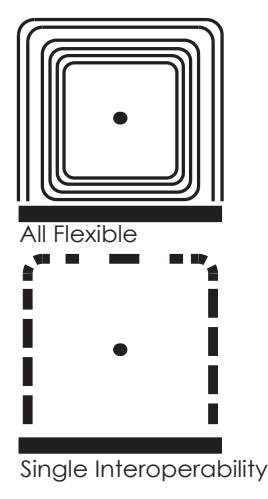

Development

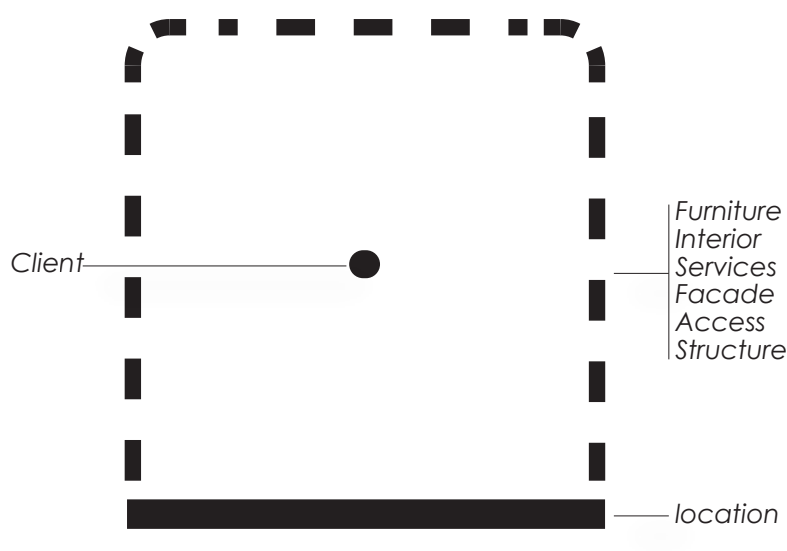

Corporate Retrofit treated separately, assisting in simplifying translation, under the umbrella of the holistic approach and Knittle-Ammerschuber's management methods within the translation matrix. Retrospectively SLA's third iteration of speed theory can now be developed further as a design tool for corporate identity

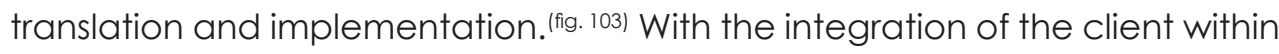
the diagram a systematic approach appears that tackles issues of both corporate identity and speed theory. Thus, the lack of time and change within corporate identity theory, and secondly, the lack of a corporations representation within speed theory is juxtaposed. The combination of these two, previously unconnected, theories have helped design a systematic way to translate corporate identity.

\subsection{IMPLEMENTATION OF CORPORATE IDENTITY}

Through the original process of developing an architectural mission statement, implementation was then undertaken on 215 Lambton Quay. For corporate identity to manifest within corporate architecture, the process of implementation was also examined. Corporate identity history, strategies, tools and methods and speed theory to were once again used, this time to implement FPA's corporate identity into corporate architecture. This section will once again chronologically present the process of investigation into implementation, refreshing the existing theory, the use or response to the theory and a discussion of what worked.

Firstly, the selection of a site and building was discussed. This was a rational approach and a rare opportunity as corporations will almost certainly already own or have purchased real estate before approaching an architect. The potential of a building, structural possibilities of the façade and superstructure need to be fully assessed in coherence with other speed theory layer interfaces from the out set of a project. This will determine the level of interventions that can be applied from an architectural mission
Figure 103. Speed theory development. 
statement. Also the slowest layer, and hardest to adapt, is the position of the building within an urban framework remains important. For FPA this is a ground breaking investigative project and an important site, visually and functionally was chosen to provide a large audience. Therefore, it can be concluded that corporations need to use architects advice before selecting a building, as some will allow more flexibility, adaption and public response to change than others. To ascertain and assess the flexibility of the existing building, it was also categorically analysed, in cohesion to speed theory, to provide a descriptive breakdown. This use of speed theory is more aligned to its original facilities management approach, however it was beneficial to discover the general potential of the building typology and unique features inherent within the selected building. After speed theory building analysis, the general holistic implementation of the architectural mission statement was then described that responded to the context of the selected building. This first step in implementation is similar to the initial holistic approach undertaken within translation. It acts as an overall concept, however lacks depth once separate elements of architecture are to be implemented. As mentioned, where existing guidelines for implementing corporate identity ceased were where specific approaches are needed. Specific approaches developed within the architectural mission statement were described through five original implementation methods, as the culmination of corporate identity translation and the implementation of corporate architecture.

Urban integration of FPA's corporate identity and corporate architecture emits an element of responsibility. The existing building is solid and does not link into the urban fabric. The design responds on a similar level to the Krupp's Margarethenhöhe settlement where an urban centre and link to corporate identity was created. A transition from urban space to the corporation through complimentary programmes that work with both the urban scale and the corporations architectural and corporate mission statements is vital. This is presented through the new integration with the park and the thoroughfares.

Podium disintegration was supplementary to urban integration, which was expressed by separating the podium into suitable functions for FPA and the public. Podiums are not standard on multistorey buildings, however, similar techniques of programming and secondary public spaces could be implemented.

The central atrium has acted as a tool to remove the hierarchy from the multistorey office tower and link into the podium space. Also by functioning 
as an environmental controller there are many intangible advantages to this intervention. For other buildings smaller central atria could be implemented if the flexibility of this building was not present.

The secondary atria provide a place for informal meeting space and socialising. Also the element of domesticity has been integrated into adjacent to office space. Furthermore, these act as spatial buffers to the central atrium and also as a communication tool to the public. If a central atrium could not be created these could act alone.

The communicative façade has given the building a face, for FPA to communicate through, and for the public to read. The direct relationship from the inside of the building through the façade, via an environmental control system, communicates different levels of the architectural mission statement. This direct physical relationship that the inhabitants have with the façade is a response to the critique of ambiguous media façades. For the honest, legible representation of corporate identity there is still a place or an element of physical interaction within a physical space.

These five implementations could be repeated in any combination, however, must respond to the context of specific corporations and buildings. Different corporations will undoubtedly require different spaces and different buildings will allow varying levels of flexibility. Also through developing this system, for the retention of corporate and architectural individuality, a stepby-step approach has not been presented, and it should not be attempted. Therefore, this thesis should be seen as an advance in the existing guidance of corporate identity translation and implementation.

\subsection{FURTHER CORPORATE IDENTITY INVESTIGATION}

From identifying the limitations of this research, further investigation can be established. Within the category of corporate identity translation further research shall be undertaken to investigate the listed limitations. Retrospectively there are significant characteristics of this project that are important to corporate identity.

\section{TRANSLATION}

Firstly, the lack of personal communication with FPA, although stated as a positive approach within chapter 3.0, can also be seen as a limitation. The choice not to contact the client was committed to throughout the process to retain the purity of their mission statement. If further research were to be undertaken it would be suggested that the client be involved from 
an early stage. This would be beneficial as the client influence could be directly compared to this study. It would also be beneficial to present this complete thesis to FPA to ascertain their response. This would allow a form of measurement and client based assessment of the techniques used.

\section{IMPLEMENTATION}

The identified issue of change in corporate identity has been represented within the building. This is significant as it reminds the public and inhabitants of the building to accept that corporate culture will continue to change. It also places the building within two eras of corporate architecture creating a multiplicity of spaces that do not present them selves as one static building but a changing building expressing that future change is inevitable. This process falls into the field of historic restoration and the sensitivity needed to retrofit ancient buildings. Then again, multistorey office towers are currently not treated as an architectural typology that needs sensible approaches, however use of these sensitive strategies within this context could develop intricacies that currently do not exist.

\section{PROCESS}

Translation of corporate identity faced lack of guidance once the existing strategies were exhausted. Speed theory was implemented to provide further theoretical guidance after this point and generate an architectural mission statement. However the success of the architectural mission statement remains ultimately unmeasurable. Further Investigation, of the translations success could once again be measured by seeking the response of FPA after reading this thesis and viewing the design case study. Also an analysis of the implementation could be undertaken via a speed theory breakdown of the design case study. This would allow a direct comparison to statements from the existing buildings speed theory review.

This section has discussed the thesis findings and the application of existing theory presented in chapter 2.0. The translation of a corporate identity to corporate architecture was discussed and how the design case study has tested existing theory. The implementation of corporate identity has also been discussed to experiment with the existing literature. Conclusions will now be presented to summarise the significance of this thesis. 


\subsection{CONCLUSIONS}

This thesis has defined corporate identity, explored its history and development, and presented contemporary methods and interpretations of implementing corporate architecture. Furthermore, a design case study consisted of selecting and translating FPA's corporate identity into an architectural mission statement to implement within an existing building.

More specifically, Chapter 2.0 analysed existing theory and provided a background of the development of corporate identity and corporate architecture. This has identified the issue that current trends of corporate architecture may repeat existing ambiguous interpretations of corporate identity. These were successful at the time, however corporate culture has been identified to be fluid and will continue to change. Strategies, tools and methods of Knittle-Ammerschuber and Messedat were discussed to set up a framework to approach the research. These were identified to have a limited approach to change, identified in the history analysis. Therefore, speed theory was introduced to provide an interpretation of time within corporate architecture and the relationship of architectural elements. This culminated in the proposition to translate and implement corporate identity through an architectural retrofit, addressing time, representation and synergy within corporate culture and identity.

The guidance and interpretation of corporate identity and architecture was used in chapter 3.0 to translate FPA's corporate identity. This was done, firstly, through a historical analysis presenting where FPA came from through a corporate, product, marketing and architectural history. KnittleAmmerschuber's declaration to use a mission statement for translation was advanced by using two of FPA's recent mission statements. This allowed a comparison to ascertain emerging trends and consolidated goals and characteristics. This analysis, via the combination of FPA's history, mission statements, management techniques and speed theory, culminated in an architectural mission statement. This new step allowed a direct evolution from FPA's corporate identity to a driver of architectural implementation.

In chapter 4.0, implementation began with the selection of suitable architecture to apply the architectural mission statement to. The architectural mission statement was then applied generally to respond to the context of the selected building. This identified the overarching concepts that drove specific implementation. The specific implementation consisted of five techniques, urban integration, podium disintegration, central atrium, secondary atria and a communicative façade. These interventions into 
corporate architecture are specific to FPA however could be combined within a similar process. For the continuing innovation and individuality of corporate architecture this is not to be seen as a set of strict implementations, but a systematic approach that is and can be used dynamically to provide the best response to the corporate and architectural context.

Chapter 5.0 discussed the ramifications of the research for existing translation and implementation theory, providing a critique of the design case study. Also, further research was suggested to provide an outlook for this thesis and corporate identity architecture concluding the thesis within this section.

The significance of this thesis increases understanding of the complex and fluid field of corporate identity, increasing the synergy of corporation and architect, corporation and architecture, and most importantly increasing architects, corporations and publics relationships to corporate identity.

\subsection{REFERENCES}

Knittel-Ammerschuber, S. (2006). Architecture of success: building strategies and business. Boston, MA: Birkhäuser. 


\section{0 apsanx}

\subsection{BIBLIOGRAPHY}

3Deluxe. (2008). 3deluxe: transdiciplinary approaches to design.

Netherlands: Frame Publishers.

Abel, C. (1997). Architecture and identity: towards a global eco-culture. Oxford: Architectural Press.

AEG. (2010). AEG History. Retrieved 16/11, 2010, from http://www.aeg. com/node367.asp.

Ambrose, G. (2008). The visual dictionary of architecture. New York: AVA Publishing SA.

ANZ. (2010). Our Company. Retrieved 09/11, 2010, from http://www.anz. co.nz/about-us/our-company/anz-new-zealand/brands/anz/.

Barry, R. (1991). Industrial: Fisher and Paykel, East Tamaki. Architecture New Zealand(September/October), 44-47.

Black's law dictionary. (2009). St. Paul, MN: West.

Brand, S. (1994). How buildings learn: what happens after they're built. London: Phoenix Illustrated.

Circ. (2007). Essay. Retrieved from http://corporate-lexicon.com/pdfs/ Essay_english.pdf.

Collins English dictionary. (2000). London: Collins.

Davies, P. (2008). Project Ironside. Artichoke(25), 59-60.

Drexler, A., \& Schulze, F. (Eds.). (1986). The Mies van der Rohe Archive (Vol. 1). New York: Garland Pub. 
Duffy, F. (1990). Measuring Building Performance. Facilities, 8(5), 17-20.

Ford Motor Company. (1915). Ford Factory Facts. from http://www.mtfca. com/books/15_factory.htm.

FPA. (15 September 2010). Fisher \& Paykel Appliances reveals refrigeration compressor technology set to revolutionise energy consumption. Retrieved 27 Nov 2010, 2010, from http://www.fisherpaykel.co.nz/ pressroom/downloads/Compressor\%20release\%20-\%20FPA\%20Press\%20 Room.pdf.

FPA. (2010a). 2010 Annual Report: Fisher \& Paykel.

FPA. (2010b). About Us. Retrieved 11/08, 2010, from http://imagebank. fisherpaykel.com/indexMain.cfm?page=1234AB99-C1 C0-45FB-848C1DFA47916F40.

FPA. (2010c). Experience. Retrieved 10/08, 2010, from http://www. fisherpaykel.co.nz/global/experience/index.cfm.

FPA. (2010d). Fisher \& Paykel voted New Zealand's most trusted whiteware brand., 1. Retrieved from http://www.fisherpaykel.co.nz/pressroom/ downloads/fisher\%20and\%20paykel\%20tops\%20most\%20trusted\%20 brand\%20survey.pdf.

FPA. (2010e). FPA Stock Exchange Release ASX/NZX, CHAIRMAN AND MANAGING DIRECTOR \& CEO'S ADDRESS TO SHAREHOLDERS. Retrieved 27 Nov 2010, 2010, from http://www.fisherpaykel.co.nz/global/investors/ Investors-PDFs/Announcements/04\%20Chairman\%20and\%20Managing\%20 Director\%20\&\%20CEO's\%20Address\%20to\%20Shareholders.pdf.

FPA. (2010f). Our Story. Retrieved 03/06, 2010, from http://www.fisherpaykel. com/global/company/who_we_are.cfm.

Friedman, S. S. (1998). Mappings: feminism and the cultural geographys of encounter. Princeton, N.J: Princeton University Press.

Gartman, D. (2009). From autos to architecture: Fordism and architectural aesthetics in the twentieth century. New York: Princeton Architectural Press. Hosey, L. (2010). Gizmo green: sustainable design deserves more than bells and whistles. Architect, 99, 29.

IRD. (2007). Wellington Inland Revenue staff to centralise. Retrieved 
3/6, 2010, from http://www.ird.govt.nz/aboutir/media-centre/mediareleases/2007/media-release-2007-10-20.html.

Jencks, C. (1991). The language of post-modern architecture. New York: Rizzoli.

Johnston, M. (2010, 10/5/2010). Survey reveals NZ's best and worst home appliances. New Zealand Herald. Retrieved from http://www.nzherald. co.nz/nz/news/article.cfm?c_id=1 \&objectid=10643928.

Knittel-Ammerschuber, S. (2006). Architecture of success: building strategies and business. Boston, MA: Birkhäuser.

Kravel, J. (2008). Corporate buildings. Barcelona, Spain: Links.

McDonough, W. (2002). Cradle to cradle: remaking the way we make things. New York: North Point Press.

McHarg, I. L. (1971). Design with nature. New York: Doubleday/Natural History Press.

Messedat, J. (2005). Corporate architecture: Development, concepts, strategies. Ludwigsburg: AV Edition.

New Zealand Trade \& Enterprise. (2009). CookSurface Typifies F\&P Design Approach. Retrieved 12/8, 2010, from http://www.betterbydesign.org.nz/ news-and-resources/design-news/news-details? objld=da9d2603-acaa4b0a-9847-cedc9e7ec7f5.

NZPA. (2008, 17/04/2010). Fisher \& Paykel move 'damages iconic brand'. New Zealand Herald.

Revington, M. (2005). Ideas Inc. Retrieved 11/08, 2010, from http://unlimited. co.nz/unlimited.nsf/growth/ideas-inc-p2.

Reichardt, J., Mass, B., et. al. (2010). Aesthetic and Efficiency. Retrieved 6 May, 2010, from http://www.r-m-a-architekten.de/index_e.html.

Rowden, M. (2000). The art of identity: creating and managing a successful corporate identity. Aldershot: Gower.

Schittich, C. (2003). Insurance Building in Munich. Boston: Birkhäuser. 
Sheppard, G. (2009). Fisher \& Paykel looks towards the future with Ironside. Retrieved 09/08, 2010, from http://www.current.com.au/2009/04/27/article/ IJEHVBACNO.html.

SL.A. (2003). Smart architecture. Rotterdam: 010 Publishers.

Sommer, D. (1993). Industriebau: Die Vision Der Lean Company:

Praxisreport. Verlag AG: Birkhäuser.

Venturi, R., \& Brown, D. S. (1972). Learning from Las Vegas. New York: Routledge.

William W. Braham, J. A. H., and John Stanislav Sadar (Eds). (2007). Rethinking technology: a reader in architectural theory. New York: Routledge.

Yeang, K. (1998). Bioclimatic skyscrapers. London: Ellipsis.

Yudelson, J. (2010). Greening existing buildings. New York: McGraw-Hill. 


\section{Original Mission Statement}

\section{Current Mission Statement}

\section{Style $\rightarrow$}

is about desirability, it reflects the way in which we do things. It's not only the way we design our products; it's the way in which we evolve in response to change.

\section{Sense + Simplicity $\rightarrow$}

We understand that our lives are becoming more complex. We believe in technology that is both leading edge and at the same time human. This approach has led to the development of refrigerators that think for themselves to keep food fresher, and cookers so smart they help clean themselves. Whether it's washing machines that use half the water you normally use or dishwashers designed to wash as well as store your dishes - above all we believe in insight led design that is tailored to peoples changing needs around the world.

\section{Integrity $\rightarrow$}

is about building relationships with our customers, it reflects the way we go about our business; the trust behind our reputation; the way in which we build our values.

\section{Heart + Soul $\rightarrow$}

Your kitchen is more than just a room; it is the heart and soul of your home. It's a space where you can share delight; fulfil a passion and taste the best life has to offer. Creating a feast for family and friends is one of life's daily rituals and simple pleasures. From our perspective food needs to be more than just fuel, it needs to be delicious as well. Each of our products has been designed to bring out the chef in you, by making cooking easier, more enjoyable. This is what drives us to do what we do - creating experiences that enhance the time we spend together.

\section{Care $\rightarrow$}

reflects how we look after all with whom we come in contact; our respect for the environment; and the way in which our people go about their roles.

\section{Today + Tomorrow $\rightarrow$}

Behind every product is a story, and that story begins with you. Your kitchen is an expression of who you are, how you cook, and how you enjoy food with others. Our passion is creating better experiences that put the joy of food at the centre of your life. Eat, share, live life - we'll take care of details.

\section{Innovation $\rightarrow$}

is our heart; we are innovative in all that we do, from the big ideas through to the detail.

\section{Passion + Performance $\rightarrow$}

Food is theatre. From mid week convenience to gourmet weekends each meal is a performance and the kitchen is your stage. Celebrating great food and cooking from around the world is the show, from the soft crust of a freshly baked baguette to the comforting fragrance of Vietnamese pho - variety is the spice of life. Just as we are seeking quality and variety in our food, we desire the same of our kitchens, we are looking for unique appliances that combine innovation with reliability and performance. Savour the taste of your next meal in tomorrow's kitchen. 


\section{Architectural Elements}

Façade, Circulation,

Environmental control acting as smart mediators of space and functions.

\section{Architectural Process Spatial Use}

Simplistic and non-

overcomplicated approach throughout design to create a simple and stylistic response.
Clarity within spatial space that makes sense to use and inhabit allowing flexibility and customisation.
Fixed elements (Structural) to be exposed and used as a feature.
Consider integration of new elements into existing throughout process to express time and change within the design.
Consider the core

functions of spaces and the levels of interaction between inhabitants and environment.
Environmental control systems and services designed to actively respond and be visible within spaces.
Design with holistic approaches considering the wider problems to foresee any future issues and changes.
Create a social and respectful environment stimulating relationships between staff, products and the environment.
All architectural elements must perform their task and fit in with other elements.
Consider elements within the overall process to ensure their performance is considered.
Functionality of spaces must nourish their need and required performance. 


\begin{tabular}{|c|c|c|}
\hline Spatial Layout & Construction Process & Construction Details \\
\hline $\begin{array}{l}\text { Be legible from all views } \\
\text { of the building and able } \\
\text { to adapt to the required } \\
\text { situations. }\end{array}$ & $\begin{array}{l}\text { Create a simple narrative of } \\
\text { construction process to express } \\
\text { time and change. }\end{array}$ & $\begin{array}{l}\text { Simple and understandable details } \\
\text { throughout the building to express } \\
\text { ideas of flexibility and change. }\end{array}$ \\
\hline $\begin{array}{l}\text { Respect and interaction to } \\
\text { be considered from micro } \\
\text { to macro scales throughout } \\
\text { the whole building and } \\
\text { surrounding environment. }\end{array}$ & $\begin{array}{l}\text { Treat the existing structure with } \\
\text { respect to express the narrative } \\
\text { of change. }\end{array}$ & $\begin{array}{l}\text { Show contrasts or interest at junc- } \\
\text { tions between old and new. Also } \\
\text { intersections between spaces } \\
\text { need to be expressed. }\end{array}$ \\
\hline
\end{tabular}

Flexibility of and adaptability of space creating efficiency within all spatial, environmental and technical systems.
Consider simplicity of construction and future construction process.
Efficient fixings to express overall approach and clarity of design.
Performance of layouts must consider others in terms of intersecting membranes to filter the required relationships.
Simple and easy to perform removing unnecessary complicated processes.
Performance of details needs to be considered at all levels of complexity and scale. 


\section{Corporation Use}

Usable space that works with the corporation to achieve their goals. $\rightarrow$ Architectural Mission Statement $\rightarrow$ Innovative Communication

Architecture that expresses innovation and leading technology whilst remaining simple, legible and adaptable to inhabitants and public.
Spaces that enhance the corporation's relationships to each other, the public and surrounding environment.

\section{$\rightarrow$ Sensitive Relationships}

A complex arrangement of spaces that work together to enhance relationships and express ideas of change and innovation.
Enhance the flat and respectful structure of the corporation.

\section{$\rightarrow$ Respectful Planning}

A product that respects its current and future surroundings, inhabitants and their goals.
All spaces must be tailored to perform the required use of the corporation.

\section{$\rightarrow$ Harnessing Potential}

A building that harnesses the inhabitants performance building productivity and potential of ideas and products. 


\subsection{EXISTING BUILDING PHOTOS}

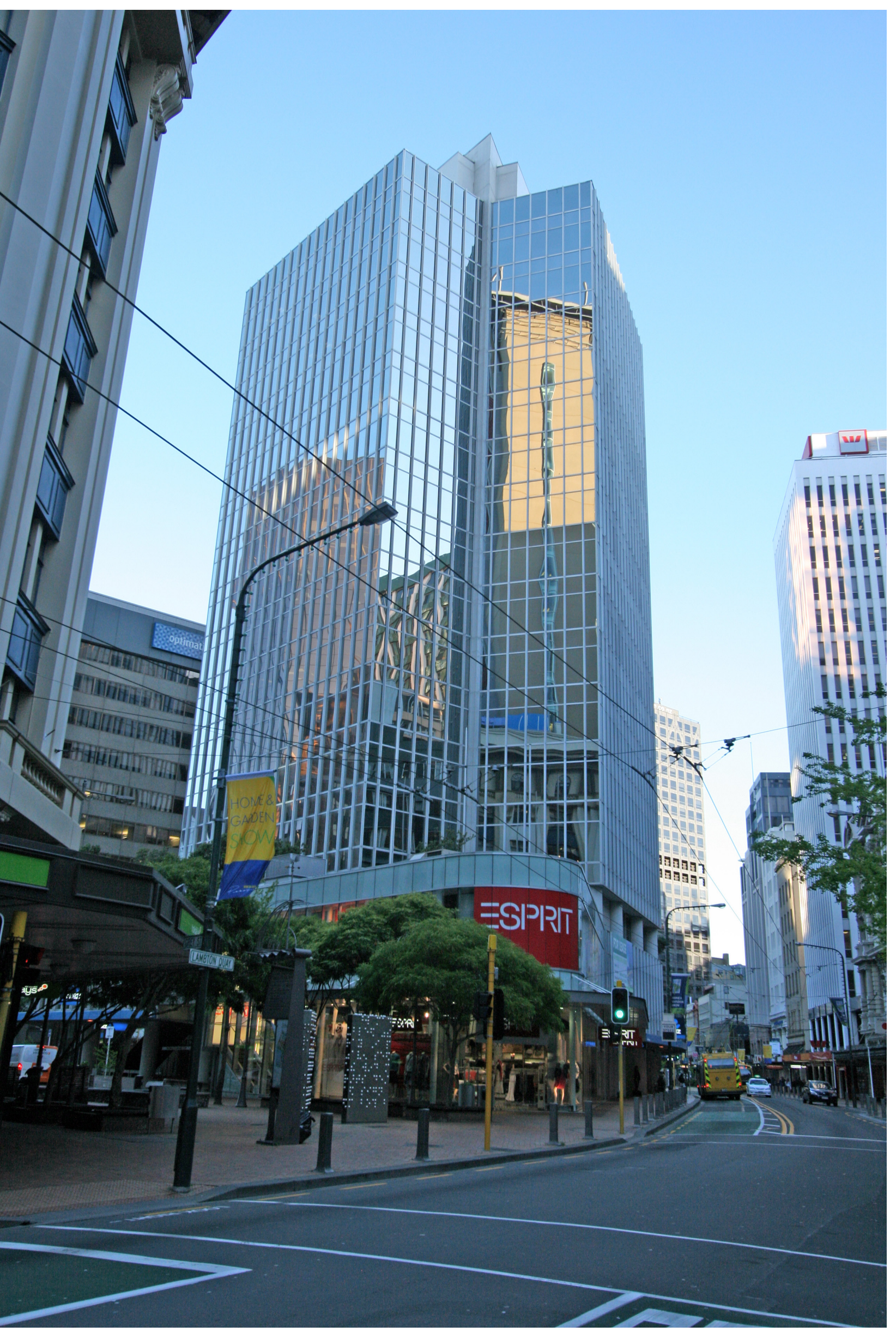



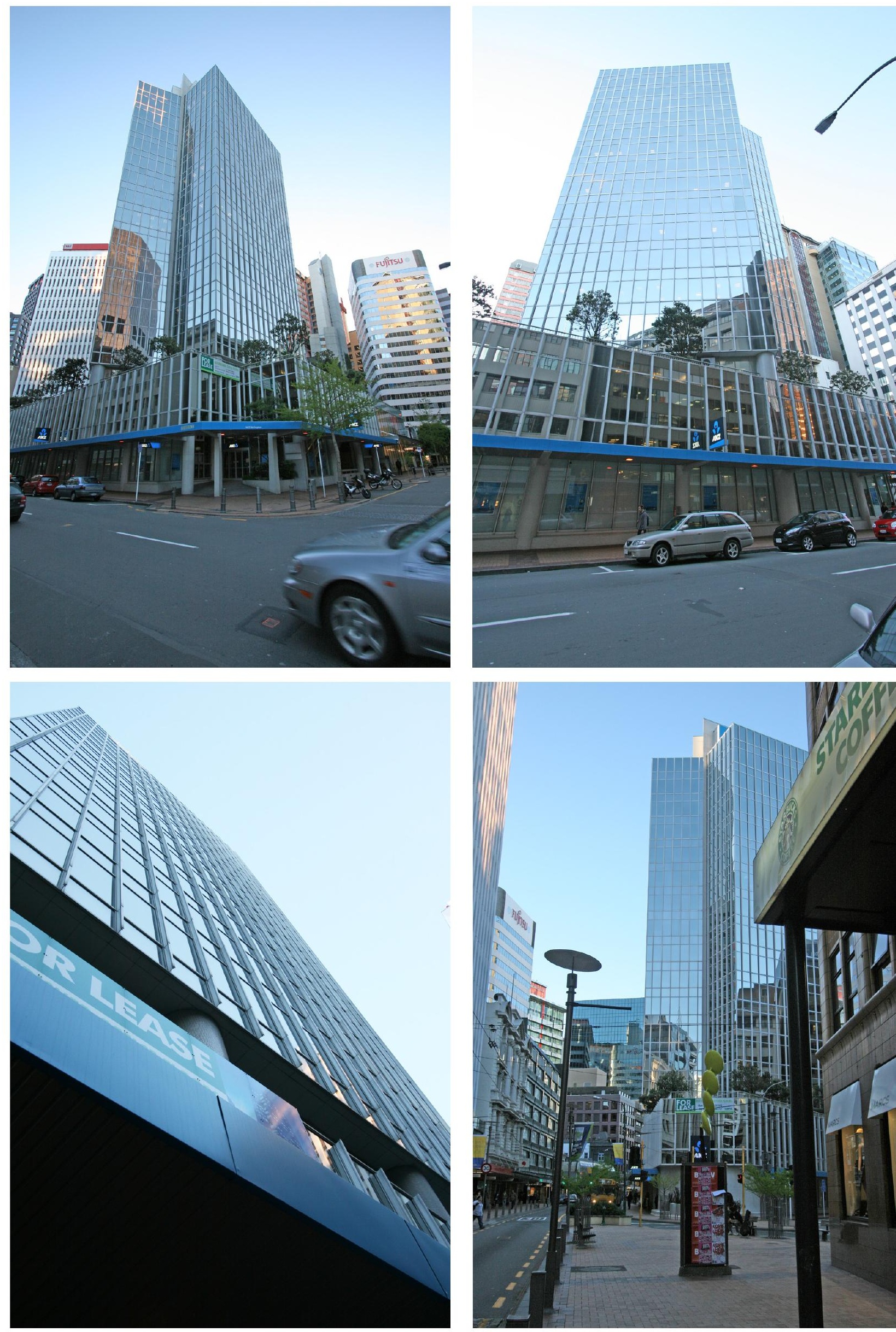

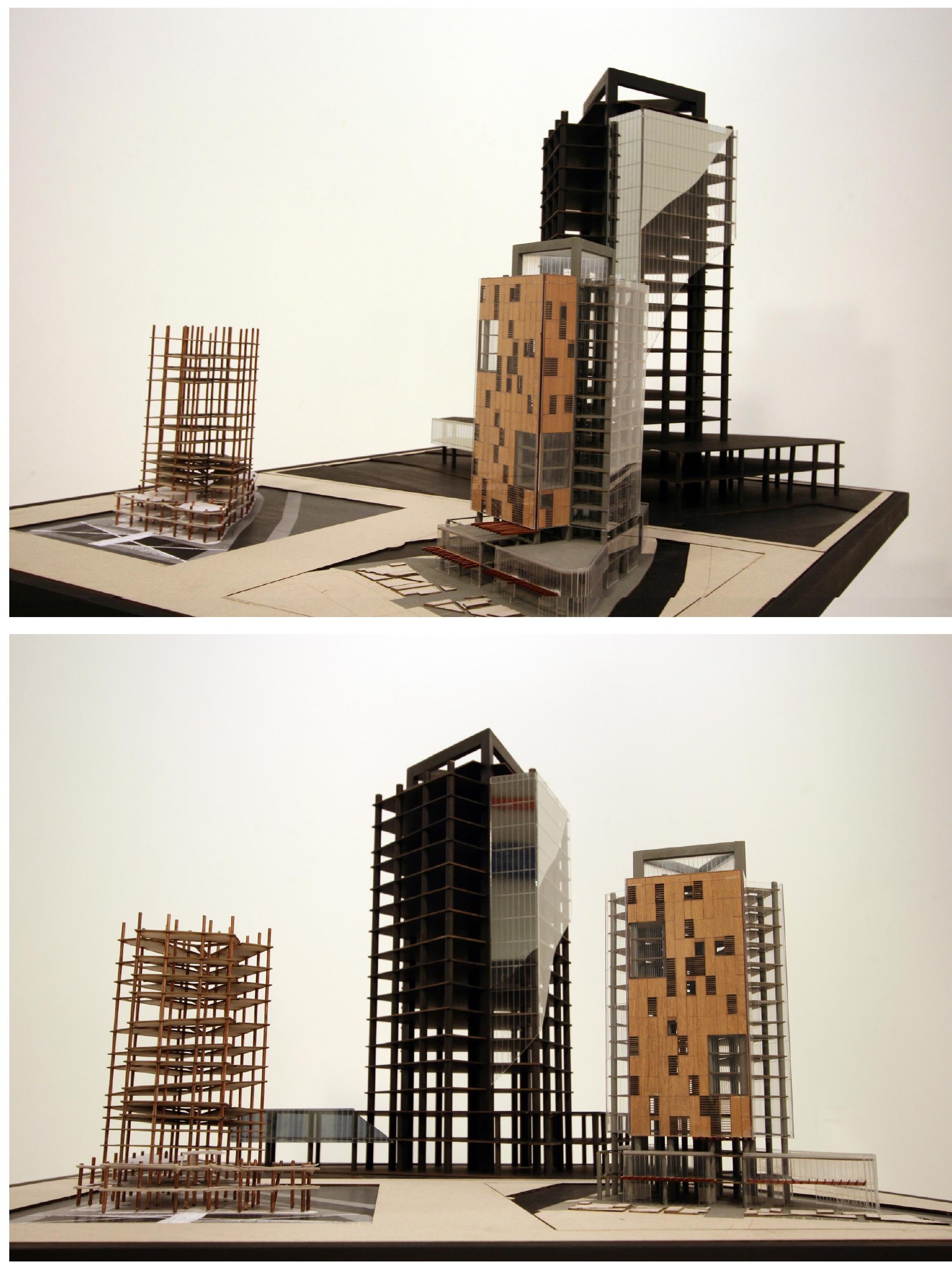


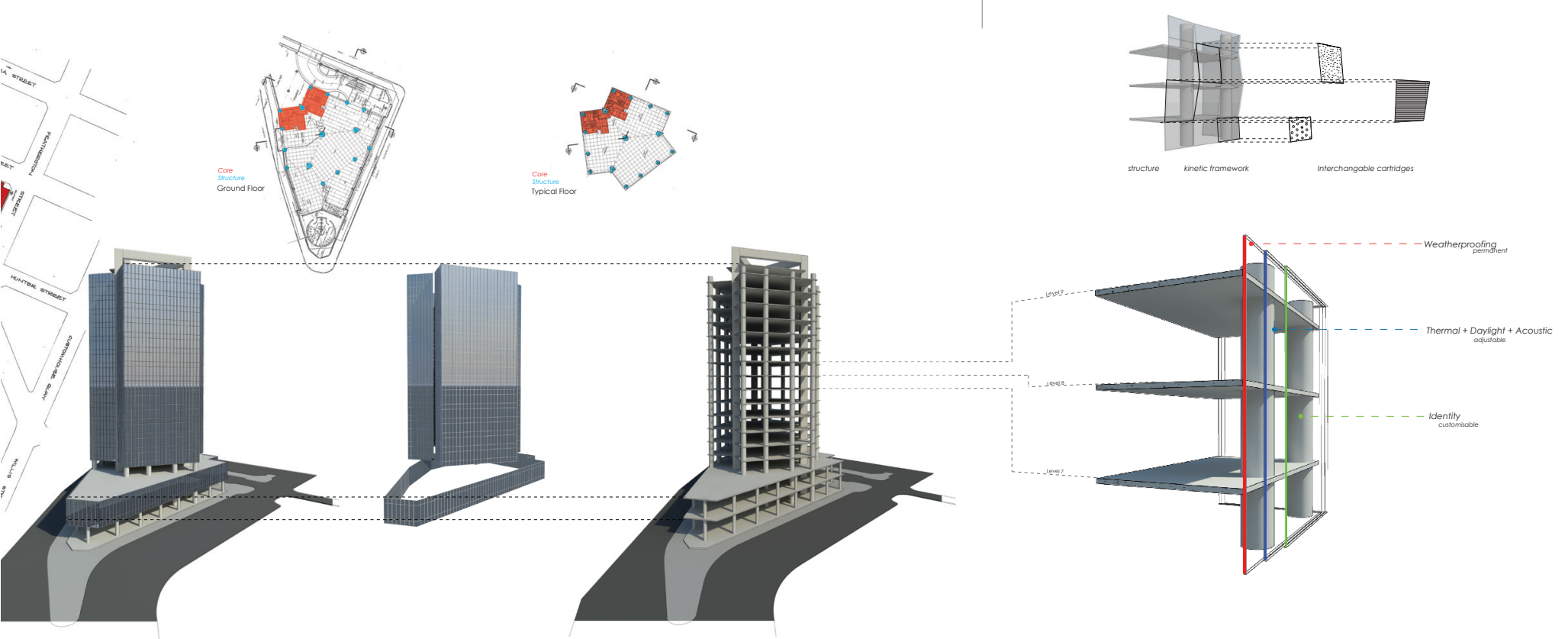




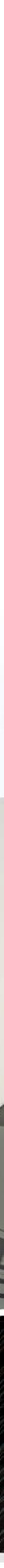

Patrick Thompso 